\title{
EXPLORING THE FRAMEWORK FOR TRUST MANAGEMENT MODEL OF INTERPERSONAL TRUST
}

by

Rahi Tajzadeh, B.Comm. Ryerson University, Toronto, Ontario, Canada, 2015

\author{
A Thesis \\ presented to Ryerson University \\ in partial fulfillment of the \\ requirements for the degree of \\ Master of Science in Management (MScM) \\ in the Program of \\ Master of Science in Management \\ Toronto, Ontario, Canada, 2017 \\ (C) Rahi Tajzadeh 2017
}




\section{Author's Declaration}

I hereby declare that I am the sole author of this thesis. This is a true copy of the thesis, including any required final revisions, as accepted by my examiners.

I authorize Ryerson University to lend this thesis to other institutions or individuals for the purpose of scholarly research.

I further authorize Ryerson University to reproduce this thesis by photocopying or by other means, in total or in part, at the request of other institutions or individuals for the purpose of scholarly research.

I understand that my thesis may be made electronically available to the public. 


\begin{abstract}
Exploring the Framework for Trust Management Model of Interpersonal Trust, 2017, Rahi Tajzadeh, Master of Science in Management, Ryerson University

Trust is a construct that is dynamic, dyadic, deep in scope and wide in breadth. A new model of interpersonal trust called the Framework for Trust Management (FTM) builds on established models of trust and behavior, amalgamating important constructs and sub-constructs into a new dyadic and dynamic model. This new model hasn't had its scales validated, nor has its survey been tested for parsimony. Additionally, a gap in the literature has been identified, in which most studies into trust do so generally, without looking at specific contexts or subpopulations. Using Exploratory Factor Analysis and data gathered from 271 Ryerson University students and employees at a staffing company, I looked at which questions in the survey represented their respective sub-constructs, how many extracted factors matched their theorized sub-constructs, whether I can increase parsimony by trimming the survey, and what the similarities and differences were between the two groups of respondents.
\end{abstract}




\section{Acknowledgements}

I'd like to acknowledge the professors, mentors, fellow master's students at Ryerson University, Ksenia Sergueeva, and Mahsa Khanbabaei who gave me the strength, confidence, and direction to make this thesis a reality. Professors S. Gedeon, D. Valliere, S. Wise, M. Lee, H. Yu, S. Tissenbaum, A. Menna, and D. Fels helped me hone my skills, adjust my sails when I went astray, and push me when I was in the right direction. I thank each and every one of you from the bottom of my heart. Lastly, I want to acknowledge Mr. Robert Scott, my high school history teacher who instilled in me a deep desire to learn, to improve, and to be humble. 


\section{Dedication}

This thesis is dedicated to my caring father Hormoz Tajzadeh, my loving mother Zohreh Tajzadeh, my best friend and brother Maani Tajzadeh, the wonderful Terry Georgatselos, and my strong and independent grandmother Anvarsadat Abtahi, without whom I would not be here, and whose positive motivation and selflessness have empowered me to take control of my own life and educational career.

I also dedicate this thesis to my wise, warm, and wonderful cousins: Massi and Sadri who taught me to love myself for who I am, and who guided me through the most difficult times in my life. Saam and Naazaneen who were the epitome of academic role models and good sense. And also to Amir and Naveed who showed me how to overcome adversity with aplomb.

Lastly, I want to dedicate this thesis to the one whose unrelenting love and dedication picked me up from my lowest point in life and lifted me up into a new era of achievement, personal development, and academic success: Asal Tajzadeh, without whom my life would be devoid of the daily joy and love that she brings.

Thank you from the bottom of my heart,

Rahi Tajzadeh

B.Comm. 


\section{Table of Contents}

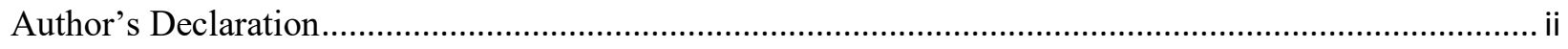

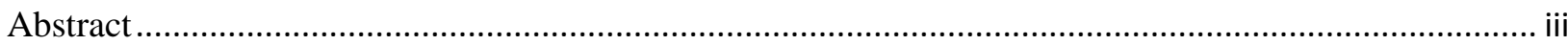

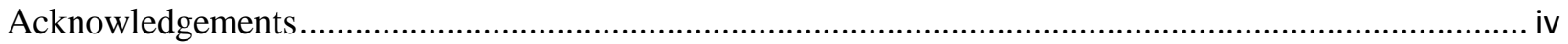

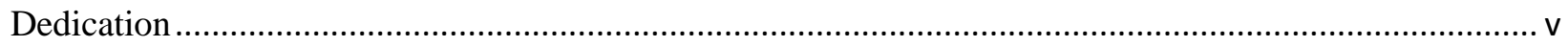

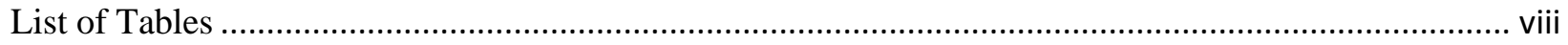

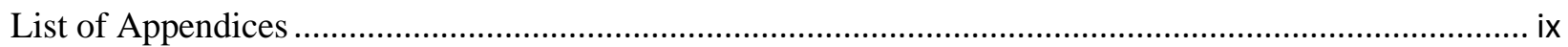

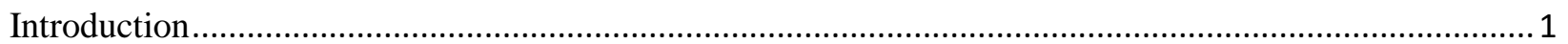

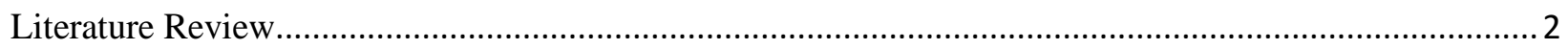

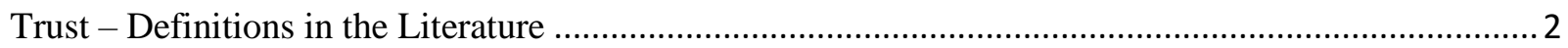

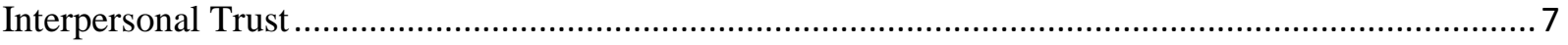

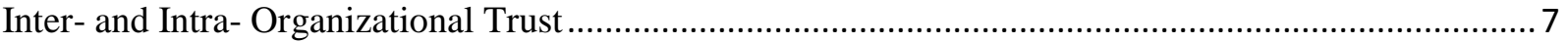

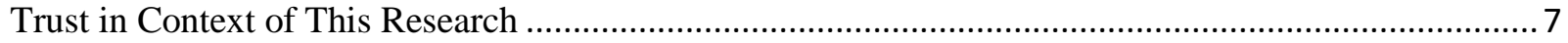

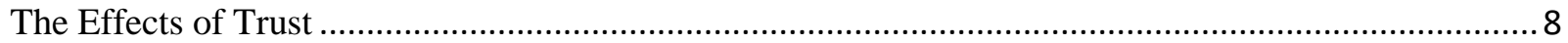

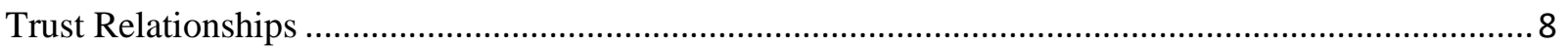

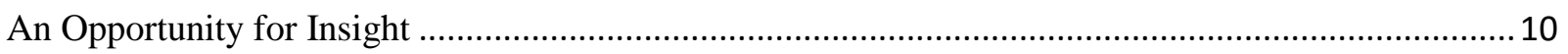

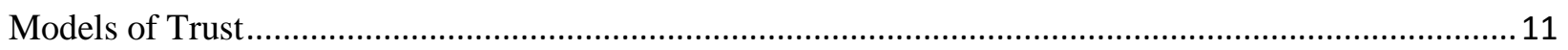

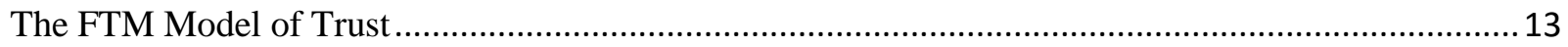

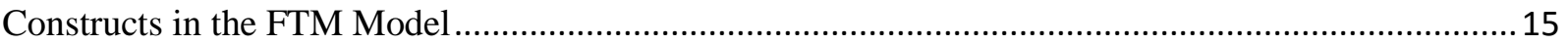

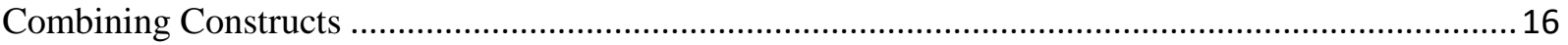

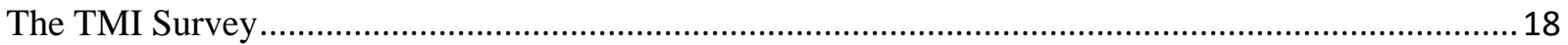

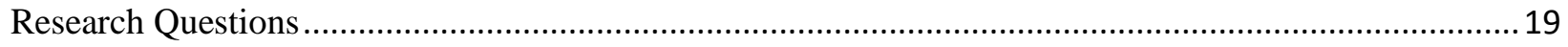

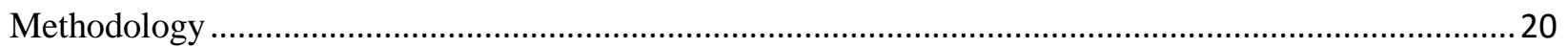

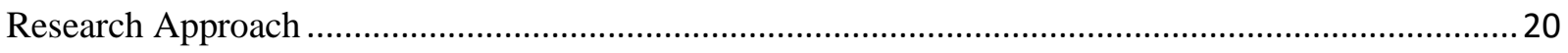

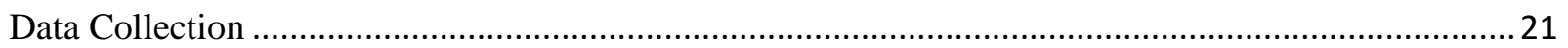

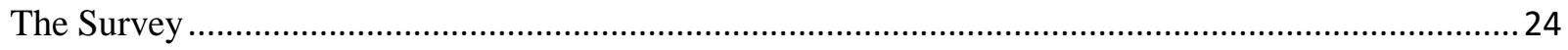

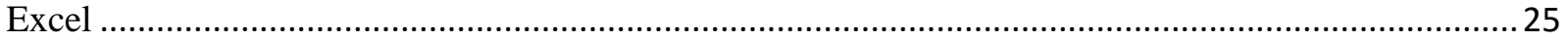

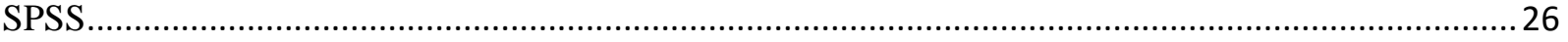

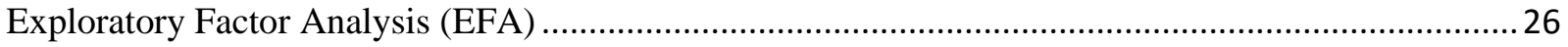

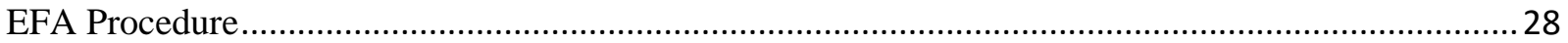

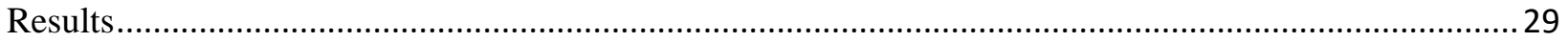

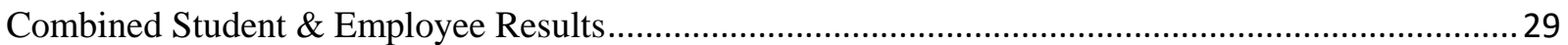




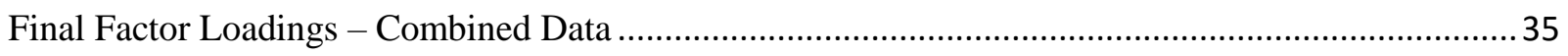

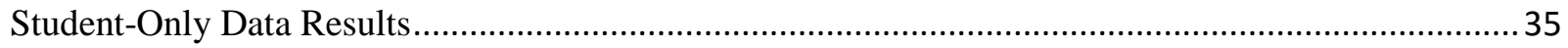

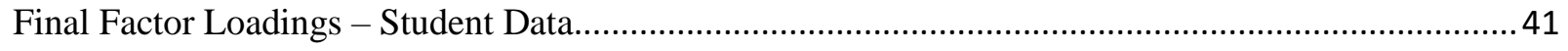

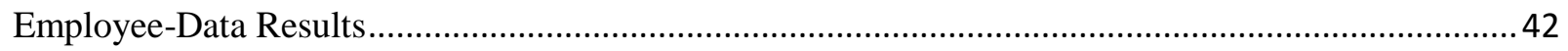

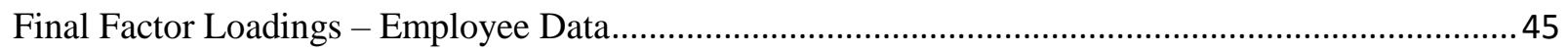

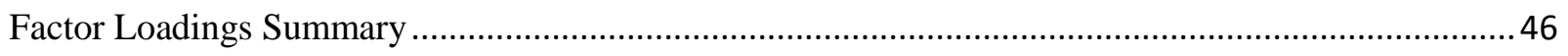

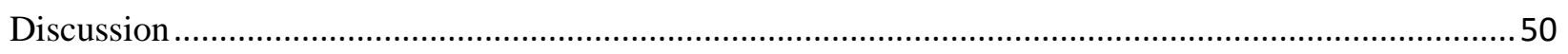

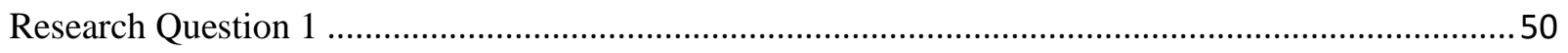

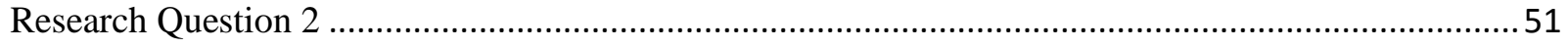

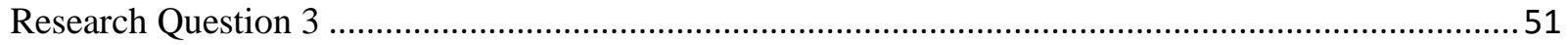

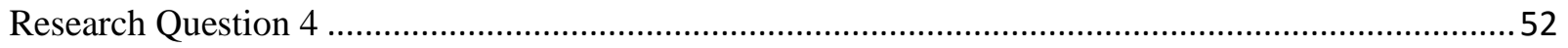

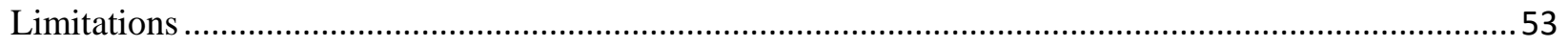

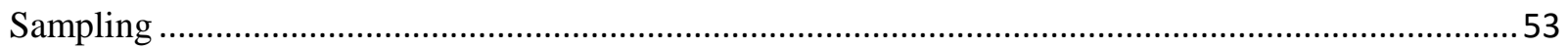

Size

Type

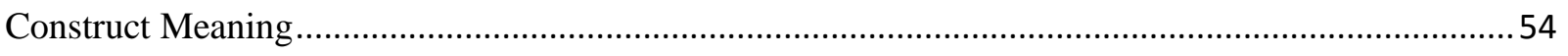

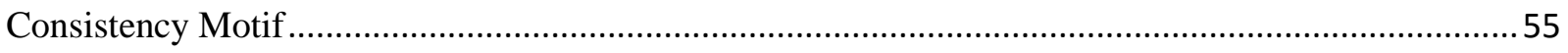

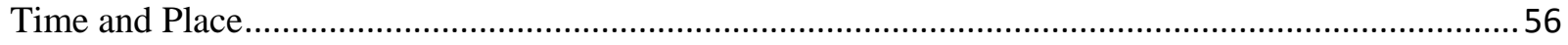

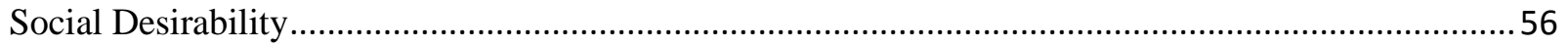

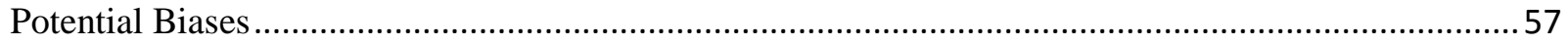

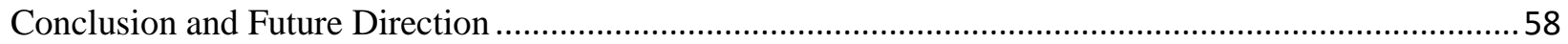

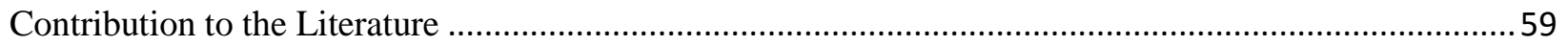

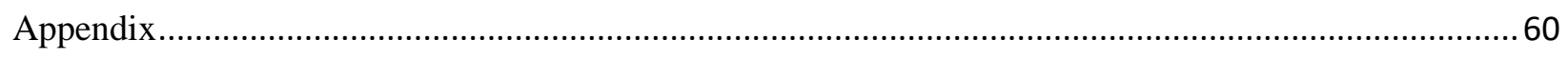

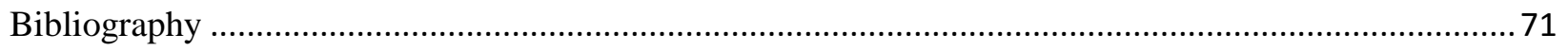




\section{List of Tables}

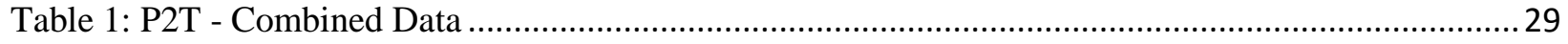

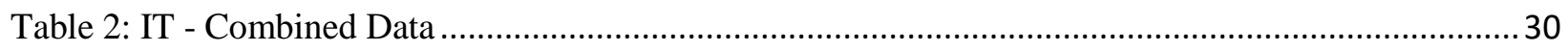

Table 3: IT - Combined Data: Final Loadings …...................................................................... 31

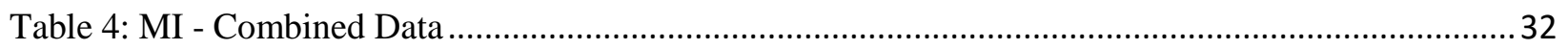

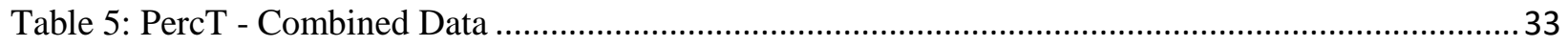

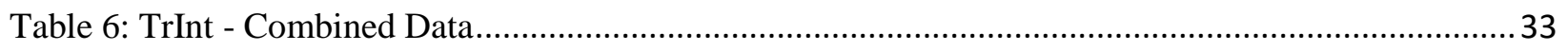

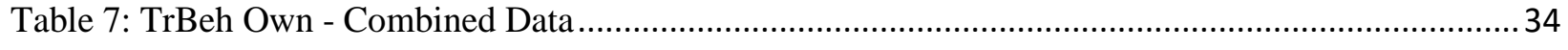

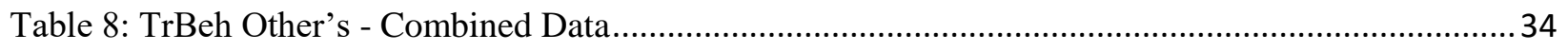

Table 9: Final Factor Loadings - Combined Data ........................................................................ 35

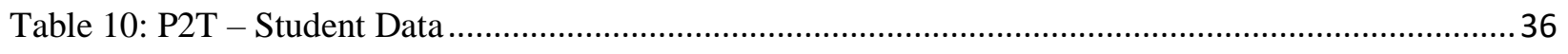

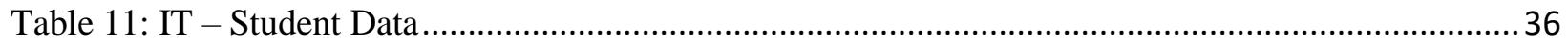

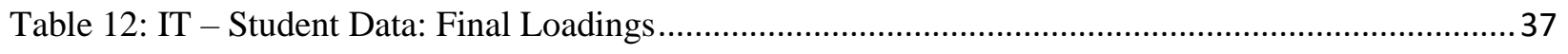

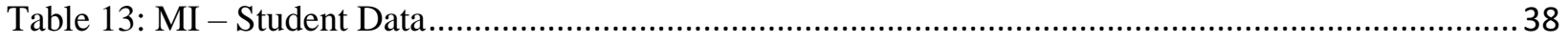

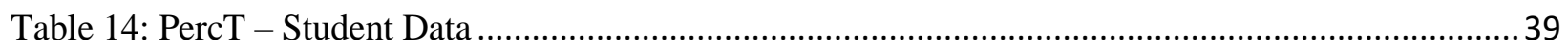

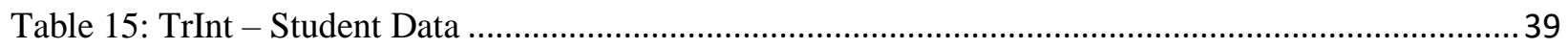

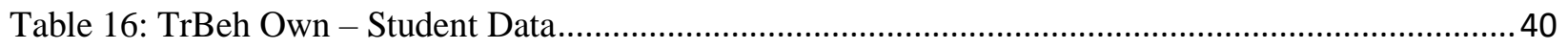

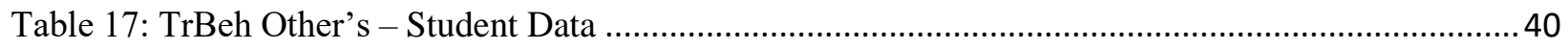

Table 18: Final Factor Loadings - Student Data .......................................................................... 41

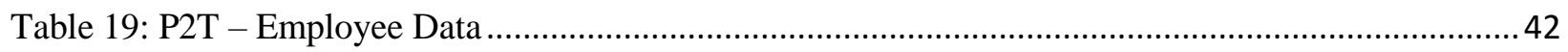

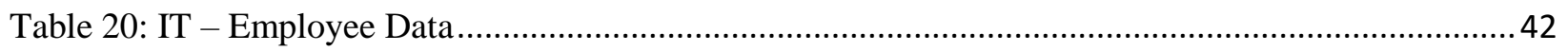

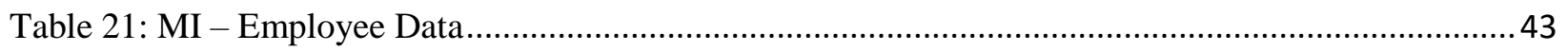

Table 22: PercT - Employee Data ............................................................................................... 44

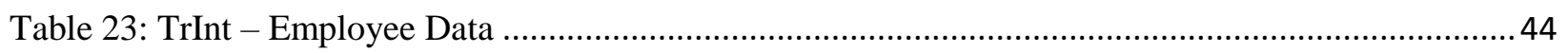

Table 24: TrBeh Own - Employee Data...................................................................................... 44

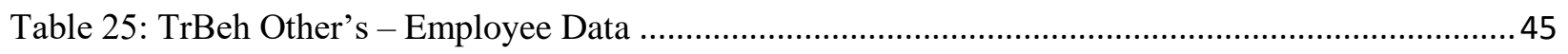

Table 26: Final Factor Loadings - Employee Data ........................................................................ 45

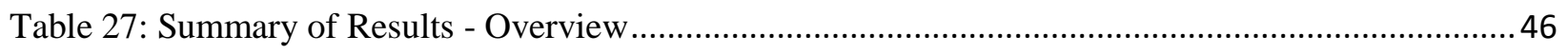

Table 28 Combined Data - Final Factor Loadings ............................................................................. 46

Table 29: Student-Only Data - Final Factor Loadings .....................................................................4 47

Table 30: Employee-Only Data - Final Factor Loadings ..................................................................47

Table 31: Theorized Constructs/Sub-Constructs, SPSS Labels, Survey Questions, Sub-Construct Source

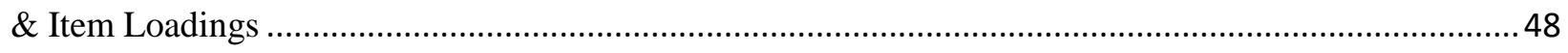

Table 32: Extracted Factors Compared to Theorized Sub-Constructs .....................................................51

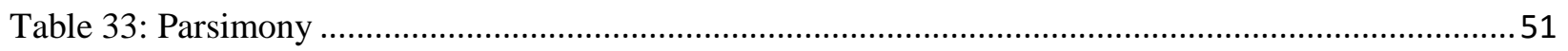


List of Appendices

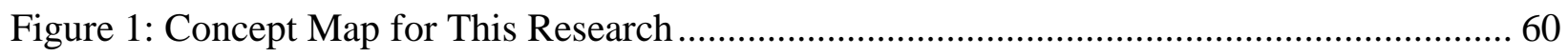

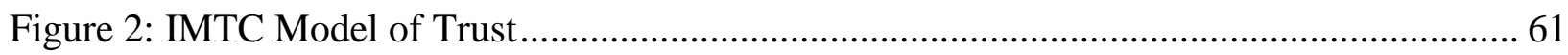

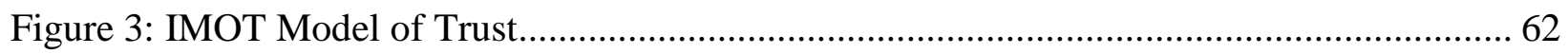

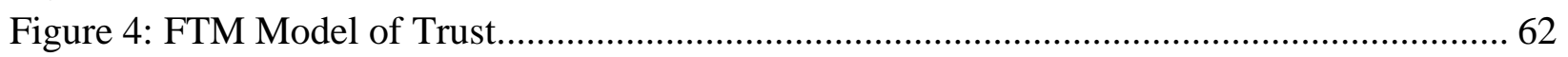

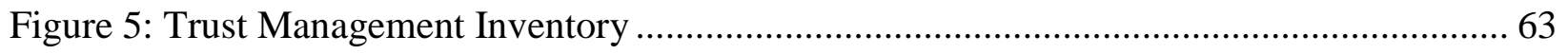

Figure 6: Theorized Constructs, Sub-Constructs and Questions ............................................ 66

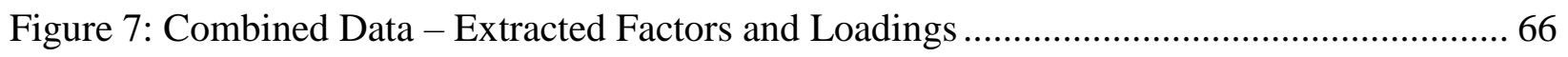

Figure 8: Student-Only Data - Extracted Factors and Loadings .......................................... 67

Figure 9: Employee-Only Data - Extracted Factors and Loadings ......................................... 68

Figure 10: Final Combined Data Extracted Factors and Loadings.......................................... 68

Figure 11: Final Students-Only Extracted Factors and Loadings .......................................... 69

Figure 12: Final Employees-Only Extracted Factors and Loadings ........................................ 69

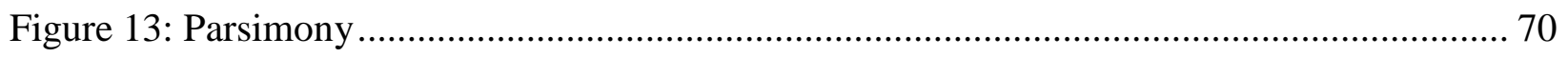




\section{Introduction}

The Framework for Trust Management model (FTM) is a newly posited model dealing with the phenomenon of trust. More specifically it deals with interpersonal inter- and intraorganizational trust. The FTM model has amalgamated constructs, sub-constructs, and scales from established and validated models of trust. The resulting model is dynamic and dyadic, and designed to be used by managers to measure, manage, and repair trust (Gedeon, 2014).

Published literature on trust is extensive and adds many characteristics to the construct, but all agree that it is universal to all human beings. Thus, most research deals with the phenomenon in a general context, leading to an opportunity for new research to focus on more specific contexts. The FTM model of interpersonal trust is written mainly within the context of business managers and their employees, but can apply to a variety of different scenarios such as University students.

The FTM model is still in its infancy, and needs to be validated. It uses a 76-question survey called the Trust Management Inventory (TMI) to measure interpersonal trust, whose questions originated in three different models. The scales and amalgamation of the constructs have not been validated to date.

This thesis will look at validating and trimming the scales in the TMI survey, and to add to the literature on trust by studying it in specific contexts. The TMI survey was deployed to two sub-populations: Students at Ryerson University and employees at a staffing company in Ontario, Canada. The results were analyzed using Exploratory Factor Analysis to answer four research questions in this thesis: 
- Do the questions in the TMI survey represent their respective sub-constructs?

- Do the number of extracted factors in Exploratory Factor Analysis match the theorized sub-constructs?

- Can we trim the scales in the TMI survey and increase parsimony?

- What (if any) are the differences in the responses from each group of respondents?

In order to fully understand, appreciate, and analyze the results of this study, trust as a concept needs to be expanded upon, clarified, and put into context as it is vast and complex in nature (Tschannen-Moran \& Hoy, 2000).

\section{Literature Review}

The subject areas of focus in this thesis are trust, interpersonal trust, its dyadic nature, and to a lesser degree, inter- and intra- organizational interpersonal trust.

\section{Trust - Definitions in the Literature}

Trust is a behavioral construct that encompasses many characteristics such as reciprocity, vulnerability, benevolence, and honesty, among others (Tschannen-Moran \& Hoy, 1999). Trust is vital to the development of relationships, creation of value, and improving cooperation (Rotter, 1967).

In the business world, interpersonal trust is vital to the relationships between and within organizations, and can have measurable and meaningful effects on competitive advantages and overall value generation (Barney \& Hansen, 1994; Jonker \& Treur, 1999). To better understand the impacts that trust has in intra- and inter- organizational interpersonal relationships, trust itself needs to be measured, categorized, analyzed, managed, and repaired as needed. 
Prior methods of analyzing and measuring trust, such as the Integrative Model of Organizational Trust (IMOT) (Mayer, Davis, \& Schoorman, 1995), and the Interdisciplinary Model of Trust Constructs (IMTC) (McKnight, Cummings, \& Chervany, 1998), have been unidirectional and/or static in nature.

Trust is ambiguous and seen as a "paradox" without a model to put it into context (Golembiewski \& McConkie, 1975, p. 131). Various researchers have published articles indicating a number of problems with researching and defining trust such as: what trustconditions are (Butler, 1991), what trust-mechanisms are (Ring \& Van de Ven, 1992), whether Trust needs a definition when it is so well understood in every-day life (Barber, 1983, p. 7), and the lack of proper measurement tools to gauge trust's constructs (Butler, 1991). Thus, to be able to work with trust, it needs to be well defined, and have its associated constructs (and subconstructs) clearly laid out.

Trust isn't simple to define due to varying points of view and underlying concepts (Hosmer, 1995), and thus the constructs associated with trust can be inexact (McKnight, Cummings, \& Chervany, 1996), which can lead to potential interpretation issues by individuals in a sample population. Additionally, there is a lack clear agreement about the formation of trust, and what trust is comprised of (McKnight et al., 1996). Identifying the full meaning of trust and contextualizing it is therefore critical to researching or working with models of trust. How a model interprets and defines trust, and what context or scope is used to further refine the construct of trust is therefore up for debate.

Looking at trust from too constricted a view doesn't encompass the scope and breadth of the modern usage of the word, and looking at trust from too wide a lens makes it difficult to build on existing theories of trust (McKnight et al., 1996). Utilizing too narrow a definition or 
too specific a context for trust can result in important constructs and depth of meaning being lost (McKnight \& Chervany, 2001). Additionally, it's been recommended that every-day uses of the term be utilized to derive scientific terminology, that can be checked to determine the degree with which it matches the broad meanings in common usage (McKnight \& Chervany, 2001); something that Gedeon (2014) has incorporated into the TMI survey.

Constructs used in trust should be all-encompassing (to convey most of the meanings of trust), not too large or complicated (to avoid becoming vague) (McKnight \& Chervany, 2001), and communicable across various disciplines (McKnight et al., 1998).

Trust must be observed from a point of view that is neither too narrow or too wide (McKnight et al., 1996), and involve terminology that is not scientific, but rather colloquial, so as to better match the every-day meanings within which it finds itself (McKnight \& Chervany, 2001). These colloquial or conversational representations of trust must also be suitable to express the full meaning of the construct without being too large or complicated, which can lead to vagueness issues (McKnight \& Chervany, 2001).

The following constructs and characteristics of trust that have been proposed begin with every-day terminology by Hosmer (1995), are not too vague or specific, and are easily conveyed in various disciplines, without losing their original meaning.

Trust:

- is an optimistic expectation about the behavior of a person;

- occurs under conditions of vulnerability;

- $\quad$ is associated with willing cooperation resulting in benefits;

- is difficult to enforce; 
- and assumes an accepted duty to protect the interests of others (also known as benevolence) (Hosmer, 1995).

Other scholars look at trust from a more systematic point of view:

- Trust is a social feature (Fukuyama, 1995).

- Trust operates on multiple levels and dimensions, and is multi-disciplinary as a construct (Rousseau, Sitkin, Burt, \& Camerer, 1998).

- Trust involves both emotional and rational components (Martin, 2014).

- Trust is dynamic, and changes between initiation, sustaining, and repairing stages in any given relationship (Tschannen-Moran \& Hoy, 2000).

- Trust is a phenomenon that is influenced by the context in which it finds itself (Misztal, 2002) such as social, cultural, hierarchical, and organizational, etc. (Tyler \& Kramer, 1995).

- Trust is dyadic (Mayer, Davis, \& Schoorman, 1995), and bidirectional (Zaheer, McEvily, \& Perrone, 1998).

Another group of scholars see the following in trust:

- Risking vulnerability;

- Benevolence;

- Reliability;

- Competence;

- Honesty;

- $\quad$ and openness (Tschannen-Moran \& Hoy, 1999). 
A less faceted view of trust claims that it can be either weak, semi-strong, or strong with various associated implications for each type (Barney \& Hansen, 1994). This view of trust categorizes many of the above characteristics of trust under these three headings (Barney \& Hansen, 1994). Each of these types of trust has its own effects on the competitive advantages of an organization; in a situation where trust is strong, all parties involved need to have strong levels of trustworthiness for a competitive advantage to provide economic value (Barney \& Hansen, 1994; Höhmann \& Malieva, 2005).

Another less-complex definition of trust includes the idea of "a belief by a person in the integrity of another" (Larzelere \& Huston, 1980, p. 595).

There is more value and meaning behind Trust if it manages to include the many characteristics listed above, otherwise it risks becoming ethereal and difficult to define easily (Ajzen \& Fishbein, 1974). Including many characteristics and constructs in the definition of trust better prepares researchers for working with trust in various settings.

A conglomeration of the characteristics and constructs of trust from the literature defines trust as:

A multi-level, multi-dimension, multi-disciplinary, dynamic, multi-staged, dyadic, and bidirectional phenomenon that is affected by the context in which it finds itself, risks vulnerability to a party, requires some form of benevolence between parties, assumes some degree of reliability and competency in at least one party, and is founded on the honesty of both parties. 


\section{Interpersonal Trust}

Interpersonal trust is defined as the extent or depth of trust in a corresponding person (Zaheer et al., 1998). Inter- and Intra- Organizational Interpersonal Trust therefore carries all the constructs and characteristics of trust stated above, but is relegated to two people within or between organizations (Zaheer et al., 1998).

\section{Inter- and Intra- Organizational Trust}

Interpersonal Trust is dyadic in which two individuals are part of the trusting pair in the relationship. Trust can be, and often is, a mechanism or requirement for human collaboration (McKnight et al., 1996). In an organizational environment, in which profit maximization and competitive advantage development (and maintenance) are critical aspects of business success (Walters, Halliday, \& Glaser, 2002), trust and interpersonal trust more specifically become an ever-more important factor in said success (Saunders, 2010).

Since inter- and intra- organizational interpersonal trust are relational constructs, they can have significant effects on the bottom line, on long term value creation, on long term relationship building (Zaheer et al., 1998), and even long term competitive advantage through improved cooperation (Saunders, 2010).

\section{Trust in Context of This Research}

In this research, only the trust between two individuals working together at the same organization (company, university, etc.) will be considered.

The trust between an individual and an organization, or between two organizations, or between more than two parties will not be part of the scope of this research. 


\section{The Effects of Trust}

Depending on the scenario, trust will have various degrees of positive or negative impact(s). Trust has been shown to reduce workplace inter-personal friction(s) (Gedeon, 2014), and improve cooperation and communication among colleagues (Tschannen-Moran \& Hoy, 2000). According to Sigmund \& Nowak (2005), trust is vital to the fostering and creation of innovation and overall performance improvements in the workplace, and along with reciprocity, is the foundation for morality and ethics.

In a business setting, trust can become a method of control between parties (Gulati, 1995), resulting in a lower cost of control (Gulati \& Nickerson, 2008). Moreover, increased trust has been found to advance inter-organizational relationships, decrease the costs of negotiations, decrease the risk of treachery, decrease transaction costs, and decrease search costs (Buckley, Glaister, Klijn, \& Tan, 2009; Gulati, 1995; Ring \& van de Ven, 1994; Smith, Carroll, \& Ashford, 1995; Squire, Cousins, \& Brown, 2009; Zaheer et al., 1998).

The consequences of poor (or low) levels of trust in a corporate environment include decreased value generation and damaged relationships. This can increase the interpersonal friction and decrease potential and actual competitive advantage(s) (Qiang, Yuanyuan, \& Wensheng, 2015).

\section{Trust Relationships}

The relationship between a trustee and trustor is dynamic, unique in each circumstance, and problematic to reproduce. Thus, we can only look at the shared characteristics between trustors and trustees. 
Trustors have a disposition or propensity to trust. The degree to which they are disposed to trust varies from situation to situation, and person to person (Mayer et al., 1995), making this important construct in a trusting relationship, dynamic.

The attributes of a trustee can help determine the degree of trust each party has for one another, partially because trustors view themselves within the context of the trustee's trustworthiness (Mayer et al., 1995).

Increased interpersonal trust has various beneficial results, not the least of which are improved performance, increased satisfaction, and even improved organizational citizenship behaviour (Colquitt, Scott, \& LePine, 2007). Thus, managers should aim to include the increasing of interpersonal trust as part of their goals.

Participative management styles have become more prevalent in the business world, demonstrating improved creativity, innovation, and moderating effects of organizational culture (Park, Lee, \& Kim, 2016), despite some evidence that it can be counterproductive to change management (Pardo-del-Val, Martínez-Fuentes, \& Roig-Dobón, 2012). The use of more working teams means that trust is even more important to the involvement and cohesiveness of employees, and the competitive advantage of organizations (Lawler, 1992).

In a performance appraisal situation trust requires a form of buffer between the perceived usefulness of said appraisal system and trust itself (Davis \& Mayer, 1999), otherwise it acts as the motivating factor and lubricant to make working together easier and reaching mutual goals more likely (Lawler, 1992). 


\section{An Opportunity for Insight}

Most research papers look at trust itself, within general situations and the general population, avoiding specific contexts like two colleagues in a staffing company, or two University students collaborating on graded work. This leaves the door open to new research that applies models of trust to unique sub-populations like said University students, etc. Moreover, researchers can look at the similarities and differences between many different sub-populations, and what the implications are to existing and new models of trust.

To contribute to the literature that looks at trust itself, within a specific context or unique set of sub-populations, this research utilized a combination of students at Ryerson University, and non-managerial employees at a staffing company in Ontario, Canada as sample subpopulations to fill out the TMI survey of the FTM model.

The University students represent a convenience sample (due to the scope and limited resources available for this study), while the employees at the staffing company represent the population closest to that which the FTM model was written for. 


\section{Models of Trust}

Trust requires a model to understand and utilize it, especially in an interpersonal context (Golembiewski \& McConkie, 1975). Understanding and working with trust requires one to use particular trust conditions (Butler, 1991), define trust's mechanisms at play (Ring \& Van de Ven, 1992), and use appropriate measurement tools (Butler, 1991).

There are two models of trust that originate in the management sciences field and which look at the associations among (and between) different constructs within trust: These models are the Integrative Model of Organizational Trust (IMOT) (Mayer et al., 1995) (Appendix Figure 3), and the Interdisciplinary Model of Trust Constructs (IMTC) (McKnight et al., 1998) (Appendix Figure 4).

Diagram 1: The IMOT Model

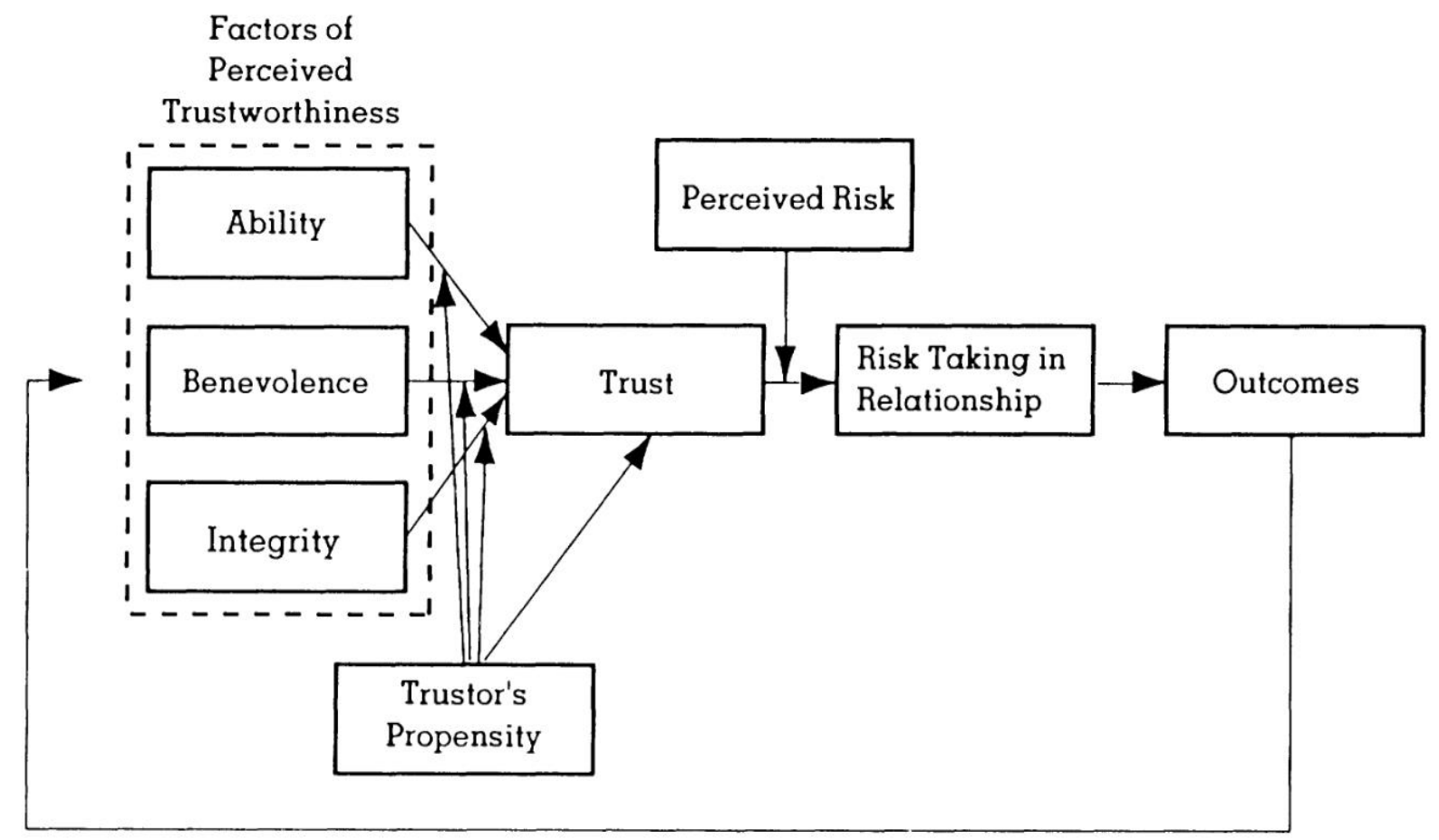

(Mayer et al., 1995) 


\section{High-Level Model of Initial Formation of Trust}

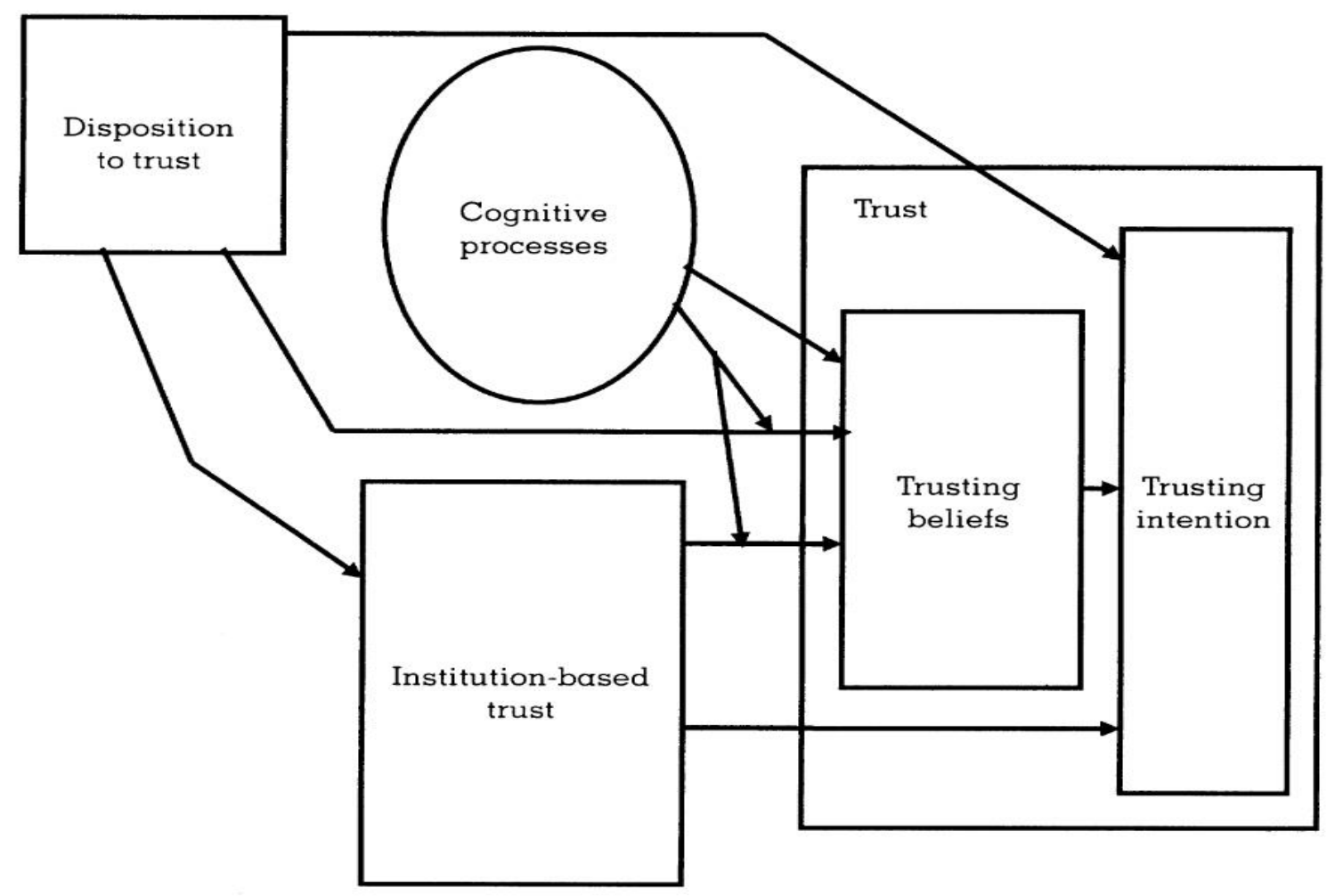

(McKnight et al., 1998)

The IMOT model isn't dyadic, and focuses on the person doing the trusting (trustor) (Mayer et al., 1995), while the IMTC model is more thorough as it incorporates more detailed categorization of trust with an expanded assortment of trusting beliefs (McKnight et al., 1998). Both models rely on, and are built on, established trust models and measurement scales from the late 1960's (Rotter, 1967).

Gedeon (2014) has identified the following gaps in the IMTC and IMOT models of trust: The dyadic nature of interpersonal trust, the phenomenon of time (i.e. trust is a dynamic process that can be built and repaired (Schoorman, Mayer, \& Davis, 2007)), and the component of reciprocity (Gedeon, 2014, p. 126). 
Gedeon (2014) has posited that several constructs from each model are compatible, or even interchangeable. According to Larzelere and Huston (1980) found that approaching trust from the dynamic and dyadic perspectives is a better reflection of reality in trusting relationships than a unidirectional model. The Framework for Trust Management (FTM) was born from these models, and their gaps in representing interpersonal trust.

\section{The FTM Model of Trust}

Gedeon (2014) started with an established action model and conceptual foundation, the Theory of Planned Behavior (Ajzen, 2001) as its base, but also builds on the IMTC and IMOT models to address the unidirectional approach to trust.

The Theory of Planned Behavior (TPB) is a very influential predictor for human conduct (Ajzen, 2011), which has grown from the older model: The Theory of Reasoned Action (Ajzen \& Fishbein, 1974). The TPB model states that behavior is rooted in intent, which itself is influenced by several factors: attitude toward behavior, subjective norms, and perceived behavior control (Ajzen, 2001). The TPB model can be used effectively to support change within an organization (Jimmieson, Peach, \& White, 2008) as well as within an individual (Hardeman, et al., 2002).

Starting from the TPB model as a foundation, Gedeon (2014) has posited in his FTM model that certain constructs from IMOT and IMTC can be combined, as well as new constructs added to create a more adaptable and dynamic model in comparison to previous models. Additionally, the unidirectional nature of the IMTC and IMOT models have led to scholarly consensus on the need to look at trust from a dyadic perspective, leading to a more complete assessment of trust (Korsgaard, Brower, \& Lester, 2015). 
The FTM model is bidirectional, and includes both affective trust (McAllister, 1995), and identity-based trust (Coleman, 1990). It is posited that the dyadic nature of this model is more powerful and inclusive than previous models, and incorporates a feedback loop which is aimed to help improve trust over time, and work in conjunction with an action guide that is also presented (Gedeon, 2014).

The FTM model looks at many of the previously listed characteristics of trust from the view of interpersonal inter- and intra- organizational situations, and works to combine many of said characteristics for the sake of simplicity, and efficiency (Gedeon, 2014). The focus of the FTM model is to use TPB as a structure to manage and change trust to increase competitive advantage in an entrepreneurial environment (Gedeon, 2014), but it can be adapted, or directly used in other fields of business.

Gedeon (2014) posits that the use of the FTM model and its TMI survey could improve management's ability to gather more relevant knowledge of the trusting nature of their organization and the employees therein, with which they may build alliances, and improve overall trust (Buckley et al., 2009).

The FTM model assumes that more trust is better than less trust (an idea that has already been established in various scenarios (Panayides \& Venus Lun, 2009)), and therefore utilizing a method by which trust can be gauged, managed, and repaired is more value-rich than other methods (Gedeon, 2014).

Finally, it is posited that the FTM model can be used to better express a variety of situations including the interaction of constructs, the relationship between intent and behavior in 
trust, reciprocal trusting behavior, management involvement and observation, and trusting behavior as it affects perceived trustworthiness (Gedeon, 2014, pp. 131-132).

A significant limitation of the FTM model and its accompanying trust management inventory (TMI) survey is that incorporating constructs from one model into another has not been validated (Gedeon, 2014).

\section{Constructs in the FTM Model}

The FTM model uses the constructs from both the IMOT and IMTC models within the framework of the TPB model, and has a survey called the Trust Management Inventory (which acts as a metric to measure trust) in the pursuit of creating, managing, and if necessary, repairing trust among employees, between and within an organization (Gedeon, 2014).

\section{Diagram 3: The FTM Model}

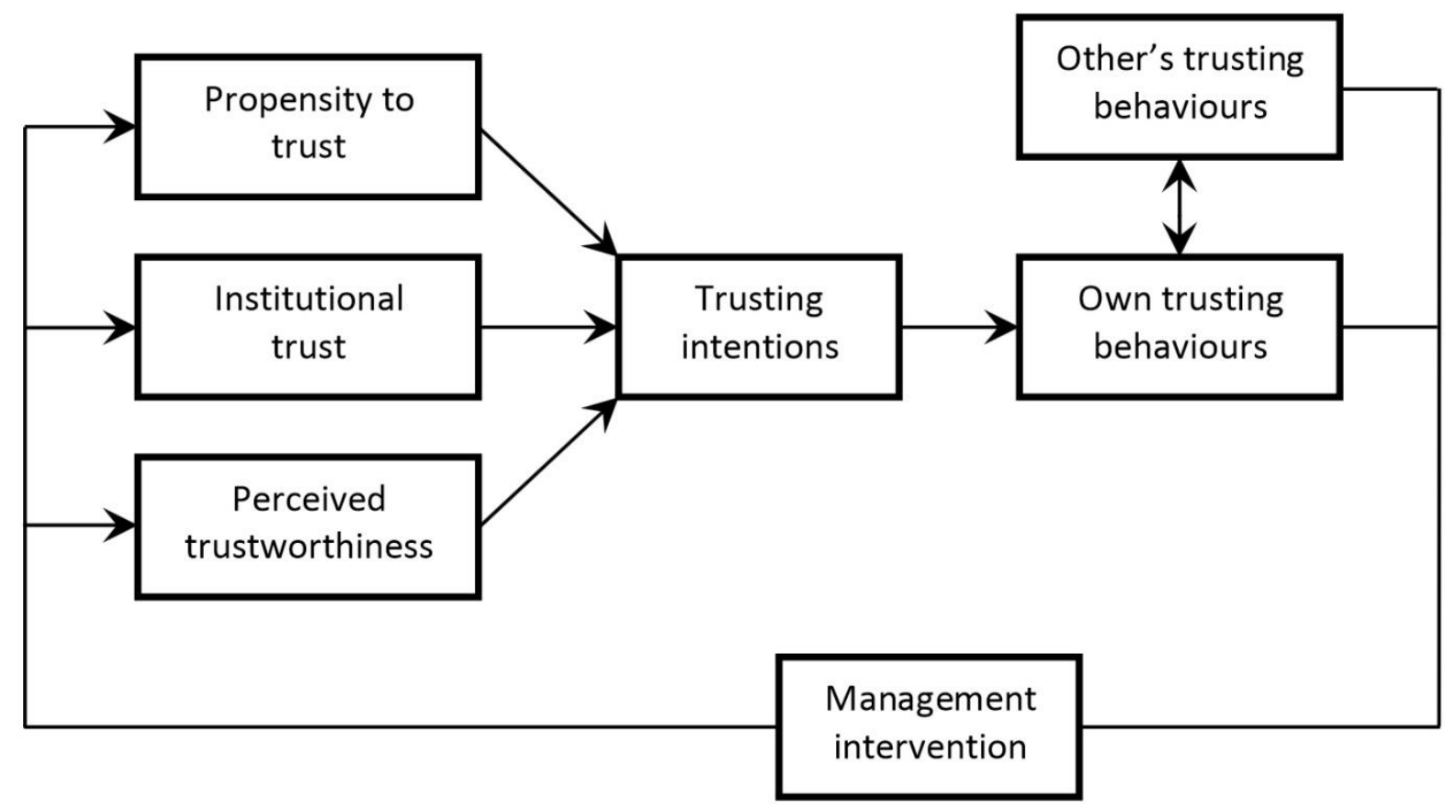

(Gedeon, 2014, p. 127) 
The constructs that the FTM model utilizes are: "Propensity to Trust", "Institutional Trust", "Perceived Trustworthiness", "Trusting Intentions", "Trusting Behaviors" (which is split into "Own Trusting Behavior" and "Other's Trusting Behavior"), and "Management Intervention" (Gedeon, 2014, p. 127).

These constructs are based on Gedeon (2014)'s observation that many constructs from the TPB, IMOT, and IMTC models of trust are congruent, and have established scales that have already been used in researching trust (Gedeon, 2014). For example, the construct "Management Intervention", is based on a feedback loop used in the IMOT model (Gedeon, 2014). The construct refers to particular instances of trust management, including how an employee perceives the process of trust management and measurement (Gedeon, 2014, p. 131). The perception of the process of trust management can have a positive effect on the propensity to trust as it demonstrates an intent to trust by management (Gill, Boies, Finegan, \& McNally, 2005).

\section{Combining Constructs}

Combining constructs, especially those that have been established in previous studies can improve the efficacy of a model, especially in fields relating to psychology (Chan, 1998). Certain TPB model constructs have already been demonstrated to be congruent with constructs from other models of trust, including (but not limited to):

- "Desirability" is compatible with "attitudes towards the behavior" (Krueger, 1993).

- "Self efficacy" (Bandura, 1977) is compatible with "perceived behavior control" (Ajzen, 2006).

- "Self-identity", "social identity", and "group norms" are compatible with sub-factors of "subjective norms" (Terry, Hogg, \& White, 1999). 
Based on these previously posited and observed congruencies with constructs in TPB and other models of trust, Gedeon (2014) has posited the following congruencies or compatibilities of constructs between TPB, IMOT, and IMTC:

i. TPB's "attitude towards the behavior" and "propensity to trust" from IMOT and “disposition to trust" from IMTC due to both IMTC and IMOT using the construct as an precursor to trust. These constructs have been researched extensively, and have existing scales congruent with earlier research into trust as a characteristic (Rotter, 1967).

ii. TPB's "subjective norms" and "system trust", "structural trust", and/or "institutional trust” from IMTC. These constructs depend heavily on the situational context as they relate to beliefs in social structures such as formal organization, informal codes of conduct, values, etc. (Welter \& Smallbone, 2006).

iii. TPB's "perceived behavioral control" and IMOT's "factors of perceived trustworthiness", and IMTC's “trusting beliefs". TPB measures each individual's self-efficacy, but when looking at someone else, the perception one has towards a trustee's trustworthiness seems to be just as important, which correspond to the latter two constructs.

iv. TPB's "intent" and IMTC's "trusting intentions" and IMOT's "trust". This construct has been described as a willingness to be vulnerable and thus a precursor to starting trustrelated behavior(s) and intention-based (Gill et al., 2005).

v. TPB's “behavior" and IMTC's “trust-related behavior" and IMOT's "risk-taking in relationship". These relate to the trustor's actions, and do not utilize reciprocity by looking at the trustee (Schoorman et al., 2007).

Thus, the FTM model assimilates constructs from IMTC and IMOT into the TPB model by including reciprocity via the trusting behaviors of both parties in a dyadic trusting situation. 
Additionally, a temporal aspect is included via a feedback loop ("Management Intervention Measures") (Gedeon, 2014).

These congruencies, and associated amalgamations of constructs are qualitatively consistent with current literature on interpersonal trust.

\section{The TMI Survey}

The TMI survey comprises of seven major sections, each representing one of the constructs in the FTM model. An example of a section is: "Trusting Intentions" which has two sub-constructs including "Willingness to Depend", itself having three questions such as "I can always rely upon in a tough situation" (Gedeon, 2014, p. 139). Gedeon (2014) adopts

these questions from the IMOT and IMTC model, as well as four sub-constructs from a model for institution-based trust by Pavlou (2002).

These sections and questions make up the survey that Gedeon (2014) proposes to be applied by entrepreneurs, managers, and researchers while utilizing the FTM model. The questions use a Likert scale with 7 degrees: Strongly Agree, Moderately Agree, Slightly Agree, Neutral, Slightly Disagree, Moderately Disagree, and Strongly Disagree. There is no distinct reason given for using a 7-point Likert scale, but there are detailed reasons provided as to why each section of the TMI survey (relating to each of the 7 constructs in the FTM model) has the number of questions that it has. For example, for "trusting intentions", Gedeon (2014) states that McKnight, et al., (2002) have established that specific intentions have resulted from scales related to e-commerce, of which 16 items (or questions) have emerged.

For the purposes of this thesis, the origin of the questions is not in question as Gedeon (2014) utilizes established models and scales to identify and utilize questions. 


\section{Research Questions}

The FTM model is new, and its TMI survey hasn't been deployed yet. The amalgamation of constructs and sub-constructs into the TMI survey has not been tested in any way.

I sought to determine whether the questions in the survey represent their theoretical subconstructs as posited in the FTM model. I wanted to know how many factors are extracted in a factor analysis on the data gathered from respondents of the TMI survey, and whether the number of extracted factors match the theorized number of sub-constructs. I also sought to determine whether the survey was parsimonious, or if questions can be removed to increase parsimony. Additionally, I wanted to address the gap in the literature on trust, in which specific sub-populations aren't typically the focus of studies into interpersonal trust. I therefor deployed the TMI survey to two distinct groups to see what differences/similarities exist between them.

The first group consists of Ryerson University students, and the second consists of employees at a staffing company in Ontario, Canada. Using a sample of 271 respondents from the two sub-populations, the following questions are addressed in this research:

1. Do the questions in the TMI survey represent their respective sub-constructs?

2. Do the number of extracted factors in Exploratory Factor Analysis match the theorized sub-constructs?

3. Can we trim the scales in the TMI survey and increase parsimony?

4. What (if any) are the differences in the responses from each group of respondents?

Rather than analyze the combined data from students and employees to answer the questions above, I decided to divide the data into three groups, and answer each question for 
each group to get a clearer picture of how the results breakdown, and what differences exist between them, if any.

The first group is comprised of both students and employees totalling 271 responses. The second group is comprised of University students only, totalling 166 responses. The third group is comprised of employees at a staffing company totalling 105 responses.

\section{Methodology}

\section{Research Approach}

Ontology is a branch of philosophy that deals with the nature of being, becoming, existence, or reality, and traditionally falls under the branch of metaphysics (Merriam Webster, 2017). Ontology is a subject in which the uniqueness of different languages does not play a role, and is thusly universal (Noy \& McGuinness, 2001). Fundamental questions in ontology usually start with "what", such as "what is a thing", or "what can be said to exist", etc.

Nunes and McPherson, 2003 state that there are two important schools of thought in ontology including objectivism (positivism), and subjectivism. The former states that entities (be they social or otherwise) exist without regard to the observer, while the latter claims that the observer has a meaningful impact on the nature of the observed entity (i.e. there is no objective truth) (Nunes \& McPherson, 2003).

Objectivism is a school of thought which claims that knowledge exists independent of the mind of the observer, and thus does not deal with thoughts and emotions of said observer. Constructivism is a school of thought which claims that observers attach meaning to what they 
observe, in association with experiences and the environment with which they are a part (Nunes \& McPherson, 2003).

Realism is a form of objectivism which posits that entities exist objectively and independently without the need for an observer.

This research adopts the view of realism, in that the epistemology is etic as I am looking at responses to the TMI survey that measures trust from outside the system, rather than from within (emic) (Morris, Leung, Ames, \& Lickel, 1999). In other words, I believe that I am measuring the data impartially and have no meaningful effect on the results.

This research is deductive in nature, as it uses validation and reliability tests to determine the validity of the FTM model and the reliability of the TMI tool. The FTM model and the TMI tool themselves are part of an inductive process of determining levels of trust and how to manage and repair them. However, inductive reasoning will be utilized to determine the need for construct removal using factor analysis in the FTM model's survey, based on the observations of the initial sample responses. Figure 1 in the Appendix better illustrates the area of focus for this research.

\section{Data Collection}

For the purposes of simplicity, and to maximize the probability of participation, this research focused on Ryerson University students, and employees at a staffing agency.

The Ryerson students represent a volunteer convenience sample, and were chosen to minimize the associated costs of deploying surveys, and the time required to gather an adequate number of responses (Ferber, 1977). 
Some inclusion criteria were required to ensure that the target population was reached. Participants must have at least one colleague (or classmate) with which they engage in workrelated (or in the case of students, graded projects-related) activities. Management (and professors) were not included in the population pool as the FTM model is not designed for their input, and the questions in the TMI survey would not always relate to a manager's position (e.g. a CEO has no 'management' above him or her and therefore questions from the "Management Intervention" section of the survey are all obsolete in this case).

Though University students are not specifically mentioned in the FTM model, their selection is justified for several reasons:

a) They deal with interpersonal trust with their colleagues in each class, especially when working on graded assignments/projects together (Ashworth, Bannister, Thorne, \& Unit, 1997);

b) They are adults and old enough to understand what trust is (due in part to social cognition, something that takes time to develop and understand, and something that children and adolescents may be lacking (Koenig \& Harris, 2005));

c) Ease of access to a large population of random students from a wide variety of backgrounds (which will better represent trust as a universal phenomenon than a population pool with a less diverse background/culture);

d) Similar to employees in a corporate environment, students are faced with the possibility of serious repercussions for misconduct (such as plagiarism), which can have lasting effects on their academic and non-academic careers;

e) Students have a relationship with their professors that is similar to that of an employee and manager depending on the degree of engagement from both sides; 
f) Other studies of interpersonal trust have focused on University students (Ennen, 2015), establishing the concept that interpersonal trust is not limited to employee/manager environments only (Rotter, 1971).

Convenience sampling has inherent disadvantages such as potential data misrepresentation and systematic bias. However, convenience sampling is often utilized in psychology and organizational behavior studies (Wilkinson, 1999) (Youssef, 2007). In most social sciences, many (if not all) of the samples are convenience samples (Landers, 2015).

Although the FTM model is written in the context of an "employee to employee" (under an employer/manager) relationship, it can carry over to "student to student" (under a professor), because in both scenarios two parties are working together towards a common goal for an entity that is hierarchically above their position. Moreover, as employees need to trust each other to perform well at their respective tasks, students who work together on a common graded project/assignment must also trust each other to attain an acceptable grade. They must trust one another to ensure that there are no issues with plagiarism, which can have significantly negative effects on their academic and post-academic careers (Ashworth et al., 1997).

Interpersonal trust among development bankers was found to be closer in similarity to University students than other white-collar workers, demonstrating the validity of reasoning that University students understand and deal with interpersonal trust similar to that of corporate employees (Farris, Senner, \& Butterfield, 1973). 


\section{The Survey}

The survey is hosted on www.surveygizmo.com for employees of the staffing company, and has been set up through Ryerson University's student research pool (SONA) to participants who sign up.

For the size of the sample required to perform factor analysis 20 or more participants per factor is an acceptable figure (Suhr, 2006), totalling 140 in this study. However, since the population pool in the scope of this study was nearly 1,000, a goal of between 269 and 278 participants, as recommended by Cohen, Manion, \& Morrison (2000), was chosen. Data was gathered from 271 participants after eliminating bad data (more details below). Moreover, other scholars recommend a minimum of 150 as a rule of thumb (Tabachnick \& Fidell, 2007).

The survey was deployed to Ryerson University students and the staffing company with the explicit assertion that none of the raw data or specific outcomes will be shared with the students or the company, and that all survey participants will remain anonymous.

Ryerson Students clicked onto the surveygizmo.com survey through Ryerson University's SONA research program, and employees in the staffing company were emailed (via their employers) a link to their version of the survey. Management at the staffing company had no way of knowing who responded to the survey.

While the original TMI survey was made available to employees at the staffing company, a reworded version was set up for Ryerson University students: Instead of using the words “manager", "co-worker", and "the company", Ryerson students' surveys used the words "professor", "classmates/colleagues", and "the University" respectively; Not taking this step 
could easily create confusion in the respondents at Ryerson as the wording of the original TMI survey is specifically written for corporate environments.

A total of 194 students and 106 employees responded. The potential for selection bias is present in this study as the randomness of the employees and students taking part is limited to that of one University and one company. More information on selection bias, and other biases are in the Limitations section.

77 total questions make up the TMI survey, with one question, the $43^{\text {rd }}$ in sequential order, being left out of all analysis. Question 43 asks participants to name a colleague/coworker/classmate for which following questions relate. In this study, we kept all names anonymous and participants were asked to use pseudonyms such as "Person A" in its place. Thus question 43 was not part of any statistical analyses performed on the data gathered, and all instances of question 43's answers were permanently removed.

\section{Excel}

No surveys were accepted without being completed (through the surveygizmo.com's website settings) so that no missing data was encountered. The 300 completed surveys were exported to an excel spreadsheet, and had their standard deviations calculated using STDEV.P function. Values that were low or high (e.g. 0 or 2) pointed me to responses that needed to be cut (i.e. participants that were likely clicking the same response for most, if not all, questions). A total of 271 responses (surveys) moved on to the next step. That data was then entered into SPSS v.23. 


\section{SPSS}

The questions in the TMI survey were labeled according the order they appear in the survey in SPSS. The survey was designed with each sub-construct's questions in order, rather than randomized. Moreover, the survey has headings indicating which sub-construct is being measured making labelling easier.

Questions were labeled in order from Q1 to Q77, with question 43 being left out as mentioned earlier. The questions were then each given a further label in SPSS to refer to their FTM construct and question: for example, the first three questions under "Propensity to Trust" were further labeled as $\mathrm{P} 2 \mathrm{~T}-1, \mathrm{P} 2 \mathrm{~T}-2$, and $\mathrm{P} 2 \mathrm{~T}-3$ respectively). This last step was performed to more easily interpret SPSS outputs.

\section{Exploratory Factor Analysis (EFA)}

The aim was to work with this sample for analysis purposes as opposed to instrument development, thus, the Principal Axis Factoring (PAF) method was used to analyze the data. In SPSS, that was accomplished using Analyze > Dimension Reduction > Factor.

The analysis was performed in three overall steps:

1. The combined data from students and employees was used to perform EFA.

2. The data from the students only was used to perform EFA.

3. The data from the employees only was used to perform EFA.

In the context of analyzing the data in SPSS, Questions are referred to as Items.

Principal Axis Factoring was utilized to perform a basic EFA on the data in which sets of questions from each theoretical construct were analyzed individually (e.g. P2T-1 to P2T-8 from 
Table 1). Then it was determined which, if any, items needed to be removed, how many factors were extracted, which remaining items loaded onto which said factor and to what degree.

Eigenvalues above 1 were used as a threshold to determine factors extracted, which is common practice (Osborne \& Costello, 2009).

A Kaiser-Meyer-Olkin (KMO) test was selected to check if there are sufficient items for each factor (sampling adequacy), with a score greater than 0.5 being the absolute minimum, and greater than 0.7 being ideal, such that distinct and reliable factors can be produced (Kaiser, 1974; MacCallum, Widaman, Zhang, \& Hong, 1999).

Bartlett's Test of Sphericity was chosen to verify the assumption that variances are equal in the sample (i.e. it has patterned relationships). With a significance $(p)$ below 0.05 there is room for dimensionality reduction.

If the Determinant is below 0.00001 (indicating an absence of collinearity) (Field, 2013), the factor analysis cannot proceed and SPSS will stop the process (Snedecor \& Cochran, 1989).

For the purpose of this study, items were not removed due to collinearity for several reasons: 1. It is more important in regression analyses than EFA. 2. Choosing which item to remove between a set of collinear items is arbitrary (Field, 2013).

A Varimax Rotation was employed, as it is an accepted rotation in exploratory factor analysis (Reise et al., 2000), even though some correlation among factors can be expected in social sciences (Osborne \& Costello, 2009).

Coefficients were sorted by size for easier interpretation, and small coefficients (below 0.3) were suppressed (Field, 2013, p. 692). 


\section{EFA Procedure}

The following procedure was carried out iteratively with each of the three sets of data, and the items (questions) in each sub-construct:

1. Items with communality below 0.3 were removed (MacCallum et al., 1999).

2. The number of factors extracted, and total variance explained with Eigenvalues greater than 1 were noted.

3. In the Rotated Factor Matrix, items that cross-loaded onto multiple factors were removed.

4. Items that loaded below 0.4 were removed (Stevens, 2012).

5. The remaining factors extracted and associated items that were loaded onto each were noted. A minimum of three items per factor, loaded at 0.4 or above was required for any remaining factor to be retained (Streiner, 1994).

6. Each extracted factor had its associated items entered into a Reliability test in SPSS (Analyze>Scale>Reliability Analysis), to determine the Cronbach's Alpha ( $\alpha$ ), which gave me insight into whether the remaining items loaded onto each extracted factor are closely related. Any score above 0.9 is considered excellent, between 0.8 and 0.89 is considered good (DeVellis, 2016), and between 0.7 and 0.79 is acceptable (Nunnally, 1978). For the purpose of this research, 0.7 will be the cut-off for $\alpha$ as it is considered an appropriate general rule of thumb (Tavakol \& Dennick, 2011).

For each construct within each of the three sets of data, the following are reported: The number of items with low communality, the number of factors extracted, the number of items loaded onto each extracted factor, KMO and P-Values ( $p$ ), the Determinant (Det), the Average Communality (Avg. Comm.), Total Variance Explained (\% Var Exp.). Cronbach's Alpha ( $\alpha$ ). Whether there is parsimony within the theoretical factor. 


\section{Results}

\section{Combined Student \& Employee Results}

Propensity to Trust (P2T): One item with low communality and two items that crossloaded were removed. The final set of five items loaded onto one factor, with KMO, p-value, and the determinant being acceptable, but the average communality was low at 0.384 , and the total variance explained at $50.6 \%$ is barely acceptable (Peterson, 2000). The low communality score may indicate that remaining items may not load significantly onto any factor, but isn't an issue when looking at the final loadings and their associated Cronbach's Alpha. The Cronbach's Alpha test on the remaining items was acceptable at 0.753 . With respect to parsimony, a total of three items were removed.

Table 1: P2T - Combined Data

\begin{tabular}{|c|c|c|c|c|c|c|c|c|}
\hline KMO & $\boldsymbol{p}$ & Det & $\begin{array}{c}\text { Low } \\
\text { Comm }\end{array}$ & Avg Comm & Factors & $\begin{array}{c}\% \text { Var } \\
\text { Exp }\end{array}$ & $\begin{array}{c}\text { Cross } \\
\text { Loaded }\end{array}$ & Action Taken \\
\hline .769 & 0 & .15 & 1 & .414 & 2 & $54.8 \%$ & 0 & $\begin{array}{c}\text { Removed Low Comm. } \\
\text { Items }\end{array}$ \\
\hline .760 & 0 & .22 & 0 & .432 & 2 & $58.4 \%$ & 2 & $\begin{array}{c}\text { Removed Cross Loaded } \\
\text { Items }\end{array}$ \\
\hline .796 & 0 & .35 & 0 & .384 & 1 & $50.6 \%$ & NA & $\begin{array}{c}\text { Cronbach's Alpha Test } \\
(\alpha)\end{array}$ \\
\hline$\alpha$ & .753 & \multicolumn{10}{|c|}{} \\
\hline
\end{tabular}

Institutional Trust (IT): No items had a low communality, but 9 items cross-loaded and were removed. Eventually, an entire extracted factor (factor four) was removed as it only had two items loaded onto it (i.e. less than the three-item minimum that is acceptable), leaving three factors extracted. Each iteration had an acceptable KMO and p-value, but the determinant was below 0.00001 , indicating that three or more items had high intercorrelations. The total variance explained was acceptable at $74.5 \%$ in the final iteration of EFA, and the remaining items had an 
acceptable $\alpha$ score within the three factors. In each iteration, the average communality score and total variance explained were acceptable.

Table 2: IT - Combined Data

\begin{tabular}{|c|c|c|c|c|c|c|c|c|}
\hline KMO & $\boldsymbol{p}$ & Det & $\begin{array}{c}\text { Low } \\
\text { Comm }\end{array}$ & $\begin{array}{c}\text { Avg } \\
\text { Comm }\end{array}$ & Factors & $\begin{array}{c}\% \text { Var } \\
\text { Exp }\end{array}$ & $\begin{array}{c}\text { Cross } \\
\text { Loaded }\end{array}$ & Action Taken \\
\hline .922 & 0 & .00 & 0 & .621 & 5 & $69.7 \%$ & 9 & $\begin{array}{c}\text { Removed Cross } \\
\text { Loaded Items }\end{array}$ \\
\hline .900 & 0 & .00 & 0 & .657 & 4 & $74.7 \%$ & 0 & $\begin{array}{c}\text { Removed Factor } 4 \\
(2 \text { items loaded })\end{array}$ \\
\hline .903 & 0 & .00 & 0 & .677 & 3 & $74.5 \%$ & 0 & $\begin{array}{c}\text { Cronbach's Alpha } \\
\text { Test }(\alpha)\end{array}$ \\
\hline \multicolumn{7}{|l}{ Factor $1 \alpha$} & .947 & .850 \\
\hline
\end{tabular}

The final set of items loaded under "Institutional Trust" include 14 of the originally theorized 25 items loaded onto three factors. The FTM model's construct consists of eight subconstructs, while the three factors extracted represent several of these sub-constructs:

- IT-1 to IT-3 load onto their own factor, matching the theoretical factor "Perceived Monitoring".

- $\quad$ IT-10 to IT-13 load onto a single factor, matching the theoretical factor "Perceived Cooperative Norms".

- IT-15, IT-16, IT-17, IT-19, IT-20, IT-21, and IT-22 loaded onto factor one, but are from three theoretical factors: "Situation Normality: Management Benevolence", “Situation Normality: Management Integrity", and "Situation Normality: Management Competence".

With respect to parsimony, the first factor extracted had items removed, while the remaining two factors had all their theoretical items loaded. The following table illustrates which 
items loaded, onto which extracted factor, as well as the total variance explained and the Cronbach's Alpha for each extracted factor.

Table 3: IT - Combined Data: Final Loadings

\begin{tabular}{|} 
Rotated Factor Matrix ${ }^{\mathrm{a}}$ \\
\begin{tabular}{|c|c|c|c|c|c|}
\hline & \multicolumn{3}{|c|}{ Factor } & $\begin{array}{c}\text { \% Var } \\
\text { Explained }\end{array}$ & $\boldsymbol{\alpha}$ \\
\cline { 2 - 5 } & $\mathbf{1}$ & $\mathbf{2}$ & $\mathbf{3}$ & & \\
IT-20 & .870 & & & & \\
IT-21 & .863 & & & & .947 \\
IT-17 & .822 & & & & \\
IT-22 & .805 & & & $76.308 \%$ & \\
IT-19 & .792 & & & & \\
IT-15 & .773 & & & & \\
IT-16 & .692 & & & & \\
\hline IT-11 & & .845 & & & \\
IT-13 & & .823 & & 650 \\
IT-10 & & .595 & & & \\
IT-12 & & .591 & & & \\
\hline IT-2 & & & .816 & & \\
IT-3 & & & .768 & $75.117 \%$ & \\
IT-1 & & & .649 & & \\
\hline
\end{tabular}
\end{tabular}

Although these items originate in separate theoretical factors within the construct Institutional Trust, they all deal with "Situation Normality".

Management Intervention Measures (MI): In total two items had low communality, and three items cross-loaded. The second of two extracted factors had to be eliminated altogether as it only had two items loaded. Each iteration of EFA had acceptable KMO, p-value, determinant, average communality, and total variance explained. With respect to parsimony, five items were removed. 
Table 4: MI - Combined Data

\begin{tabular}{|c|c|c|c|c|c|c|c|c|}
\hline KMO & $\boldsymbol{p}$ & Det & $\begin{array}{c}\text { Low } \\
\text { Comm }\end{array}$ & $\begin{array}{c}\text { Avg } \\
\text { Comm }\end{array}$ & Factors & $\begin{array}{c}\% \text { Var } \\
\text { Exp }\end{array}$ & $\begin{array}{c}\text { Cross } \\
\text { Loaded }\end{array}$ & Action Taken \\
\hline .744 & 0 & .02 & 1 & .594 & 3 & $70.8 \%$ & 2 & $\begin{array}{c}\text { Removed Low Comm. } \\
\text { Items }\end{array}$ \\
\hline .725 & 0 & .03 & 0 & .525 & 2 & $64.1 \%$ & 1 & $\begin{array}{c}\text { Removed Cross } \\
\text { Loaded Items }\end{array}$ \\
\hline .715 & 0 & .04 & 1 & .563 & 2 & $67.8 \%$ & 0 & $\begin{array}{c}\text { Removed Low Comm. } \\
\text { Items }\end{array}$ \\
\hline .715 & 0 & .05 & 0 & .619 & 2 & $73.8 \%$ & 0 & $\begin{array}{c}\text { Removed Factor 2 } 2 \\
\text { items loaded })\end{array}$ \\
\hline .749 & 0 & .09 & 0 & .637 & 1 & $73.4 \%$ & NA & $\begin{array}{c}\text { Cronbach's Alpha Test } \\
(\alpha)\end{array}$ \\
\hline$\alpha$ & .863 & & & & & \\
\hline \multicolumn{2}{|c|}{$\alpha$}
\end{tabular}

Eventually only one factor was extracted with four items (MI4, MI-7, MI-8, and MI-9).

MI-4 was the only item that was from a different theoretical sub-construct ("Analysis"), but the question itself qualitatively compliments the remaining items (MI-7, MI-8, and MI-9) which originate in the theoretical sub-construct "Implementation": MI-4 refers to the company (or University) seriously evaluating the results of the survey, while the remaining items refer to the company (or University) acting on the results of the survey, implementing outcomes based on the survey, and being serious about managing trust, all of which can qualitatively be described as “evaluating, acting on, implementing, and taking seriously the results of this survey".

An interesting observation is that the participants had read to and signed a consent form that made it clear that the results of the survey would not be shared with their company or University. Given that the participants knew their answers (or the amalgamation of all their answers) were not being shared, any number of scenarios may have played out including participants not paying attention to the consent form, not taking its claim (to keep information private) seriously, or genuinely mistrusted the claims made in said consent form. 
Perceived Trustworthiness (PercT): Only two items had low communality, while 10 items cross-loaded. The KMO values decreased with each iteration of EFA, down to a barely acceptable 0.500 , while average communality and p-value were acceptable in each iteration, and total variance explained increased to $94.9 \%$. Only two items remained loaded onto a single factor, which is below the three-item minimum that is acceptable, leading me to eliminate all of the items in the construct.

Table 5: PercT - Combined Data

\begin{tabular}{|c|c|c|c|c|c|c|c|c|}
\hline KMO & $\boldsymbol{p}$ & Det & $\begin{array}{c}\text { Low } \\
\text { Comm }\end{array}$ & $\begin{array}{c}\text { Avg } \\
\text { Comm }\end{array}$ & Factors & $\begin{array}{c}\% \text { Var } \\
\text { Exp }\end{array}$ & $\begin{array}{c}\text { Cross } \\
\text { Loaded }\end{array}$ & Action Taken \\
\hline .961 & 0 & .00 & 0 & .753 & 2 & $79.7 \%$ & 8 & Removed Cross Loaded Items \\
\hline .870 & 0 & .01 & 0 & .731 & 2 & $83.8 \%$ & 1 & Removed Cross Loaded Items \\
\hline .797 & 0 & .02 & 0 & .730 & 2 & $85.3 \%$ & 1 & Removed Cross Loaded Items \\
\hline .630 & 0 & .11 & 2 & .535 & 1 & $62.1 \%$ & NA & Removed Low Comm. Items \\
\hline .500 & 0 & .19 & 0 & .898 & 1 & $94.9 \%$ & NA & Removed Remaining 2 Items \\
\hline
\end{tabular}

Trusting Intentions (TrInt): Only one iteration of EFA was necessary to determine that all the items in this factor can be kept as the KMO, p-value, average communality, total variance explained, and $\alpha$ were all acceptable, although the determinant was low indicating high intercollinearity.

Table 6: TrInt - Combined Data

\begin{tabular}{|c|c|c|c|c|c|c|c|c|}
\hline KMO & $\boldsymbol{p}$ & Det & $\begin{array}{c}\text { Low } \\
\text { Comm }\end{array}$ & $\begin{array}{c}\text { Avg } \\
\text { Comm }\end{array}$ & Factors & $\begin{array}{c}\text { \% Var } \\
\text { Exp }\end{array}$ & $\begin{array}{c}\text { Cross } \\
\text { Loaded }\end{array}$ & Action Taken \\
\hline .917 & 0 & .00 & 0 & .825 & 1 & $85.4 \%$ & NA & Cronbach's Alpha Test $(\alpha)$ \\
\hline$\alpha$ & .965 & \multicolumn{10}{|l}{} \\
\hline
\end{tabular}

The theoretical construct consists of two sub-constructs, each with three questions. The sub-constructs are "Willingness to Depend" and "Subjective Probability of Depending". This factor is parsimonious in its original form. 
Own Trusting Behaviors (TrBeh Own): One iteration of EFA was performed as all the items loaded onto a single factor, matching the theoretical sub-construct "willingness to depend" with acceptable KMO, p-value, determinant, average communality, $\alpha$, and total variance explained.

Table 7: TrBeh Own - Combined Data

\begin{tabular}{|c|c|c|c|c|c|c|c|c|}
\hline KMO & $\boldsymbol{p}$ & Det & $\begin{array}{c}\text { Low } \\
\text { Comm }\end{array}$ & $\begin{array}{c}\text { Avg } \\
\text { Comm }\end{array}$ & Factors & $\begin{array}{c}\text { \% Var } \\
\text { Exp }\end{array}$ & $\begin{array}{c}\text { Cross } \\
\text { Loaded }\end{array}$ & Action Taken \\
\hline .887 & 0 & .03 & 0 & .696 & 1 & $75.6 \%$ & NA & Cronbach's Alpha Test $(\alpha)$ \\
\hline$\alpha$ & .916 & \multicolumn{7}{|l}{} \\
\hline
\end{tabular}

With the theoretical and extracted factors having identical items loaded, the factor is parsimonious in its original form.

Other's Trusting Behaviors (TrBeh Other's): Two iterations of EFA were performed to eliminate one item with low communality, loading the remaining items onto a single factor. This does not match the theory in which two sub-constructs “Other's Reciprocal Trusting Behaviors" and "Other's Trust Outcome Behaviors" are posited.

Table 8: TrBeh Other's - Combined Data

\begin{tabular}{|c|c|c|c|c|c|c|c|c|}
\hline KMO & $\boldsymbol{p}$ & Det & $\begin{array}{c}\text { Low } \\
\text { Comm }\end{array}$ & $\begin{array}{c}\text { Avg } \\
\text { Comm }\end{array}$ & Factors & $\begin{array}{c}\text { \% Var } \\
\text { Exp }\end{array}$ & $\begin{array}{c}\text { Cross } \\
\text { Loaded }\end{array}$ & Action Taken \\
\hline .937 & 0 & .00 & 1 & .694 & 1 & $72.4 \%$ & NA & Removed Low Comm. Items \\
\hline .935 & 0 & .00 & 0 & .746 & 1 & $77.6 \%$ & NA & Cronbach's Alpha Test $(\alpha)$ \\
\hline$\alpha$ & .958 & \multicolumn{10}{|l}{} \\
\hline
\end{tabular}

$\mathrm{KMO}, \mathrm{p}$-value, average communality, total variance explained, and $\alpha$ values were acceptable, though the determinant was low in each iteration indicating high inter-collinearity. With regards to parsimony, one item was removed. 


\section{Final Factor Loadings - Combined Data}

The final factor loadings for the combined data are listed below in Table 10:

Table 9: Final Factor Loadings - Combined Data

\begin{tabular}{|c|c|c|c|c|c|c|}
\hline \multicolumn{7}{|c|}{ Final Factor Loadings - Combined Data } \\
\hline P2T & IT & MI & PercT & Trlnt & TrBeh Own & TrBeh Other's \\
\hline P2T-3 & IT-1 & MI-4 & NA & TrInt-1 & Tbeh-1 & Tbeh-6 \\
P2T-5 & IT-2 & MI-7 & & TrInt-2 & Tbeh-2 & Tbeh-7 \\
P2T-6 & IT-3 & MI-8 & & Trlnt-3 & Tbeh-3 & Tbeh-8 \\
P2T-7 & IT-10 & MI-9 & & TrInt-4 & Tbeh-4 & Tbeh-10 \\
P2T-8 & IT-11 & & & TrInt-5 & Tbeh-5 & Tbeh-11 \\
& IT-12 & & & Trlnt-6 & & Tbeh-12 \\
& IT-13 & & & & & Tbeh-13 \\
\cline { 2 - 2 } & IT-15 & & & & & Tbeh-14 \\
& IT-16 & & & & & \\
& IT-17 & & & & & \\
& IT-19 & & & & & \\
& IT-20 & & & & & \\
& IT-21 & & & & & \\
& IT-22 & & & & & \\
\hline
\end{tabular}

42 of the original 76 items, eight extracted factors, and six of the original seven

constructs are represented in the final loadings. Note that Institutional Trust had three factors extracted, divided by a line in the above table.

\section{Student-Only Data Results}

Propensity to Trust (P2T): Six items were removed in total, leaving only two loaded items on one factor, which is below the three-item per factor threshold. Thus, all the items from this construct were removed. Note that the KMO score was barely acceptable at 0.500 , and the average communality was below acceptable levels at 0.373 on the final iteration. 
Table 10: P2T - Student Data

\begin{tabular}{|c|c|c|c|c|c|c|c|c|}
\hline KMO & $\boldsymbol{p}$ & Det & $\begin{array}{c}\text { Low } \\
\text { Comm }\end{array}$ & $\begin{array}{c}\text { Avg } \\
\text { Comm }\end{array}$ & Factors & $\begin{array}{c}\% \text { Var } \\
\text { Exp }\end{array}$ & $\begin{array}{c}\text { Cross } \\
\text { Loaded }\end{array}$ & Action Taken \\
\hline .656 & 0 & .40 & 5 & .289 & 2 & $44.96 \%$ & 0 & $\begin{array}{c}\text { Removed Low } \\
\text { Comm. Items }\end{array}$ \\
\hline .505 & 0 & .85 & 1 & .253 & 1 & $46.23 \%$ & NA & $\begin{array}{c}\text { Removed Low } \\
\text { Comm. Items }\end{array}$ \\
\hline .500 & 0 & .86 & 0 & .373 & 1 & $68.70 \%$ & NA & $\begin{array}{c}\text { Removed } \\
\text { Remaining 2 Items }\end{array}$ \\
\hline
\end{tabular}

Institutional Trust (IT): Four factors were extracted, and four items were removed.

There was an acceptable KMO, p-value, average communality, total variance explained, and $\alpha$ for each of the four extracted factors.

Table 11: IT - Student Data

\begin{tabular}{|c|c|c|c|c|c|c|c|c|}
\hline KMO & $p$ & Det & $\begin{array}{l}\text { Low } \\
\text { Comm }\end{array}$ & $\begin{array}{l}\text { Avg } \\
\text { Comm }\end{array}$ & Factors & $\begin{array}{l}\text { \% Var } \\
\text { Exp }\end{array}$ & $\begin{array}{l}\text { Cross } \\
\text { Loaded }\end{array}$ & Action Taken \\
\hline .865 & 0 & .00 & 1 & .571 & 6 & $67.81 \%$ & 4 & $\begin{array}{l}\text { Removed Low } \\
\text { Comm. Items }\end{array}$ \\
\hline .870 & 0 & .00 & 0 & .582 & 6 & $69.26 \%$ & 3 & $\begin{array}{l}\text { Removed Cross } \\
\text { Loaded Items }\end{array}$ \\
\hline .854 & 0 & .00 & 0 & .605 & 6 & $72.45 \%$ & 0 & $\begin{array}{c}\text { Removed Factors } \\
5 \& 6 \text { (only } 2 \text { items } \\
\text { loaded) }\end{array}$ \\
\hline .869 & 0 & .00 & 0 & .626 & 4 & $71.63 \%$ & 0 & $\begin{array}{c}\text { Cronbach's Alpha } \\
\text { Test }\end{array}$ \\
\hline \multicolumn{3}{|c|}{ Factor $1 \alpha$} & .936 & & & & & \\
\hline \multicolumn{3}{|c|}{ Factor $2 \alpha$} & .826 & & & & & \\
\hline \multicolumn{3}{|c|}{ Factor $3 \alpha$} & .810 & & & & & \\
\hline \multicolumn{3}{|c|}{ Factor $4 \alpha$} & .775 & & & & & \\
\hline
\end{tabular}

The final loadings for "Institutional Trust" include 17 of the originally theorized 25 items loaded onto four factors. The FTM model's construct consists of eight sub-constructs, while the four factors extracted include items from various theorized sub-constructs: 
- The first factor is almost identical to the combined data, with the exception of IT-14 which only loaded with the student data.

- Items IT-1 to IT-3 loaded onto their own factor, mimicking the results of the combined data.

- Items IT-23 to IT-25 loaded onto another factor in the student data but not the combined data, indicating that perhaps the theoretical factor they represent ("Structural Assurances") was better reflected in the questions, in the eyes of students in comparison to the combined group.

- Items IT-11 to IT-13 loaded onto a single factor as in the combined data, but without IT-10 which did not load here.

Table 12: IT - Student Data: Final Loadings

Rotated Factor Matrix ${ }^{a}$

\begin{tabular}{|c|c|c|c|c|c|c|}
\hline & \multicolumn{4}{|c|}{ Factor } & \multirow{2}{*}{$\%$ Var Explained } & \multirow{2}{*}{$\alpha$} \\
\hline & 1 & 2 & 3 & 4 & & \\
\hline IT-21 & .864 & & & & \multirow{7}{*}{$69.188 \%$} & \multirow{7}{*}{.936} \\
\hline $\begin{array}{l}\text { IT-20 } \\
\text { IT-17 }\end{array}$ & $\begin{array}{l}.849 \\
809\end{array}$ & & & & & \\
\hline IT-15 & .784 & & & & & \\
\hline IT-19 & .776 & & & & & \\
\hline IT-16 & .758 & & & & & \\
\hline IT-22 & .743 & & & & & \\
\hline IT-14 & .715 & & & & & \\
\hline IT-13 & & .766 & & & \multirow[b]{2}{*}{$74.141 \%$} & \multirow[b]{2}{*}{.826} \\
\hline IT-12 & & .753 & & & & \\
\hline$\frac{11-11}{\mid T-23}$ & & & & & \multirow{3}{*}{$72.764 \%$} & \multirow{3}{*}{.810} \\
\hline IT-25 & & & . 7201 & & & \\
\hline IT-24 & & & .654 & & & \\
\hline IT-2 & & & & 785 & \multirow{3}{*}{$69.968 \%$} & \multirow{3}{*}{.775} \\
\hline IT-3 & & & & .744 & & \\
\hline IT-1 & & & & .586 & & \\
\hline
\end{tabular}

In terms of parsimony, two extracted factors had all their items loaded (in comparison to the theorized sub-constructs) which tells me that they are already parsimonious, while the other 
two factors had items removed. Once again, the determinant was below 0.00001 pointing to high inter-correlations among the items.

Management Intervention Measures (MI): A single extracted factor emerged. The final KMO, p-value, average communality, total variance explained, and determinant were all acceptable. A higher $\alpha$ score would result if MI-9 were removed, but that would leave only two loaded items.

Table 13: MI - Student Data

\begin{tabular}{|c|c|c|c|c|c|c|c|c|}
\hline KMO & $\boldsymbol{p}$ & Det & $\begin{array}{c}\text { Low } \\
\text { Comm }\end{array}$ & $\begin{array}{c}\text { Avg } \\
\text { Comm }\end{array}$ & Factors & $\begin{array}{c}\% \text { Var } \\
\text { Exp }\end{array}$ & $\begin{array}{c}\text { Cross } \\
\text { Loaded }\end{array}$ & Action Taken \\
\hline .770 & 0 & .03 & 2 & .556 & 3 & $69.38 \%$ & 2 & $\begin{array}{c}\text { Removed Low } \\
\text { Comm. Items }\end{array}$ \\
\hline .765 & 0 & .04 & 1 & .553 & 2 & $65.89 \%$ & 0 & $\begin{array}{c}\text { Removed Low } \\
\text { Comm. Items }\end{array}$ \\
\hline .748 & 0 & .05 & 0 & .646 & 2 & $73.38 \%$ & 1 & $\begin{array}{c}\text { Removed } \\
\text { Cross Loaded } \\
\text { Items }\end{array}$ \\
\hline .684 & 0 & .09 & 0 & .646 & 2 & $78.01 \%$ & 0 & $\begin{array}{c}\text { Removed } \\
\text { Factor 2 (only 2 } \\
\text { items loaded) }\end{array}$ \\
\hline .663 & 0 & .16 & 0 & .714 & 1 & $79.19 \%$ & NA & $\begin{array}{c}\text { Cronbach's } \\
\text { Alpha Test }\end{array}$ \\
\hline$\alpha$ & & .867 & &
\end{tabular}

Apart from MI-4 (which didn't load in the student-only data), the other three items matched those that loaded in the combined data. With respect to parsimony, several items were removed.

Perceived Trustworthiness (PercT): Nine items loaded onto a single factor with an acceptable KMO, p-value, average communality, total variance explained, and $\alpha$ scores. However, the determinant was low in each iteration. 
Table 14: PercT-Student Data

\begin{tabular}{|c|c|c|c|c|c|c|c|c|}
\hline KMO & $\boldsymbol{p}$ & Det & $\begin{array}{c}\text { Low } \\
\text { Comm }\end{array}$ & $\begin{array}{c}\text { Avg } \\
\text { Comm }\end{array}$ & Factors & $\begin{array}{c}\% \text { Var } \\
\text { Exp }\end{array}$ & $\begin{array}{c}\text { Cross } \\
\text { Loaded }\end{array}$ & Action Taken \\
\hline .944 & 0 & .00 & 0 & .717 & 2 & $76.45 \%$ & 4 & $\begin{array}{c}\text { Removed Cross } \\
\text { Loaded Items }\end{array}$ \\
\hline .935 & 0 & .00 & 1 & .695 & 1 & $71.88 \%$ & 0 & $\begin{array}{c}\text { Removed Low } \\
\text { Comm. Items }\end{array}$ \\
\hline .939 & 0 & .00 & 0 & .767 & 1 & $79.23 \%$ & NA & $\begin{array}{c}\text { Cronbach's Alpha } \\
\text { Test }\end{array}$ \\
\hline \multicolumn{2}{|c|}{$\alpha$} & .967 & \multicolumn{10}{c}{} \\
\hline
\end{tabular}

The one remaining factor contains items loaded from several theoretical sub-constructs, and with five items removed, there is parsimony.

The fact that any factors loaded with three or more items is notable as none of the items loaded onto any factors from the combined data.

Trusting Intentions (TrInt): Only one iteration of EFA was required to extract a single factor with all six of the original items loaded onto it. The KMO, p-value, average communality, total variance explained, and $\alpha$ were acceptable, though the determinant was low. With respect to parsimony, no items were removed.

Table 15: TrInt - Student Data

\begin{tabular}{|c|c|c|c|c|c|c|c|c|}
\hline KMO & $\boldsymbol{p}$ & Det & $\begin{array}{c}\text { Low } \\
\text { Comm }\end{array}$ & $\begin{array}{c}\text { Avg } \\
\text { Comm }\end{array}$ & Factors & $\begin{array}{c}\text { \% Var } \\
\text { Exp }\end{array}$ & $\begin{array}{c}\text { Cross } \\
\text { Loaded }\end{array}$ & Action Taken \\
\hline .898 & 0 & .00 & 0 & .785 & 1 & $81.94 \%$ & NA & $\begin{array}{c}\text { Cronbach's Alpha } \\
\text { Test }\end{array}$ \\
\hline \multicolumn{2}{|c|}{$\alpha$} & .955 & \multicolumn{1}{|c|}{} & & & \\
\hline
\end{tabular}

Own Trusting Behaviors (TrBeh Own): One iteration of EFA was performed to load all items onto a single factor, matching the results of the combined data and the theory. The $\mathrm{KMO}$, p-value, determinant, $\alpha$, and total variance explained were acceptable, though the average communality was below 0.6 . 
Table 16: TrBeh Own-Student Data

\begin{tabular}{|c|c|c|c|c|c|c|c|c|}
\hline KMO & $\boldsymbol{p}$ & Det & $\begin{array}{c}\text { Low } \\
\text { Comm }\end{array}$ & $\begin{array}{c}\text { Avg } \\
\text { Comm }\end{array}$ & Factors & $\begin{array}{c}\% \text { Var } \\
\text { Exp }\end{array}$ & $\begin{array}{c}\text { Cross } \\
\text { Loaded }\end{array}$ & Action Taken \\
\hline .848 & 0 & .09 & 0 & .590 & 1 & $67.157 \%$ & NA & Cronbach's Alpha Test \\
\hline$\alpha$ & .873 & \multicolumn{10}{|l}{} \\
\hline
\end{tabular}

The factor is already parsimonious as no items were removed.

Other's Trusting Behaviors (TrBeh Other's): Only two iterations of EFA were necessary to remove an item with low communality and extract a single factor. Despite the $\mathrm{KMO}$, p-value, average communality, total variance explained, and $\alpha$ scores being acceptable, the determinant was too low. Items that theoretically were assigned to two sub-constructs, loaded onto a single factor with the student data. This factor is parsimonious.

Table 17: TrBeh Other's - Student Data

\begin{tabular}{|c|c|c|c|c|c|c|c|c|}
\hline KMO & $\boldsymbol{p}$ & Det & $\begin{array}{c}\text { Low } \\
\text { Comm }\end{array}$ & $\begin{array}{c}\text { Avg } \\
\text { Comm }\end{array}$ & Factors & $\begin{array}{c}\% \text { Var } \\
\text { Exp }\end{array}$ & $\begin{array}{c}\text { Cross } \\
\text { Loaded }\end{array}$ & Action Taken \\
\hline .918 & 0 & .00 & 1 & .666 & 2 & $63.66 \%$ & 6 & $\begin{array}{c}\text { Removed Low } \\
\text { Comm. Items }\end{array}$ \\
\hline .921 & 0 & .00 & 0 & .655 & 1 & $69.51 \%$ & NA & $\begin{array}{c}\text { Cronbach's Alpha } \\
\text { Test }\end{array}$ \\
\hline \multicolumn{2}{|c|}{$\alpha$} & .935 & \multicolumn{1}{|c|}{} \\
\hline
\end{tabular}




\section{Final Factor Loadings - Student Data}

The final factor loadings from the student data are listed below:

Table 18: Final Factor Loadings - Student Data

\begin{tabular}{|c|c|c|c|c|c|c|}
\hline \multicolumn{7}{|c|}{ Final Factor Loadings - Student Data Only } \\
\hline P2T & IT & MI & PercT & TrInt & TrBeh Own & TrBeh Other's \\
\hline NA & IT-1 & MI-7 & PercT-1 & Trlnt-1 & Tbeh-1 & Tbeh-6 \\
& IT-2 & MI-8 & PercT-2 & Trlnt-2 & Tbeh-2 & Tbeh-7 \\
& IT-3 & MI-9 & PercT-3 & Trlnt-3 & Tbeh-3 & Tbeh-8 \\
\cline { 1 - 2 } & IT-11 & & PercT-5 & Trlnt-4 & Tbeh-4 & Tbeh-10 \\
& IT-12 & & PercT-7 & Trlnt-5 & Tbeh-5 & Tbeh-11 \\
& IT-13 & & PercT-8 & Trlnt-6 & & Tbeh-12 \\
\cline { 1 - 1 } & IT-14 & & PercT-9 & & & Tbeh-13 \\
& IT-15 & & PercT-10 & & & Tbeh-14 \\
& IT-16 & & PercT-11 & & & \\
& IT-17 & & & & & \\
& IT-19 & & & & & \\
& IT-20 & & & & & \\
& IT-21 & & & & & \\
& IT-22 & & & & & \\
\cline { 1 - 1 } & IT-23 & & & & & \\
& IT-24 & & & & & \\
& IT-25 & & & & \\
\hline
\end{tabular}

48 of the original 76 items, 9 extracted factors, and six of the original seven constructs are represented in the final loadings. Note that $\mathrm{P} 2 \mathrm{~T}$ and PercT didn't share any loaded items between the combined and student-only data. Note also that Institutional Trust had four factors extracted, each divided by a line in the above table. 


\section{Employee-Data Results}

Propensity to Trust (P2T): The removal of items due to cross-loading and low communality resulted in two remaining factors with only two items loaded onto each. Thus, the remaining items were removed despite acceptable KMO, p-value, average communality (in the final iteration), and total variance explained. Parsimony does not apply as there are no items remaining.

Table 19: P2T - Employee Data

\begin{tabular}{|c|c|c|c|c|c|c|c|c|}
\hline KMO & $\boldsymbol{P}$ & Det & Low Comm & $\begin{array}{c}\text { Avg } \\
\text { Comm }\end{array}$ & Factors & $\begin{array}{c}\text { \% Var } \\
\text { Exp }\end{array}$ & $\begin{array}{c}\text { Cross } \\
\text { Loaded }\end{array}$ & Action Taken \\
\hline .771 & 0 & .01 & 0 & .738 & 3 & $81.74 \%$ & 3 & $\begin{array}{c}\text { Removed Cross } \\
\text { Loaded Items }\end{array}$ \\
\hline .590 & 0 & .09 & 1 & .562 & 5 & NA & NA & $\begin{array}{c}\text { Removed Low } \\
\text { Comm. Items }\end{array}$ \\
\hline .558 & 0 & .11 & 0 & .798 & 2 & $89.92 \%$ & 0 & $\begin{array}{c}\text { Both Factors only } \\
\text { had 2 Items Loaded }\end{array}$ \\
\hline
\end{tabular}

Institutional Trust (IT): A single factor loaded with three items after low communality and cross-loaded items were removed. There were acceptable KMO, p-value, determinant, average communality, and $\alpha$ values and there is parsimony.

Table 20: IT - Employee Data

\begin{tabular}{|c|c|c|c|c|c|c|c|c|}
\hline KMO & $\boldsymbol{p}$ & Det & Low Comm & $\begin{array}{c}\text { Avg } \\
\text { Comm }\end{array}$ & Factors & $\begin{array}{c}\% \text { Var } \\
\text { Exp }\end{array}$ & $\begin{array}{c}\text { Cross } \\
\text { Loaded }\end{array}$ & Action Taken \\
\hline .880 & 0 & .00 & 0 & .779 & 4 & $81.45 \%$ & 20 & $\begin{array}{c}\text { Removed Cross } \\
\text { Loaded Items }\end{array}$ \\
\hline .817 & 0 & .01 & 2 & .648 & 1 & $68.86 \%$ & NA & $\begin{array}{c}\text { Removed Low } \\
\text { Comm. Items }\end{array}$ \\
\hline .761 & 0 & .01 & 0 & .922 & 1 & $94.76 \%$ & NA & $\begin{array}{c}\text { Cronbach's Alpha } \\
\text { Test }\end{array}$ \\
\hline$\alpha$ & .972 & \multicolumn{10}{|c|}{} \\
\hline
\end{tabular}

Unlike the combined and student data, very few (three) items loaded onto this factor, all representing the theorized "Situation Normality - Management Competence" perfectly. 
Management Intervention Measures (MI): Communalities exceeding 1.0 required me to force three factors rather than use Eigenvalues above 1. Initially there were three factors extracted, but when reliability analyses were performed, one factor and three items remained.

MI-4, MI-7, and MI-8 match three of the items loaded from the combined data, and two of the three items loaded from the student data. Adequate KMO, p-value, determinant, and total variance scores resulted, but average communality was low at 0.582 .

Table 21: MI-Employee Data

\begin{tabular}{|c|c|c|c|c|c|c|c|c|}
\hline KMO & $\boldsymbol{p}$ & Det & $\begin{array}{c}\text { Low } \\
\text { Comm }\end{array}$ & $\begin{array}{c}\text { Avg } \\
\text { Comm }\end{array}$ & Factors & $\begin{array}{c}\% \text { Var } \\
\text { Exp }\end{array}$ & $\begin{array}{c}\text { Cross } \\
\text { Loaded }\end{array}$ & Action Taken \\
\hline .704 & 0 & .01 & 0 & .582 & 3 & $75.38 \%$ & NA & $\begin{array}{c}\text { Communality } \\
\text { Exceeded 1. Forcing } \\
3 \text { factors }\end{array}$ \\
\hline .704 & 0 & .01 & 0 & .582 & 3 & $75.38 \%$ & NA & $\begin{array}{c}\text { Same error as } \\
\text { before, Attempting } \\
\text { Cronbach's }\end{array}$ \\
\hline \multicolumn{2}{|c|}{ CA } & .902 & \multicolumn{10}{|c|}{} \\
\hline
\end{tabular}

If we look qualitatively at the three items loaded (MI-4, MI-7, and MI-8), they refer to the company (or University) seriously evaluating the results of the survey, act on the results of the survey, and implement the outcomes from said survey. These three questions in the survey can be qualitatively argued to be one factor, and there is parsimony.

Perceived Trustworthiness (PercT): Only one iteration of EFA was required as all but two items cross-loaded, leading me to remove the remaining two items as well. 
Table 22: PercT-Employee Data

\begin{tabular}{|c|c|c|c|c|c|c|c|c|}
\hline KMO & $\boldsymbol{p}$ & Det & $\begin{array}{c}\text { Low } \\
\text { Comm }\end{array}$ & $\begin{array}{c}\text { Avg } \\
\text { Comm }\end{array}$ & Factors & $\begin{array}{c}\% \text { Var } \\
\text { Exp }\end{array}$ & $\begin{array}{c}\text { Cross } \\
\text { Loaded }\end{array}$ & Action Taken \\
\hline .929 & 0 & .00000 & 0 & .825 & 2 & $85.58 \%$ & 12 & $\begin{array}{c}\text { All but } 2 \text { items } \\
\text { Cross Loaded }\end{array}$ \\
\hline
\end{tabular}

Note that the determinant was essentially zero, and that despite KMO, p-value, average communality, and total variance explained being acceptable, all items were removed, and parsimony does not apply.

Trusting Intentions (TrInt): One iteration of EFA and one iteration of $\alpha$ lead to all the items from this factor loading adequately along with acceptable KMO, p-value, average communality, total variance explained, and $\alpha$ values.

Table 23: TrInt - Employee Data

\begin{tabular}{|c|c|c|c|c|c|c|c|c|}
\hline KMO & $\boldsymbol{p}$ & Det & $\begin{array}{c}\text { Low } \\
\text { Comm }\end{array}$ & $\begin{array}{c}\text { Avg } \\
\text { Comm }\end{array}$ & Factors & $\begin{array}{c}\text { \% Var } \\
\text { Exp }\end{array}$ & $\begin{array}{c}\text { Cross } \\
\text { Loaded }\end{array}$ & Action Taken \\
\hline .915 & 0 & .00 & 0 & .887 & 1 & $90.57 \%$ & NA & $\begin{array}{c}\text { Cronbach's } \\
\text { Alpha Test }\end{array}$ \\
\hline$\alpha$ & .978 & \multicolumn{1}{|c|}{} \\
\hline
\end{tabular}

The theorized model has these items split into two sub-constructs, but they load onto a single factor. This factor is already parsimonious.

Own Trusting Behaviors (TrBeh Own): Again, only one instance of EFA and $\alpha$ were required to load all items onto a single factor with acceptable values of KMO, p-value, determinant, average communality, total variance explained, and $\alpha$.

Table 24: TrBeh Own - Employee Data

\begin{tabular}{|c|c|c|c|c|c|c|c|c|}
\hline KMO & $\boldsymbol{p}$ & Det & $\begin{array}{c}\text { Low } \\
\text { Comm }\end{array}$ & $\begin{array}{c}\text { Avg } \\
\text { Comm }\end{array}$ & Factors & $\begin{array}{c}\text { \% Var } \\
\text { Exp }\end{array}$ & $\begin{array}{c}\text { Cross } \\
\text { Loaded }\end{array}$ & Action Taken \\
\hline .887 & 0 & .01 & 0 & .795 & 1 & $83.54 \%$ & NA & $\begin{array}{c}\text { Cronbach's } \\
\text { Alpha Test }\end{array}$ \\
\hline \multicolumn{2}{|c|}{$\alpha$} & .949 & \multicolumn{10}{|c|}{} \\
\hline
\end{tabular}

The factor is already parsimonious as all the items remained. 
Other's Trusting Behaviors (TrBeh Other's): One iteration of EFA and two iterations

of $\alpha$ resulted in one item being removed, and the remaining being loaded onto a single factor.

KMO, p-value, average communality, total variance explained, and the final $\alpha$ values were

acceptable.

Table 25: TrBeh Other's - Employee Data

\begin{tabular}{|c|c|c|c|c|c|c|c|c|}
\hline KMO & $\boldsymbol{p}$ & Det & $\begin{array}{c}\text { Low } \\
\text { Comm }\end{array}$ & $\begin{array}{c}\text { Avg } \\
\text { Comm }\end{array}$ & Factors & $\begin{array}{c}\text { \% Var } \\
\text { Exp }\end{array}$ & $\begin{array}{c}\text { Cross } \\
\text { Loaded }\end{array}$ & Action Taken \\
\hline .936 & 0 & .00 & 0 & .827 & 1 & $84.35 \%$ & NA & $\begin{array}{c}\text { Cronbach's } \\
\text { Alpha Test }\end{array}$ \\
\hline \multicolumn{2}{|c|}{$\alpha$} & .976 & \multicolumn{7}{c|}{.982 if Tbeh-9 Removed } \\
\hline \multicolumn{2}{|c|}{$\alpha$} & .982 & \multicolumn{7}{c}{} \\
\hline
\end{tabular}

Despite the determinant being zero, the same item (TrBeh-9) was removed in all three data sets (combined data, student-only data, and employee-only data). The factor is parsimonious.

\section{Final Factor Loadings - Employee Data}

The final factor loadings from the employee data are listed below, with items that loaded from both employees and combined data highlighted:

Table 26: Final Factor Loadings - Employee Data

\begin{tabular}{|c|c|c|c|c|c|c|}
\hline \multicolumn{7}{|c|}{ Final Factor Loadings - Employee Data Only } \\
\hline P2T & IT & MI & PercT & TrInt & TrBeh Own & TrBeh Other's \\
\hline NA & IT-20 & MI-4 & NA & TrInt-1 & Tbeh-1 & Tbeh-6 \\
& IT-21 & MI-7 & & TrInt-2 & Tbeh-2 & Tbeh-7 \\
& IT-22 & MI-8 & & TrInt-3 & Tbeh-3 & Tbeh-8 \\
& & & TrInt-4 & Tbeh-4 & Tbeh-10 \\
& & & TrInt-5 & Tbeh-5 & Tbeh-11 \\
& & & TrInt-6 & & Tbeh-12 \\
& & & & & Tbeh-13 \\
& & & & & & Tbeh-14 \\
\hline
\end{tabular}

25 of the original 76 items, five extracted factors, and five of the original seven constructs are represented in the final loadings. 


\section{Factor Loadings Summary}

Table 27: Summary of Results - Overview

\begin{tabular}{|c|c|c|c|c|}
\hline & Theory & Combined & Student & Employee \\
\hline Constructs & 7 & 6 & 6 & 5 \\
\hline Factors & 21 (Sub-constructs) & 8 & 9 & 5 \\
\hline Items & 76 (TMI Questions) & 42 & 48 & 25 \\
\hline
\end{tabular}

The final factor loadings from the combined data yielded 42 items from six of the

theorized seven constructs of the FTM model. A total of 48 items loaded from the student-only data from six of the FTM model's constructs. Only 25 of the 76 total items loaded onto five of the theorized seven constructs from the FTM model.

In the tables below, highlighted factors indicate item loadings that match the theorized sub-construct's questions perfectly.

Table 28 Combined Data - Final Factor Loadings

\begin{tabular}{|c|c|c|c|c|c|c|c|c|}
\hline \multicolumn{7}{|c|}{ Combined Data - Factors and Loadings } \\
\hline P2T & \multicolumn{3}{|c|}{ IT } & MI & PercT & TrInt & TrBeh Own & TrBeh Other's \\
\hline Factor 1 & Factor 1 & Factor 2 & Factor 3 & Factor 1 & & Factor 1 & Factor 1 & Factor 1 \\
\hline P2T-3 & IT-15 & IT-10 & IT-1 & MI-4 & & TrInt-1 & TrBeh-1 & TrBeh-6 \\
\hline P2T-5 & IT-16 & IT-11 & IT-2 & Ml-7 & & TrInt-2 & TrBeh-2 & TrBeh-7 \\
\hline P2T-6 & IT-17 & IT-12 & IT-3 & MI-8 & & TrInt-3 & TrBeh-3 & TrBeh-8 \\
\hline P2T-7 & IT-19 & IT-13 & & MI-9 & & TrInt-4 & TrBeh-4 & TrBeh-10 \\
\hline P2T-8 & IT-20 & & & & & TrInt-5 & TrBeh-5 & TrBeh-11 \\
\hline & IT-21 & & & & & TrInt-6 & & TrBeh-12 \\
\hline & IT-22 & & & & & & & TrBeh-13 \\
\hline & & & & & & & & TrBeh-14 \\
\hline
\end{tabular}

Factor three under Institutional Trust had items corresponding perfectly with the sub-

construct "Perceived Monitoring", and factor one under Trusting Behavior-Own also had items loaded that corresponded to the theoretical model identically. The construct "Perceived Trustworthiness" didn't have any remaining items loaded. 
Table 29: Student-Only Data - Final Factor Loadings

\begin{tabular}{|c|c|c|c|c|c|c|c|c|c|}
\hline \multicolumn{7}{|c|}{ Students-Only Data - Factors and Loadings } \\
\hline P2T & \multicolumn{3}{|c|}{} & MI & PercT & Trlnt & TrBeh Own & $\begin{array}{c}\text { TrBeh } \\
\text { Other }\end{array}$ \\
\hline & Factor 1 & Factor 2 & Factor 3 & Factor 4 & Factor 1 & Factor 1 & Factor 1 & Factor 1 & Factor 1 \\
\hline & IT-14 & IT-11 & IT-23 & IT-1 & MI-7 & PercT-1 & TrInt-1 & TrBeh-1 & TrBeh-6 \\
\hline & IT-15 & IT-12 & IT-24 & IT-2 & MI-8 & PercT-2 & TrInt-2 & TrBeh-2 & TrBeh-7 \\
\hline & IT-16 & IT-13 & IT-25 & IT-3 & MI-9 & PercT-3 & TrInt-3 & TrBeh-3 & TrBeh-8 \\
\hline & IT-17 & & & & & PercT-5 & TrInt-4 & TrBeh-4 & TrBeh-10 \\
\hline & IT-19 & & & & & PercT-7 & TrInt-5 & TrBeh-5 & TrBeh-11 \\
\hline & IT-20 & & & & & PercT-8 & TrInt-6 & & TrBeh-12 \\
\hline & IT-21 & & & & & PercT-9 & & & TrBeh-13 \\
\hline & IT-22 & & & & & PercT-10 & & & TrBeh-14 \\
\hline
\end{tabular}

Factors three and four in "Institutional Trust" had items loaded that corresponded with the theoretical sub-constructs "Structural Assurances" and "Perceived Monitoring". Additionally, the sole extracted factor under "Management Intervention Measures" had the same items loaded as the theoretical sub-construct "Implementation". Note that the construct "Propensity to Trust" did not have any items loaded.

Table 30: Employee-Only Data - Final Factor Loadings

\begin{tabular}{|c|c|c|c|c|c|c|}
\hline \multicolumn{7}{|c|}{ Employees-Only Data - Factors and Loadings } \\
\hline P2T & IT & MI & PercT & TrInt & TrBeh Own & TrBeh Other's \\
\hline & Factor 1 & Factor 1 & & Factor 1 & Factor 1 & Factor 1 \\
\hline & IT-20 & MI-4 & & TrInt-1 & TrBeh-1 & TrBeh-6 \\
\hline & IT-21 & MI-7 & & TrInt-2 & TrBeh-2 & TrBeh-7 \\
\hline & IT-22 & MI-8 & & TrInt-3 & TrBeh-3 & TrBeh-8 \\
\hline & & & & TrInt-4 & TrBeh-4 & TrBeh-10 \\
\hline & & & & TrInt-5 & TrBeh-5 & TrBeh-11 \\
\hline & & & & TrInt-6 & & TrBeh-12 \\
\hline & & & & & & TrBeh-13 \\
\hline
\end{tabular}

Like the last two sets of data, "Trusting Behavior Own" had a single extracted factor with items loaded that matched the theoretical model perfectly. Additionally, "Institutional Trust" had only one extracted factor, whose loaded items corresponded with the theoretical sub-factor 
"Management Competence" perfectly. "Propensity to Trust" and "Perceived Trustworthiness" didn't have any items loaded.

The following table lays out the theorized constructs, sub-constructs, survey questions, the sources for each sub-construct (and associated survey questions), as well as item loadings under each of the three sets of data. Extracted Factors are separated by color, with green indicating a perfect loading of items with respect to the theorized model:

Table 31: Theorized Constructs/Sub-Constructs, SPSS Labels, Survey Questions, Sub-Construct Source \& Item Loadings

\begin{tabular}{|c|c|c|c|c|c|c|c|}
\hline \multirow{2}{*}{ Construct } & \multirow{2}{*}{ Sub-Construct } & \multirow{2}{*}{$\begin{array}{l}\text { Label in } \\
\text { SPSS }\end{array}$} & \multirow{2}{*}{$\begin{array}{c}\text { Survey } \\
\text { Question }\end{array}$} & \multirow{2}{*}{ Source } & \multicolumn{3}{|c|}{ Item Loadings } \\
\hline & & & & & Combined & Student & Employee \\
\hline \multirow{8}{*}{ 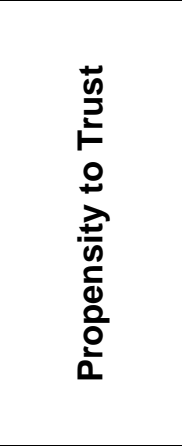 } & \multirow{8}{*}{$\begin{array}{c}\text { Propensity to } \\
\text { Trust }\end{array}$} & $\mathrm{P} 2 \mathrm{~T}-1$ & Q1 & \multirow{8}{*}{ IMOT } & & & \\
\hline & & P2T-2 & Q2 & & & & \\
\hline & & P2T-3 & Q3 & & Factor 1 & & \\
\hline & & P2T-4 & Q4 & & & & \\
\hline & & P2T-5 & Q5 & & Factor 1 & & \\
\hline & & Р2Т-6 & Q6 & & Factor 1 & & \\
\hline & & P2T-7 & Q7 & & Factor 1 & & \\
\hline & & P2T-8 & Q8 & & Factor 1 & & \\
\hline \multirow{15}{*}{ 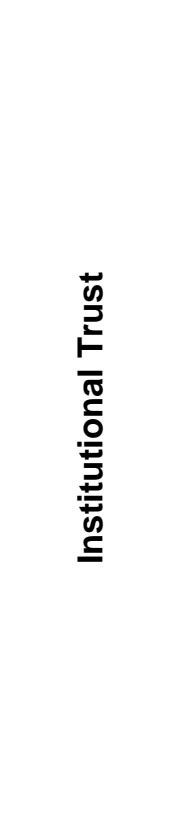 } & \multirow{3}{*}{$\begin{array}{l}\text { Perceived } \\
\text { Monitoring }\end{array}$} & IT-1 & Q9 & \multirow{13}{*}{$\begin{array}{l}\text { Pavlou } \\
\text { (2002) }\end{array}$} & Factor 3 & Factor 4 & \\
\hline & & IT-2 & Q10 & & Factor 3 & Factor 4 & \\
\hline & & IT-3 & Q11 & & Factor 3 & Factor 4 & \\
\hline & \multirow{2}{*}{$\begin{array}{c}\text { Perceived Legal } \\
\text { Bonds }\end{array}$} & IT-4 & Q12 & & & & \\
\hline & & IT-5 & Q13 & & & & \\
\hline & \multirow{3}{*}{$\begin{array}{l}\text { Perceived } \\
\text { Feedback }\end{array}$} & IT-6 & Q14 & & & & \\
\hline & & IT-7 & Q15 & & & & \\
\hline & & IT-8 & Q16 & & & & \\
\hline & \multirow{5}{*}{$\begin{array}{c}\text { Perceived } \\
\text { Cooperative } \\
\text { Norms }\end{array}$} & IT-9 & Q17 & & & & \\
\hline & & IT-10 & Q18 & & Factor 2 & & \\
\hline & & IT-11 & Q19 & & Factor 2 & Factor 2 & \\
\hline & & IT-12 & Q20 & & Factor 2 & Factor 2 & \\
\hline & & IT-13 & Q21 & & Factor 2 & Factor 2 & \\
\hline & \multirow{2}{*}{$\begin{array}{l}\text { Situation } \\
\text { Normality - }\end{array}$} & IT-14 & Q22 & \multirow{2}{*}{ IMTC } & & Factor 1 & \\
\hline & & IT-15 & Q23 & & Factor 1 & Factor 1 & \\
\hline
\end{tabular}




\begin{tabular}{|c|c|c|c|c|c|c|c|}
\hline & $\begin{array}{l}\text { Management } \\
\text { Benevolence }\end{array}$ & IT-16 & Q24 & & Factor 1 & Factor 1 & \\
\hline & \multirow{3}{*}{$\begin{array}{c}\text { Situation } \\
\text { Normality - } \\
\text { Management } \\
\text { Integrity }\end{array}$} & $\mathrm{IT}-17$ & Q25 & & Factor 1 & Factor 1 & \\
\hline & & IT-18 & Q26 & & & & \\
\hline & & IT-19 & Q27 & & Factor 1 & Factor 1 & \\
\hline & \multirow{3}{*}{$\begin{array}{c}\text { Situation } \\
\text { Normality - } \\
\text { Management } \\
\text { Competence }\end{array}$} & IT-20 & Q28 & & Factor 1 & Factor 1 & Factor 1 \\
\hline & & IT-21 & Q29 & & Factor 1 & Factor 1 & Factor 1 \\
\hline & & IT-22 & Q30 & & Factor 1 & Factor 1 & Factor 1 \\
\hline & \multirow{3}{*}{$\begin{array}{c}\text { Structural } \\
\text { Assurances }\end{array}$} & IT-23 & Q31 & & & Factor 3 & \\
\hline & & IT-24 & Q32 & & & Factor 3 & \\
\hline & & IT-25 & Q33 & & & Factor 3 & \\
\hline \multirow{9}{*}{ 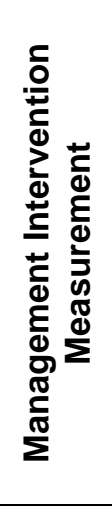 } & \multirow{3}{*}{ Measurement } & $\mathrm{Ml}-1$ & Q34 & \multirow{9}{*}{ IMOT } & & & \\
\hline & & MI-2 & Q35 & & & & \\
\hline & & $\mathrm{MI}-3$ & Q36 & & & & \\
\hline & \multirow{3}{*}{ Analysis } & $\mathrm{MI}-4$ & Q37 & & Factor 1 & & Factor 1 \\
\hline & & MI-5 & Q38 & & & & \\
\hline & & MI-6 & Q39 & & & & \\
\hline & \multirow{3}{*}{ Implementation } & MI-7 & Q40 & & Factor 1 & Factor 1 & Factor 1 \\
\hline & & MI-8 & Q41 & & Factor 1 & Factor 1 & Factor 1 \\
\hline & & MI-9 & Q42 & & Factor 1 & Factor 1 & \\
\hline \multirow{14}{*}{ 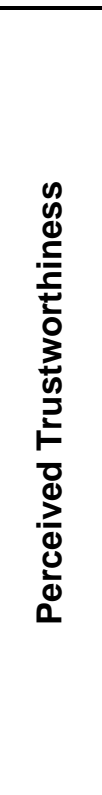 } & \multirow{3}{*}{ Benevolence } & PercT-1 & Q44 & \multirow{14}{*}{ IMTC } & & Factor 1 & \\
\hline & & PercT-2 & Q45 & & & Factor 1 & \\
\hline & & PercT-3 & Q46 & & & Factor 1 & \\
\hline & \multirow{4}{*}{ Integrity } & PercT-4 & Q47 & & & & \\
\hline & & PercT-5 & Q48 & & & Factor 1 & \\
\hline & & PercT-6 & Q49 & & & Factor 1 & \\
\hline & & PercT-7 & Q50 & & & Factor 1 & \\
\hline & \multirow{4}{*}{ Competence } & PercT-8 & Q51 & & & Factor 1 & \\
\hline & & PercT-9 & Q52 & & & Factor 1 & \\
\hline & & PercT-10 & Q53 & & & Factor 1 & \\
\hline & & PercT-11 & Q54 & & & Factor 1 & \\
\hline & \multirow{3}{*}{ Predictability } & PercT-12 & Q55 & & & & \\
\hline & & PercT-13 & Q56 & & & & \\
\hline & & PercT-14 & Q57 & & & & \\
\hline \multirow{6}{*}{ 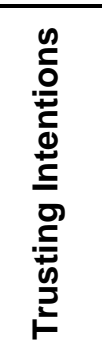 } & \multirow{3}{*}{$\begin{array}{l}\text { Willingness to } \\
\text { Depend }\end{array}$} & $\mathrm{TI}-1$ & Q58 & \multirow{6}{*}{ IMTC } & Factor 1 & Factor 1 & Factor 1 \\
\hline & & $\mathrm{TI}-2$ & Q59 & & Factor 1 & Factor 1 & Factor 1 \\
\hline & & TI-3 & Q60 & & Factor 1 & Factor 1 & Factor 1 \\
\hline & \multirow{3}{*}{$\begin{array}{l}\text { Subjective } \\
\text { Probability of } \\
\text { Depending }\end{array}$} & TI-4 & Q61 & & Factor 1 & Factor 1 & Factor 1 \\
\hline & & TI-5 & Q62 & & Factor 1 & Factor 1 & Factor 1 \\
\hline & & TI-6 & Q63 & & Factor 1 & Factor 1 & Factor 1 \\
\hline
\end{tabular}




\begin{tabular}{|c|c|c|c|c|c|c|c|}
\hline \multirow{14}{*}{ 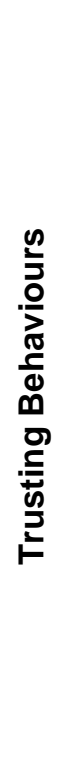 } & \multirow{5}{*}{$\begin{array}{l}\text { Own Trusting } \\
\text { Behaviors }\end{array}$} & Tbeh-1 & Q64 & \multirow{5}{*}{ IMTC } & Factor 1 & Factor 1 & Factor 1 \\
\hline & & Tbeh-2 & Q65 & & Factor 1 & Factor 1 & Factor 1 \\
\hline & & Tbeh-3 & Q66 & & Factor 1 & Factor 1 & Factor 1 \\
\hline & & Tbeh-4 & Q67 & & Factor 1 & Factor 1 & Factor 1 \\
\hline & & Tbeh-5 & Q68 & & Factor 1 & Factor 1 & Factor 1 \\
\hline & \multirow{5}{*}{$\begin{array}{c}\text { Other's } \\
\text { Reciprocal } \\
\text { Trusting } \\
\text { Behaviors }\end{array}$} & Tbeh-6 & Q69 & \multirow{9}{*}{ IMTC } & Factor 1 & Factor 1 & Factor 1 \\
\hline & & Tbeh-7 & Q70 & & Factor 1 & Factor 1 & Factor 1 \\
\hline & & Tbeh-8 & Q71 & & Factor 1 & Factor 1 & Factor 1 \\
\hline & & Tbeh-9 & Q72 & & & & \\
\hline & & Tbeh-10 & Q73 & & Factor 1 & Factor 1 & Factor 1 \\
\hline & \multirow{4}{*}{$\begin{array}{c}\text { Other's Trust } \\
\text { Outcome } \\
\text { Behaviors }\end{array}$} & Tbeh-11 & Q74 & & Factor 1 & Factor 1 & Factor 1 \\
\hline & & Tbeh-12 & Q75 & & Factor 1 & Factor 1 & Factor 1 \\
\hline & & Tbeh-13 & Q76 & & Factor 1 & Factor 1 & Factor 1 \\
\hline & & Tbeh-14 & Q77 & & Factor 1 & Factor 1 & Factor 1 \\
\hline
\end{tabular}

To see the above table split into theorized constructs, see Figures 6-12 in the Appendix. Figure 6 illustrates the theorized construct/sub-construct and question associations, while the remaining Figures illustrate the extracted factors and loaded items for each of the three sets of data. Figures 7-12 have loaded items highlighted for comparison to the theorized sub-constructs and associated questions.

\section{Discussion}

\section{Research Question 1}

The first research question asks whether the questions in the TMI survey represent their theorized sub-constructs (in the eyes of the respondents). The number of items that loaded onto extracted factors in groups that matched the theorized groupings of questions within their respective sub-constructs are:

- Combined Data: 20 items, of which eight loaded identically to the theorized model.

- Student Data: 14 items, of which 14 loaded identically to the theorized model. 
- Employee Data: Eight items, all of which loaded identically to the theorized model.

\section{Research Question 2}

The second research question asks whether the extracted factors (for each of the three cases) match the number of sub-constructs proposed by Gedeon (2014) in the FTM model. The answer is presented in the following table:

Table 32: Extracted Factors Compared to Theorized Sub-Constructs

\begin{tabular}{|l|c|c|c|c|c|c|c|c|}
\hline \multicolumn{10}{|c|}{ FTM Model } \\
Constructs & P2T & IT & MI & PercT & TrInt & TrBeh Own & TrBeh Other & Total \\
\hline Sub-Constructs & 1 & 8 & 3 & 4 & 2 & 1 & 2 & 21 \\
\hline \multicolumn{10}{|c|}{ Extracted Factors } \\
Constructs & P2T & IT & MI & PercT & TrInt & TrBeh Own & TrBeh Other & Total \\
\hline Combined Data & 1 & 3 & 1 & 0 & 1 & 1 & 1 & 8 \\
\hline Student Data & 0 & 4 & 1 & 1 & 1 & 1 & 1 & 9 \\
\hline Employee Data & 0 & 1 & 1 & 0 & 1 & 1 & 1 & 5 \\
\hline
\end{tabular}

From the data, we see that only "Propensity to Trust", and "Trusting Behavior-Own" had the same number of sub-constructs as extracted factors in the combined data. In the student data and the employee data, only "Trusting Behavior-Own" had the same number of sub-constructs as extracted factors.

\section{Research Question 3}

The third research question asks whether scales can be trimmed to increase parsimony. The following table illustrates the findings with regards to this question:

Table 33: Parsimony

\begin{tabular}{|l|c|c|c|c|c|c|c|}
\hline $\begin{array}{l}\text { Combined } \\
\text { Data }\end{array}$ & $\begin{array}{c}\text { Propensi } \\
\text { ty to } \\
\text { Trust }\end{array}$ & $\begin{array}{c}\text { Institutional } \\
\text { Trust }\end{array}$ & $\begin{array}{c}\text { Management } \\
\text { Intervention }\end{array}$ & $\begin{array}{c}\text { Perceived } \\
\text { Trustworthiness }\end{array}$ & $\begin{array}{c}\text { Trusting } \\
\text { Intentions }\end{array}$ & $\begin{array}{c}\text { Trust } \\
\text { Beh. } \\
\text { Own }\end{array}$ & $\begin{array}{c}\text { Trust } \\
\text { Beh. } \\
\text { Other's }\end{array}$ \\
\hline $\begin{array}{l}\text { Can we } \\
\text { Remove } \\
\text { Items? }\end{array}$ & Yes & Yes & Yes & NA & No & No & Yes \\
\hline$\underline{\text { Student }}$ Data & $\begin{array}{c}\text { Propensi } \\
\text { ty to } \\
\text { Trust }\end{array}$ & $\begin{array}{c}\text { Institutional } \\
\text { Trust }\end{array}$ & $\begin{array}{l}\text { Management } \\
\text { Intervention }\end{array}$ & $\begin{array}{c}\text { Perceived } \\
\text { Trustworthiness }\end{array}$ & $\begin{array}{c}\text { Trusting } \\
\text { Intentions }\end{array}$ & $\begin{array}{c}\text { Trust } \\
\text { Beh. } \\
\text { Own }\end{array}$ & $\begin{array}{c}\text { Trust } \\
\text { Beh. } \\
\text { Other's }\end{array}$ \\
\hline
\end{tabular}




\begin{tabular}{|l|c|c|c|c|c|c|c|}
\hline $\begin{array}{l}\text { Can we } \\
\text { Remove } \\
\text { Items? }\end{array}$ & NA & $\begin{array}{c}1 / 4 \\
\text { Extracted } \\
\text { Factors }\end{array}$ & Yes & Yes & No & No & Yes \\
\hline $\begin{array}{l}\text { Employee } \\
\text { Data }\end{array}$ & $\begin{array}{c}\text { Propensi } \\
\text { ty to } \\
\text { Trust }\end{array}$ & $\begin{array}{c}\text { Institutional } \\
\text { Trust }\end{array}$ & $\begin{array}{c}\text { Management } \\
\text { Intervention }\end{array}$ & $\begin{array}{c}\text { Perceived } \\
\text { Trustworthiness }\end{array}$ & $\begin{array}{c}\text { Trusting } \\
\text { Intentions }\end{array}$ & $\begin{array}{c}\text { Trust } \\
\text { Beh. } \\
\text { Own }\end{array}$ & $\begin{array}{c}\text { Trust } \\
\text { Beh. } \\
\text { Other's }\end{array}$ \\
\hline $\begin{array}{l}\text { Can we } \\
\text { Remove } \\
\text { Items? }\end{array}$ & NA & Yes & Yes & NA & No & No & Yes \\
\hline
\end{tabular}

In the Combined data, items from the constructs "Propensity to Trust", "Institutional Trust", “Management Intervention Measures", “Trusting Intentions”, and “Trusting Behavior-Other's" were removed, increasing their parsimony. The remaining constructs (except for "Perceived Trustworthiness" which did not have any of its theorized items loaded) and their associated extracted factors had all their items remaining, indicating they are already parsimonious.

In the Student data, one of the four extracted factors in "Institutional Trust", and each of the factors extracted in "Management Intervention Measures", "Perceived Trustworthiness", and "Trusting Behavior-Other's" had items removed, increasing parsimony. Except for "Propensity to Trust" which did not have any of their theorized items loaded, the remaining constructs, and their extracted factors were already parsimonious as no items could be removed.

In the Employee data, items were removed from "Institutional Trust", "Management Intervention Measures”, and “Trusting Behavior-Other's”, increasing their parsimony. Two constructs "Propensity to Trust" and "Perceived Trustworthiness" which did not have any of their items loaded. The remaining constructs and their extracted factors were already parsimonious.

\section{Research Question 4}

The fourth research question asks what, if any, differences occur between each group analyzed. The results have demonstrated that each of the two sub-populations have different 
interpretations of which questions best represent which sub-constructs in the FTM model, based on the items and extracted factors from performing EFA. Moreover, the data suggests that students' responses are closer to the original model, in that they had the least number of items removed. The FTM model's suggested area of focus, employees, had the most number of items removed. More constructs (and their extracted factors) had items removed in the student data than the other two sets of data.

\section{Limitations}

Limitations of this study may have had effects on the results, but without another study it is difficult to determine which of the following limitations had what effect, and to what degree.

\section{Sampling}

The total potential population for this study can include any adult in a working environment who engages with colleagues on a day-to-day basis and works under one or more managers, as well as students in a University setting who work with fellow students on graded work, under a professor. Although age is not a strict requirement (as there are children working in various environments around the world), the FTM model and its TMI survey is designed for adults.

Ideally, a random and more representative sample of employees and University students from a diverse geographic background should take part in the survey. Thus, there is a limitation on the inferential power of any conclusions reached in this study, as it may not apply to the entire global population pool. 


\section{Size}

The population size is not specifically determined as it can include professionals working with one or more colleagues under some form of management, anywhere in the world. The total population pool in this calculation is in the billions, so a smaller population pool was utilized, consisting of less than 1,000 people from Ryerson University, and a staffing company in Ontario Canada, which requires a sample size anywhere between 269 and 278 participants. In this scenario, the confidence interval would be 5.09 for the sample size to fall between 269 and 278 participants (Cohen et al., 2000, p. 94). However, determining an adequate sample size does not always follow these rules of thumb, and can be dependent on aspects of the study including its variables and design (MacCallum e al., 1999), and thus a more detailed study may be necessary to determine the ideal sample size for analyzing this model. The final sample size, with incomplete surveys and bad data removed, was 271, which falls into the range listed above.

\section{Type}

The opinions of employees at the staffing company, and University students at Ryerson University may not represent that of the total potential population, which is globally distributed rather than limited to the Toronto, Ontario area. Moreover, with a wider geographical scope for sampling different outcomes may result in similar tests on the FTM model and its TMI survey.

\section{Construct Meaning}

Students and employees may interpret the constructs/sub-constructs from the FTM model differently, especially as they are used as actual headings in the TMI survey. For example, "Institutional Trust" can easily be interpreted differently for students who may not see the value inherent in institutional trust, as opposed to employees who value it significantly (Costigan, Iiter, \& Berman, 1998). Furthermore, in a corporate environment, trust can lead to improved 
innovation and outcomes, while that is not clear in a University setting (Ellonen, Blomqvist, \& Puumalainen, 2008). This study only determined which questions in the TMI survey best represent their theorized constructs from the point of view of students, employees, and their combined data, and not necessarily the meaning behind the concept itself.

\section{Consistency Motif}

A difficult issue to avoid, consistency motif is the respondent's inner desire, or urge to answer consistently, especially when questions dealing with a single construct are arranged in a series, or consistent line (Podsakoff \& Organ, 1986). This brings out personal biases and can affect the respondent to a degree that results in inaccurate answers.

As an example, an employee may be in a situation in which management isn't genuinely interested in their performance, ability to work as a team with colleagues, achieve goals, or even grow as an employee. However, because of prior events or personal beliefs, they may answer the question "I feel that most managers would act in my best interest" with a "Strongly Agree", rather than a lower score which would be a more accurate representation of their current situation. If the questions were regarding a particular event, then this issue is less likely to be a factor in the answers provided, but the TMI survey is an example of self-reporting, and likely a contributing factor to some degree in the data acquired.

The TMI survey isn't worded to measure specific instances of interpersonal trust, but is rather a series of questions that mainly measure current beliefs and perceptions of a general condition such as work-place norms and management benevolence. Moreover, the survey's sections have titles that can lead the respondents to answer in a manner consistent with either their beliefs about the meaning behind each title (for example: Perceived Legal Bonds), or their 
beliefs about what a consistent answer is, whether that is from their own perspective and biases or that of management (or what they believe management thinks).

\section{Time and Place}

A potential issue that can be difficult to circumvent when gathering data with any survey is the time and place in which a participant is recording their answers, and how they can affect respondent's answers (Podsakoff \& Organ, 1986). For example, an employee may have just received a substantial pay raise the day before taking the survey, perhaps they were demoted, or even had serious problems with their health or at home, each of which can influence their responses.

This survey was completed by Ryerson Students and employees of a staffing company, and although the answers were provided at various times of day and on varying days between October $25^{\text {th }}, 2016$, and November $13^{\text {th }}$ of the same year, there is no clear way to determine what effect time and place had on the answers.

\section{Social Desirability}

Questions that can make the respondent look more favorable (regardless of whether someone is reading each answer and relating back to that individual) may get responses that are biased in favor of the respondent, and may be more of an exercise in ego massaging than accurate portrayals of their working environment and relationships with colleagues (Podsakoff \& Organ, 1986).

Once again, the "Own Trusting Behaviours" section of the TMI survey is suspect as the respondent can indicate that they cooperate well with a given colleague, that they share useful 
information with them, and freely share decision-making power with them, not because that is reality, but because that is how they would like to be seen.

The issue of social desirability does not come up with many of the TMI survey's questions, but enough that entire constructs (Trusting Intentions) can become clouded by bias, and lead to correlations to other constructs that are not an accurate representation of reality. Cues in the survey, such as the titles of each section, can lead to inaccurate answers and thus covariance (Podsakoff \& Organ, 1986) that would otherwise not be present.

\section{Potential Biases}

Data-collector and observer biases were not a factor in this research as the data was collected via an online survey and no observer(s) were necessary.

Researcher bias did not play a role in this research as the goal is to objectively test the FTM model and its TMI survey for various forms of validity, and were not carried out by the author of the FTM model

Selection bias is a very real potential in this study, and in an ideal study employees from different nations and backgrounds would be selected to better represent the total potential population, and increase the randomness of the sample overall. 


\section{Conclusion and Future Direction}

This study looked at a newly posited model of interpersonal trust, and its survey: The Framework for Trust Management, and the TMI survey. The focus was on the survey itself, and whether combining constructs and sub-constructs from other models, yielded a survey with questions that respondents felt represented their theorized sub-constructs. Moreover, this study utilized two sub-populations to deploy the survey among, to illustrate the similarities and differences between their answers.

By determining how many factors were extracted in EFA, and which items (survey questions) loaded onto each, the degree of parsimony (for each theorized sub-construct) was demonstrated under each of the three sets of data. The number of extracted factors that fell under each theorized construct was notable as it demonstrated the number of sub-constructs within each theorized construct that participants felt best represented it.

I have demonstrated that from the data acquired, at least 25 , and at most 48 , of the 76 questions in the TMI survey represent their theorized sub-construct. Between five and 9 subconstructs (out of a possible 21) were represented by extracted factors. Only one to two constructs were not represented in the extracted factors among the three sets of data.

The remaining items (survey questions) adequately represented their respective subconstructs, while in only a few instances did the number of extracted factors (from either of the three sets of data) match the theorized sub-constructs. Removing items increased the parsimony of the survey. Which items were removed and how many factors were extracted depended on the sub-population that was being used with the employee data set ending up with the fewest extracted factors, loaded items, and represented constructs. The student group, although not 
explicitly mentioned in the FTM model (Gedeon, 2014), ended up with the most number of items, extracted factors, and represented constructs; an outcome that was not predicted as the focus of the FTM model is mainly on employee-to-employee interpersonal trust. These differences between the two sub-populations warrant further investigation, and justify the strategy of looking at more than one.

Future studies will have to validate the FTM model itself, as well as its ability to craft training programs (Gedeon, 2014).

\section{Contribution to the Literature}

The FTM model of interpersonal trust sees trust as dyadic and dynamic, amalgamates important constructs/sub-constructs, and utilizes established questions and scales to measure them from existing and accepted models.

This research had demonstrated that the many of the questions do reflect their associated sub-constructs in the eyes of two sub-populations, but the number of extracted factors (in each set of data) were fewer than the theorized sub-constructs. This increases parsimony, but removes potentially important facets of each construct. Lastly, this research has demonstrated that there is indeed a meaningful difference between the responses of students and employees.

These findings justify further study into the FTM model and its TMI survey, among and between populations, and in such a manner that addresses the limitations of this study. A more randomized study of University students and employees, especially in a global context (as opposed to just Ontario, Canada) will either refute or bolster the findings of this study, and is recommended as a next step. 


\section{Appendix}

Figure 1: Concept Map for This Research (with the area of focus circled)

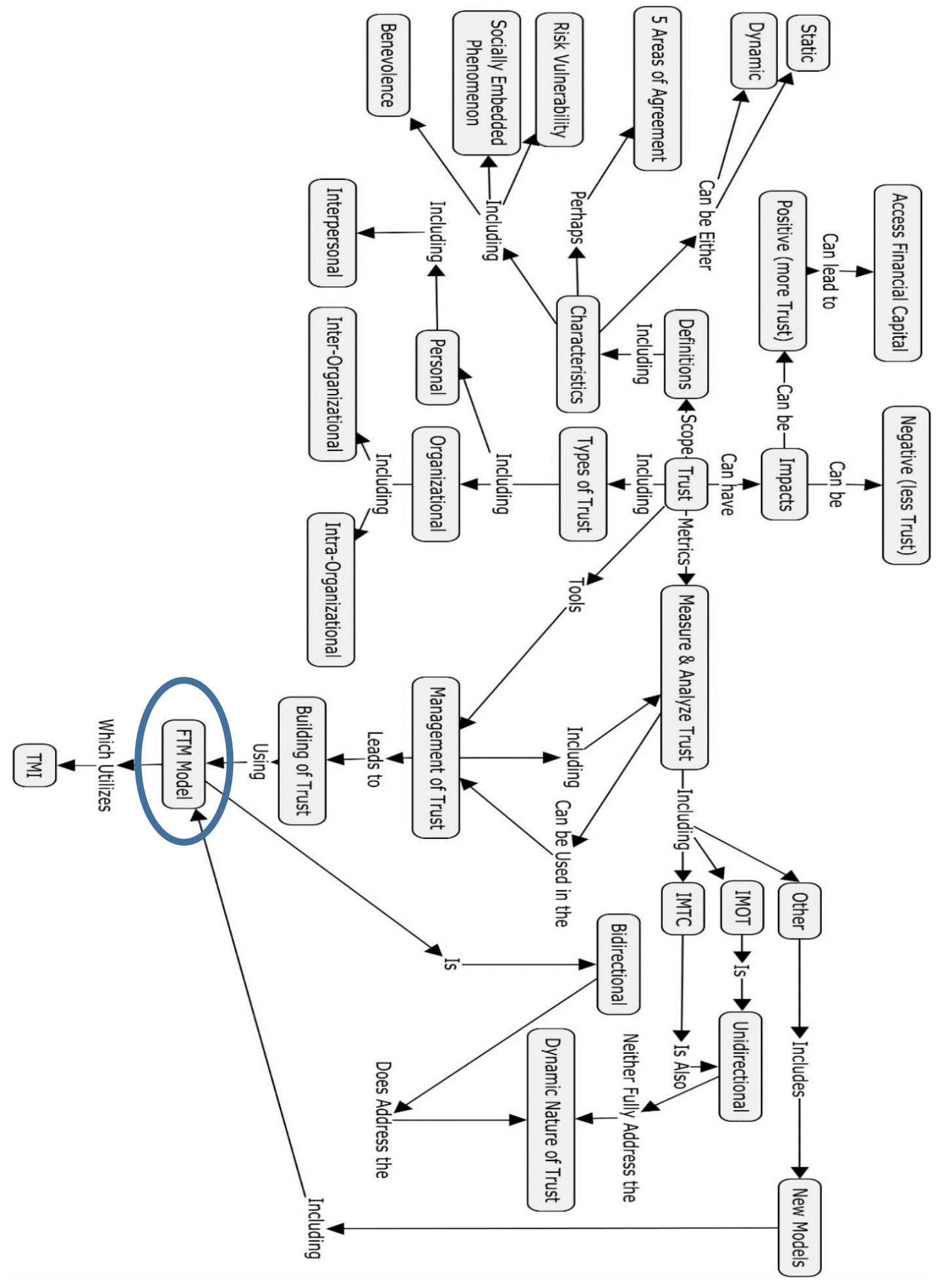


Figure 2: IMTC Model of Trust

High-Level Model of Initial Formation of Trust

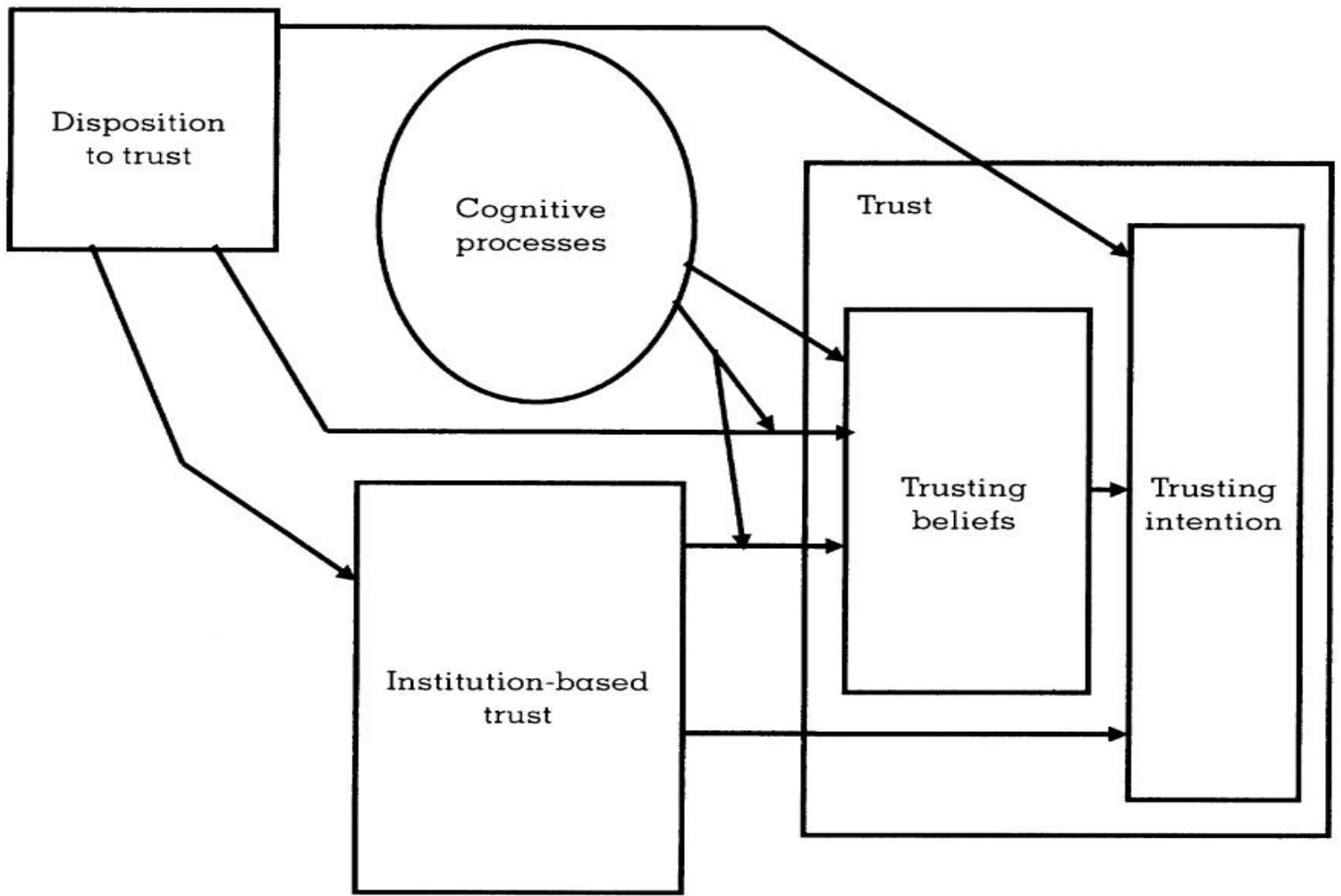

(McKnight, Cummings, \& Chervany, 1998, p. 475) 
Figure 3: IMOT Model of Trust

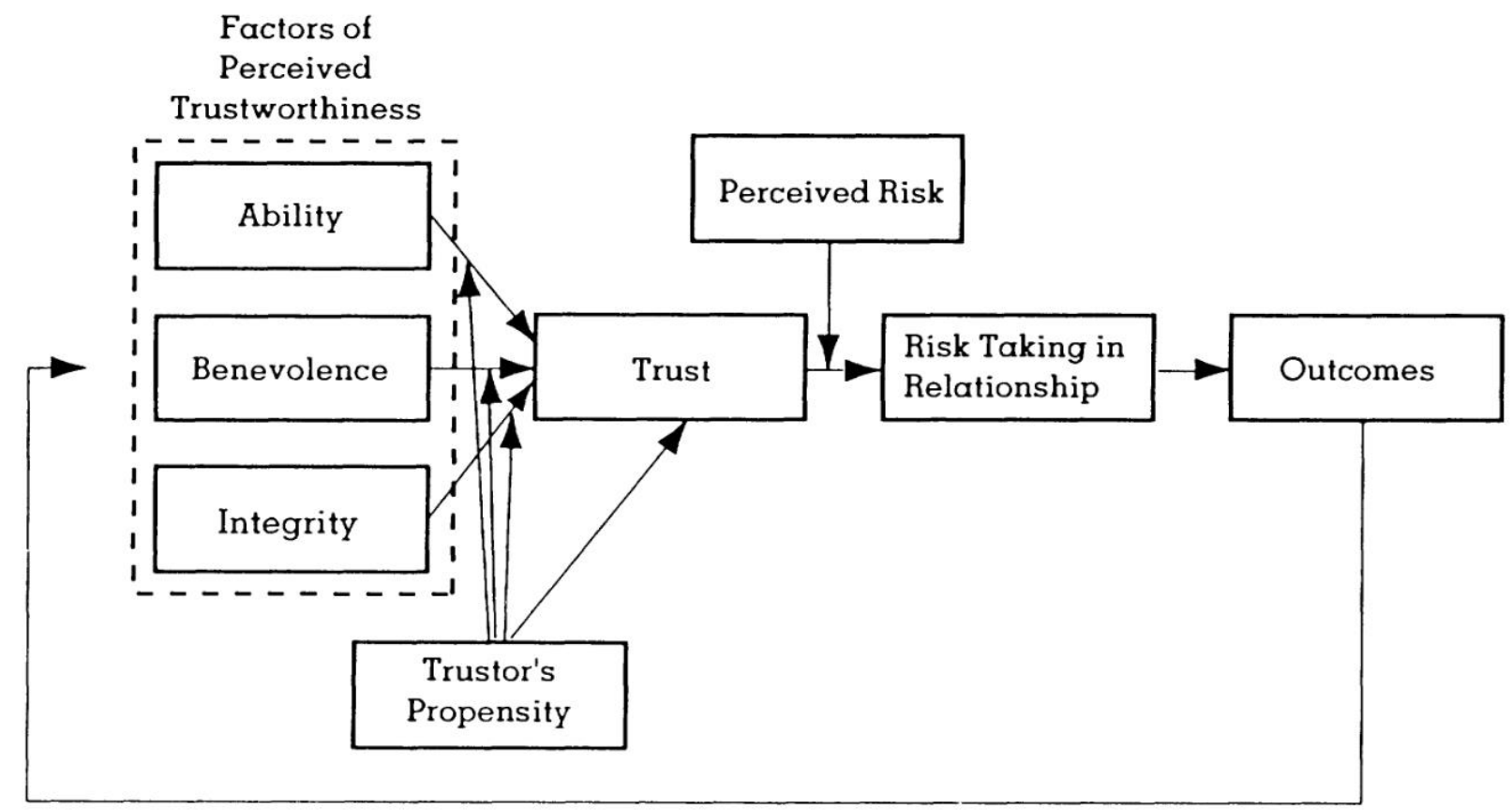

(Mayer, Davis, \& Schoorman, 1995, p. 715)

Figure 4: FTM Model of Trust

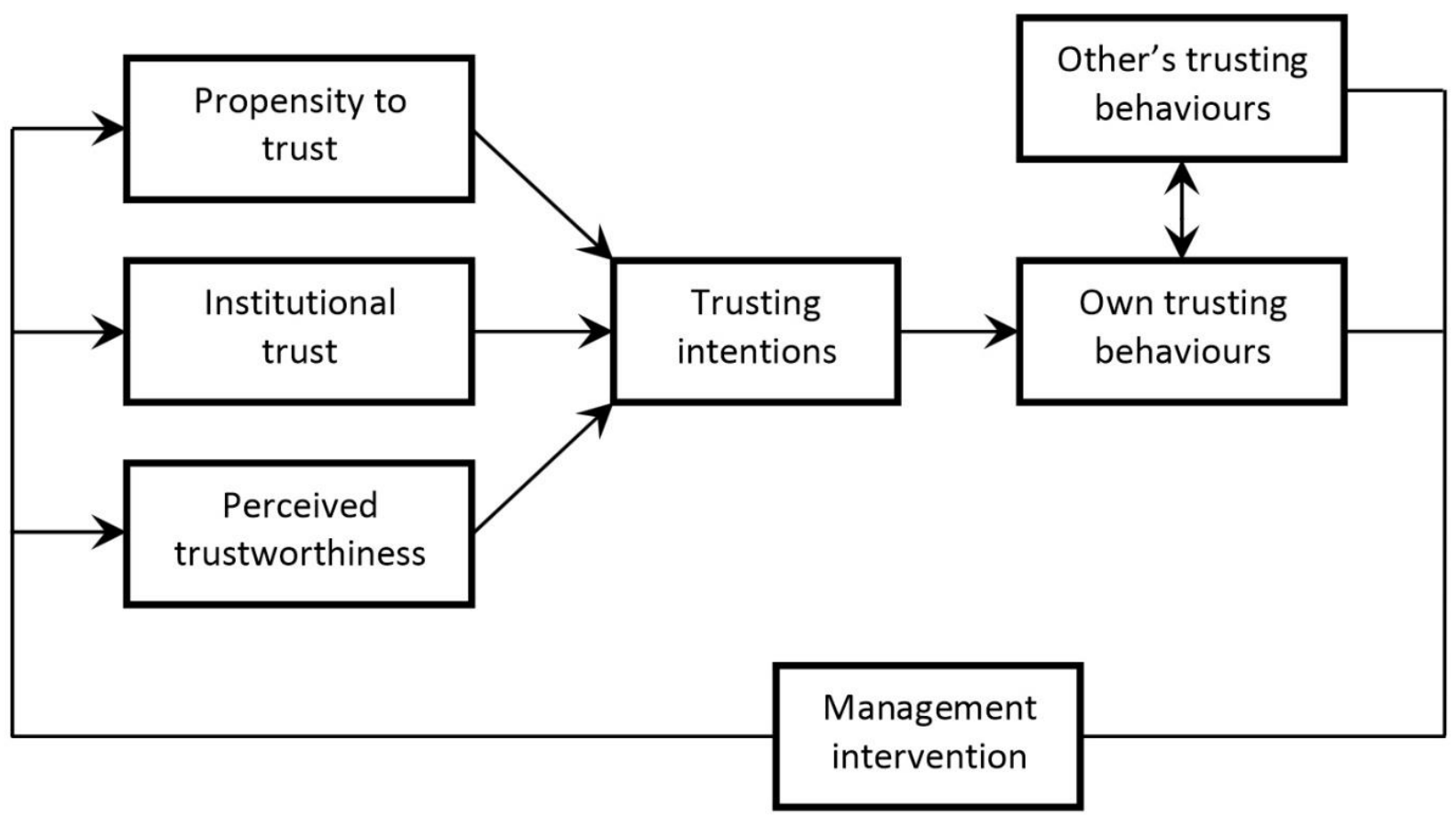

(Gedeon, 2014, p. 127) 


\section{Figure 5: Trust Management Inventory}

\section{Propensity to Trust}

1. One should be very cautious with strangers. (*reverse scored)

2. Most experts tell the truth about the limits of their knowledge.

3. Most people can be counted on to do what they say they will do.

4. These days, you must be alert or someone is likely to take advantage of you. (* reverse scored)

5. Most salespeople are honest in describing their products.

6. Most repair people will not overcharge people who are ignorant of their specialty.

7. Most people answer public opinion polls honestly.

8. Most adults are competent at their jobs.

\section{Institutional Trust}

\section{Perceived Monitoring}

1. There is an effective authority monitoring this relationship to help resolve conflicts.

2. There is an effective mechanism in place to assure that my peers' agreements are fulfilled.

3. There is an effective enforcement mechanism in place to assure that all agreements are conducted properly.

\section{Perceived Legal Bonds}

1. My company (and the other company) imposes formal agreements regarding my peers' obligations.

2. There is an appropriate legal agreement in place regarding my relationship with my peers.

\section{Perceived Feedback}

1. I have a considerable amount of information about the performance history of my peers.

2. If any peer exhibits misconduct, a reliable feedback mechanism is provided to inform me.

3. There is an effective mechanism to allow me to provide feedback on my experience with my peers.

\section{Perceived Cooperative Norms}

1. My company (and the other company) culture promotes cooperative behavior.

2. My peers rarely take advantage of me.

3. Most of my peers are willing to make cooperative adjustments to help me accomplish tasks.

4. My peers and I exchange a considerable amount of information.

5. In general, I can depend upon my peers.

\section{Situation Normality - Management Benevolence}

1. I feel that most managers would act in my best interest.

2. If I required help, most managers would do their best to help.

3. Most managers are interested in my well-being, not just their own well-being.

\section{Situation Normality - Management Integrity}

1. I am comfortable relying upon managers to fulfill their obligations.

2. I feel fine working with my peers since managers generally fulfill their agreements.

3. I always feel confident that I can rely upon managers to do their part when I rely on them.

\section{Situation Normality - Management Competence}

1. In general, most managers are competent at serving my needs. 
2. Most managers do a competent job.

3. I feel that most managers are good at what they do.

\section{Structural Assurances}

1. My company (and the other company) has enough safeguards to make me feel comfortable relying upon my peers.

2. I feel assured that legal and technical structures are in place that adequately protect me from problems when relying upon my peers.

3. In general, my company (and the other company) is a robust and safe environment in which to rely upon my peers.

\section{Perceived Trustworthiness: (Rate the Trustworthiness of the individual peer named "___") Benevolence}

1. I believe that would act in my best interest.

2. If I required help, would do his/her best to help me.

3. __ is interested in my well-being, not just his/her own.

Integrity

1. is truthful in his/her dealings with me.

2. I would characterize as honest.

3. would keep his/her commitments.

4. is sincere and genuine.

\section{Competence}

1. __ is competent and effective in providing the collaboration I need.

2. performs his/her role of collaborating with me very well.

3. Overall, is a capable and proficient person.

4. In General, is a very knowledgeable person.

\section{Predictability}

1. is predictable.

2. can be relied upon to be consistent in his/her dealings with me.

3. My prior dealings with lead me to believe that he/she will continue to act in a similar way.

\section{Trusting Intentions}

\section{Willingness to Depend}

1. When an important issue arises, I would feel comfortable depending on

2. I can always rely upon in a tough situation.

3. I feel that I could count on to help me with a crucial problem.

\section{Subjective Probability of Depending}

1. If I had a challenging problem, I would want to work with

2. I would feel comfortable acting on the information given to me by

3. I would feel comfortable giving important information to

\section{Trusting Behaviors}

Own Trusting Behaviors

1. I cooperate well with 
2. I share important and useful information freely with

3. I work closely with without the need for formal written agreements.

4. I do not need to carefully control

5. I freely share decision-making power with

\section{Other's Reciprocal Trusting Behaviors}

1. cooperates well with me

2. shares important and useful information freely with me.

3. _ works closely with me without the need for formal written agreements.

4. __ does not need to carefully control me.

$5 . \quad$ freely shares decision-making power with me.

\section{Other's Trust Outcome Behaviors}

1. I can depend on

2. I can rely upon to live up to expectations.

3. I am more effective in accomplishing company goals by working with

4. My company is more successful as a result of my working relationship with

\section{Management Intervention}

\section{Measurement}

1. I think that measuring and managing trust is a good idea.

2. I think the way my company measures trust is appropriate.

3. Trust is too vague and personal for my company to measure (* reverse scored) Analysis

1. I think my company will seriously evaluate the results of this questionnaire.

2. Trust should be carefully analyzed to improve organizational performance.

3. Analyzing trust will improve my ability to be successful in this company.

\section{Implementation}

1. I believe my company will act on the results of this questionnaire.

2. I think my company will implement any outcomes from this questionnaire.

3. My company "walks the talk" when it says it is serious about managing trust.

(Gedeon, 2014) 
Figure 6: Theorized Constructs, Sub-Constructs and Questions

\begin{tabular}{|c|c|c|c|c|c|c|c|c|}
\hline \multicolumn{9}{|c|}{ Theorized Constructs, Sub-Constructs and Questions } \\
\hline P2T & \multicolumn{8}{|c|}{ IT } \\
\hline $\begin{array}{c}\text { Prop To } \\
\text { Trust }\end{array}$ & $\begin{array}{l}\text { Perc } \\
\text { Mon }\end{array}$ & $\begin{array}{l}\text { Perc Leg } \\
\text { Bonds }\end{array}$ & $\begin{array}{c}\text { Perc } \\
\text { Feedback }\end{array}$ & $\begin{array}{c}\text { Perc Coop } \\
\text { Norms }\end{array}$ & $\begin{array}{l}\text { Mng } \\
\text { Benev }\end{array}$ & $\begin{array}{l}\text { Mng } \\
\text { Integ }\end{array}$ & $\begin{array}{c}\text { Mng } \\
\text { Cmptnc }\end{array}$ & $\begin{array}{c}\text { Str } \\
\text { Assur }\end{array}$ \\
\hline P2T-1 & IT-1 & IT-4 & IT-6 & IT-9 & $\mathrm{IT}-14$ & $\mathrm{IT}-17$ & IT-20 & IT-23 \\
\hline P2T-2 & IT-2 & IT-5 & IT-7 & $\mathrm{IT}-10$ & $\mathrm{IT}-15$ & $\mathrm{IT}-18$ & IT-21 & IT-24 \\
\hline P2T-3 & IT-3 & & IT-8 & $\mathrm{IT}-11$ & IT-16 & IT-19 & IT-22 & IT-25 \\
\hline P2T-4 & & & & $\mathrm{IT}-12$ & & & & \\
\hline P2T-5 & & & & IT-13 & & & & \\
\hline P2T-6 & & & & & & & & \\
\hline Р2T-7 & & & & & & & & \\
\hline Р2T-8 & & & & & & & & \\
\hline
\end{tabular}

\begin{tabular}{|c|c|c|c|c|c|c|c|c|c|c|c|}
\hline \multicolumn{12}{|c|}{ Theorized Constructs, Sub-Constructs and Questions } \\
\hline \multicolumn{3}{|c|}{ MI } & \multicolumn{4}{|c|}{ PercT } & \multicolumn{2}{|c|}{ Trlnt } & \multirow{2}{*}{$\begin{array}{c}\begin{array}{c}\text { TrBeh } \\
\text { Own }\end{array} \\
\text { Own } \\
\text { Trusting } \\
\text { Behavior }\end{array}$} & \multicolumn{2}{|c|}{ TrBeh Other's } \\
\hline $\begin{array}{c}\text { Msrmn } \\
t\end{array}$ & $\begin{array}{c}\text { Analysi } \\
\mathrm{s}\end{array}$ & $\operatorname{Imp}$ & Ben & $\begin{array}{c}\text { Integrit } \\
y\end{array}$ & Cmptnc & $\begin{array}{c}\text { Prdctblt } \\
y\end{array}$ & $\begin{array}{l}\text { Will to } \\
\text { Dep }\end{array}$ & $\begin{array}{c}\text { Sub } \\
\text { Prob } \\
\text { Dep }\end{array}$ & & $\begin{array}{c}\text { Other's } \\
\text { Recprcl } \\
\text { Trstng } \\
\text { Bhvr }\end{array}$ & $\begin{array}{l}\text { Other's } \\
\text { Trust } \\
\text { Outcom } \\
\text { e Bhvrs }\end{array}$ \\
\hline $\mathrm{Ml}-1$ & MI-4 & $\begin{array}{c}\text { Ml- } \\
7\end{array}$ & $\begin{array}{c}\text { PercT- } \\
1\end{array}$ & $\begin{array}{c}\text { PercT- } \\
4\end{array}$ & PercT-8 & $\begin{array}{c}\text { PercT- } \\
12\end{array}$ & $\begin{array}{c}\text { Trlnt- } \\
1\end{array}$ & $\begin{array}{c}\text { Trlnt- } \\
4\end{array}$ & TrBeh-1 & TrBeh-6 & $\begin{array}{c}\text { TrBeh- } \\
11\end{array}$ \\
\hline Ml-2 & MI-5 & $\begin{array}{c}\mathrm{Ml}- \\
8\end{array}$ & $\begin{array}{l}\text { PercT- } \\
2\end{array}$ & $\begin{array}{l}\text { PercT- } \\
5\end{array}$ & PercT-9 & $\begin{array}{c}\text { PercT- } \\
13\end{array}$ & $\begin{array}{c}\text { Trlnt- } \\
2\end{array}$ & $\begin{array}{c}\text { Trint- } \\
5\end{array}$ & TrBeh-2 & TrBeh-7 & $\begin{array}{c}\text { TrBeh- } \\
12\end{array}$ \\
\hline \multirow[t]{3}{*}{ MI-3 } & MI-6 & $\begin{array}{c}\mathrm{Ml}- \\
9\end{array}$ & $\begin{array}{c}\text { PercT- } \\
3\end{array}$ & $\begin{array}{l}\text { PercT- } \\
6\end{array}$ & $\begin{array}{l}\text { PercT- } \\
10\end{array}$ & $\begin{array}{c}\text { PercT- } \\
14\end{array}$ & $\begin{array}{c}\text { Trlnt- } \\
3\end{array}$ & $\begin{array}{c}\text { TrInt- } \\
6\end{array}$ & TrBeh-3 & TrBeh-8 & $\begin{array}{c}\text { TrBeh- } \\
13\end{array}$ \\
\hline & & & & $\begin{array}{c}\text { PercT- } \\
7\end{array}$ & $\begin{array}{c}\text { PercT- } \\
11\end{array}$ & & & & TrBeh-4 & TrBeh-9 & $\begin{array}{c}\text { TrBeh- } \\
14\end{array}$ \\
\hline & & & & & & & & & TrBeh-5 & $\begin{array}{c}\text { TrBeh- } \\
10\end{array}$ & \\
\hline
\end{tabular}

Figure 7: Combined Data - Extracted Factors and Loadings

\begin{tabular}{|c|c|c|c|c|c|c|c|c|}
\hline \multicolumn{9}{|c|}{ Combined Data - Factors and Loadings } \\
\hline P2T & \multicolumn{8}{|c|}{ IT } \\
\hline $\begin{array}{c}\text { Prop To } \\
\text { Trust }\end{array}$ & $\begin{array}{l}\text { Perc } \\
\text { Mon }\end{array}$ & $\begin{array}{l}\text { Perc Leg } \\
\text { Bonds }\end{array}$ & $\begin{array}{c}\text { Perc } \\
\text { Feedback }\end{array}$ & $\begin{array}{l}\text { Perc Coop } \\
\text { Norms }\end{array}$ & $\begin{array}{l}\text { Mngmnt } \\
\text { Benev }\end{array}$ & $\begin{array}{c}\text { Mngmnt } \\
\text { Integ }\end{array}$ & $\begin{array}{l}\text { Mngmnt } \\
\text { Cmptnc }\end{array}$ & $\begin{array}{c}\text { Str } \\
\text { Assur }\end{array}$ \\
\hline P2T-1 & IT-1 & IT-4 & IT-6 & IT-9 & IT-14 & IT-17 & IT-20 & IT-23 \\
\hline P2T-2 & IT-2 & IT-5 & IT-7 & IT-10 & IT-15 & IT-18 & IT-21 & IT-24 \\
\hline P2T-3 & IT-3 & & IT-8 & IT-11 & IT-16 & IT-19 & IT-22 & IT-25 \\
\hline P2T-4 & & & & IT-12 & & & & \\
\hline P2T-5 & & & & IT-13 & & & & \\
\hline P2T-6 & & & & & & & & \\
\hline P2T-7 & & & & & & & & \\
\hline P2T-8 & & & & & & & & \\
\hline
\end{tabular}




\begin{tabular}{|c|c|c|c|c|c|c|c|c|c|c|c|}
\hline \multicolumn{12}{|c|}{ Combined Data - Factors and Loadings } \\
\hline \multicolumn{3}{|c|}{ MI } & \multicolumn{4}{|c|}{ PercT } & \multicolumn{2}{|c|}{ Trlnt } & \multirow{2}{*}{$\begin{array}{c}\begin{array}{c}\text { TrBeh } \\
\text { Own }\end{array} \\
\begin{array}{c}\text { Own } \\
\text { Trusting } \\
\text { Behavior }\end{array}\end{array}$} & \multicolumn{2}{|c|}{ TrBeh Other's } \\
\hline$\underset{t}{\text { Msrmn }}$ & $\begin{array}{c}\text { Analysi } \\
\mathrm{s}\end{array}$ & Imp & Ben & $\begin{array}{c}\text { Integrit } \\
y\end{array}$ & Cmptnc & $\begin{array}{c}\text { Prdctblt } \\
y\end{array}$ & $\begin{array}{l}\text { Will to } \\
\text { Dep }\end{array}$ & $\begin{array}{l}\text { Sub } \\
\text { Prob } \\
\text { Dep }\end{array}$ & & $\begin{array}{c}\text { Other's } \\
\text { Recprcl } \\
\text { Trstng } \\
\text { Bhvr }\end{array}$ & $\begin{array}{l}\text { Other's } \\
\text { Trust } \\
\text { Outcom } \\
\text { e Bhvrs }\end{array}$ \\
\hline $\mathrm{Ml}-1$ & MI-4 & $\begin{array}{c}\text { Ml- } \\
7\end{array}$ & $\begin{array}{c}\text { PercT- } \\
1\end{array}$ & $\begin{array}{c}\text { PercT- } \\
4\end{array}$ & PercT-8 & $\begin{array}{c}\text { PercT- } \\
12\end{array}$ & $\begin{array}{c}\text { Trlnt- } \\
1\end{array}$ & $\begin{array}{c}\text { Trlnt- } \\
4\end{array}$ & TrBeh-1 & TrBeh-6 & $\begin{array}{c}\text { TrBeh- } \\
11\end{array}$ \\
\hline Ml-2 & MI-5 & $\begin{array}{c}\text { Ml- } \\
8\end{array}$ & $\begin{array}{c}\text { PercT- } \\
2\end{array}$ & $\begin{array}{c}\text { PercT- } \\
5\end{array}$ & PercT-9 & $\begin{array}{c}\text { PercT- } \\
13\end{array}$ & $\begin{array}{c}\text { Trlnt- } \\
2\end{array}$ & $\begin{array}{c}\text { Trlnt- } \\
5\end{array}$ & TrBeh-2 & TrBeh-7 & $\begin{array}{c}\text { TrBeh- } \\
12\end{array}$ \\
\hline \multirow[t]{3}{*}{ MI-3 } & MI-6 & $\begin{array}{c}\text { Ml- } \\
9\end{array}$ & $\begin{array}{c}\text { PercT- } \\
3\end{array}$ & $\begin{array}{c}\text { PercT- } \\
6\end{array}$ & $\begin{array}{c}\text { PercT- } \\
10\end{array}$ & $\begin{array}{c}\text { PercT- } \\
14\end{array}$ & $\begin{array}{c}\text { Trlnt- } \\
3\end{array}$ & $\begin{array}{c}\text { Trlnt- } \\
6\end{array}$ & TrBeh-3 & TrBeh-8 & $\begin{array}{c}\text { TrBeh- } \\
13\end{array}$ \\
\hline & & & & $\begin{array}{c}\text { PercT- } \\
7\end{array}$ & $\begin{array}{c}\text { PercT- } \\
11\end{array}$ & & & & TrBeh-4 & TrBeh-9 & $\begin{array}{c}\text { TrBeh- } \\
14\end{array}$ \\
\hline & & & & & & & & & TrBeh-5 & $\begin{array}{c}\text { TrBeh- } \\
10\end{array}$ & \\
\hline
\end{tabular}

\section{Figure 8: Student-Only Data - Extracted Factors and Loadings}

\begin{tabular}{|c|c|c|c|c|c|c|c|c|}
\hline \multicolumn{9}{|c|}{ Students-Only Data - Factors and Loadings } \\
\hline P2T & \multicolumn{8}{|c|}{ IT } \\
\hline $\begin{array}{c}\text { Prop To } \\
\text { Trust }\end{array}$ & $\begin{array}{l}\text { Perc } \\
\text { Mon }\end{array}$ & $\begin{array}{l}\text { Perc Leg } \\
\text { Bonds }\end{array}$ & $\begin{array}{c}\text { Perc } \\
\text { Feedback }\end{array}$ & $\begin{array}{l}\text { Perc Coop } \\
\text { Norms }\end{array}$ & $\begin{array}{c}\text { Mngmnt } \\
\text { Benev }\end{array}$ & $\begin{array}{c}\text { Mngmnt } \\
\text { Integ }\end{array}$ & $\begin{array}{l}\text { Mngmnt } \\
\text { Cmptnc }\end{array}$ & $\begin{array}{l}\text { Str } \\
\text { Assur }\end{array}$ \\
\hline P2T-1 & IT-1 & IT-4 & IT-6 & IT-9 & IT-14 & IT-17 & IT-20 & IT-23 \\
\hline P2T-2 & IT-2 & IT-5 & IT-7 & IT-10 & IT-15 & IT-18 & IT-21 & IT-24 \\
\hline P2T-3 & IT-3 & & IT-8 & IT-11 & IT-16 & IT-19 & IT-22 & IT-25 \\
\hline P2T-4 & & & & IT-12 & & & & \\
\hline P2T-5 & & & & IT-13 & & & & \\
\hline P2T-6 & & & & & & & & \\
\hline P2T-7 & & & & & & & & \\
\hline P2T-8 & & & & & & & & \\
\hline
\end{tabular}

\begin{tabular}{|c|c|c|c|c|c|c|c|c|c|c|c|}
\hline \multicolumn{12}{|c|}{ Students-Only Data - Factors and Loadings } \\
\hline \multicolumn{3}{|c|}{ MI } & \multicolumn{4}{|c|}{ PercT } & \multicolumn{2}{|c|}{ Trlnt } & \multirow{2}{*}{$\begin{array}{c}\begin{array}{c}\text { TrBeh } \\
\text { Own }\end{array} \\
\begin{array}{c}\text { Own } \\
\text { Trusting } \\
\text { Behavior }\end{array}\end{array}$} & \multicolumn{2}{|c|}{ TrBeh Other's } \\
\hline Msrmnt & $\begin{array}{c}\text { Analysi } \\
\mathrm{s}\end{array}$ & Imp & Ben & Integrity & $\begin{array}{c}\text { Cmptn } \\
\mathrm{c}\end{array}$ & $\begin{array}{c}\text { Prdctblt } \\
y\end{array}$ & $\begin{array}{l}\text { Will to } \\
\text { Dep }\end{array}$ & $\begin{array}{l}\text { Sub } \\
\text { Prob } \\
\text { Dep }\end{array}$ & & $\begin{array}{c}\text { Other's } \\
\text { Recprcl } \\
\text { Trstng } \\
\text { Bhvr }\end{array}$ & $\begin{array}{l}\text { Other's } \\
\text { Trust } \\
\text { Outcom } \\
\text { e Bhvrs }\end{array}$ \\
\hline Ml-1 & MI-4 & $\begin{array}{c}\text { Ml- } \\
7\end{array}$ & $\begin{array}{c}\text { PercT- } \\
1\end{array}$ & PercT-4 & $\begin{array}{l}\text { PercT- } \\
8\end{array}$ & $\begin{array}{c}\text { PercT- } \\
12\end{array}$ & $\begin{array}{c}\text { Trlnt- } \\
1\end{array}$ & $\begin{array}{c}\text { Trlnt- } \\
4\end{array}$ & TrBeh-1 & TrBeh-6 & $\begin{array}{c}\text { TrBeh- } \\
11\end{array}$ \\
\hline MI-2 & MI-5 & $\begin{array}{c}\text { Ml- } \\
8\end{array}$ & $\begin{array}{l}\text { PercT- } \\
2\end{array}$ & PercT-5 & $\begin{array}{l}\text { PercT- } \\
9\end{array}$ & $\begin{array}{c}\text { PercT- } \\
13\end{array}$ & $\begin{array}{c}\text { Trlnt- } \\
2\end{array}$ & $\begin{array}{c}\text { Trlnt- } \\
5\end{array}$ & TrBeh-2 & TrBeh-7 & $\begin{array}{c}\text { TrBeh- } \\
12\end{array}$ \\
\hline \multirow[t]{3}{*}{ Ml-3 } & MI-6 & $\begin{array}{c}\mathrm{Ml}- \\
9\end{array}$ & $\begin{array}{l}\text { PercT- } \\
3\end{array}$ & PercT-6 & $\begin{array}{l}\text { PercT- } \\
10\end{array}$ & $\begin{array}{c}\text { PercT- } \\
14\end{array}$ & $\begin{array}{c}\text { Trlnt- } \\
3\end{array}$ & $\begin{array}{c}\text { Trlnt- } \\
6\end{array}$ & TrBeh-3 & TrBeh-8 & $\begin{array}{c}\text { TrBeh- } \\
13\end{array}$ \\
\hline & & & & PercT-7 & $\begin{array}{l}\text { PercT- } \\
11\end{array}$ & & & & TrBeh-4 & TrBeh-9 & $\begin{array}{c}\text { TrBeh- } \\
14\end{array}$ \\
\hline & & & & & & & & & TrBeh-5 & $\begin{array}{c}\text { TrBeh- } \\
10\end{array}$ & \\
\hline
\end{tabular}


Figure 9: Employee-Only Data - Extracted Factors and Loadings

\begin{tabular}{|c|c|c|c|c|c|c|c|c|}
\hline \multicolumn{9}{|c|}{ Employees-Only Data - Factors and Loadings } \\
\hline P2T & \multicolumn{8}{|c|}{ IT } \\
\hline $\begin{array}{c}\text { Prop To } \\
\text { Trust }\end{array}$ & $\begin{array}{l}\text { Perc } \\
\text { Mon }\end{array}$ & $\begin{array}{l}\text { Perc Leg } \\
\text { Bonds }\end{array}$ & $\begin{array}{c}\text { Perc } \\
\text { Feedback }\end{array}$ & $\begin{array}{l}\text { Perc Coop } \\
\text { Norms }\end{array}$ & $\begin{array}{l}\text { Mngmnt } \\
\text { Benev }\end{array}$ & $\begin{array}{c}\text { Mngmnt } \\
\text { Integ }\end{array}$ & $\begin{array}{l}\text { Mngmnt } \\
\text { Cmptnc }\end{array}$ & $\begin{array}{c}\text { Str } \\
\text { Assur }\end{array}$ \\
\hline P2T-1 & IT-1 & IT-4 & IT-6 & IT-9 & IT-14 & IT-17 & IT-20 & IT-23 \\
\hline P2T-2 & IT-2 & IT-5 & IT-7 & IT-10 & IT-15 & IT-18 & IT-21 & IT-24 \\
\hline P2T-3 & IT-3 & & IT-8 & IT-11 & IT-16 & IT-19 & IT-22 & IT-25 \\
\hline P2T-4 & & & & IT-12 & & & & \\
\hline P2T-5 & & & & IT-13 & & & & \\
\hline P2T-6 & & & & & & & & \\
\hline P2T-7 & & & & & & & & \\
\hline P2T-8 & & & & & & & & \\
\hline
\end{tabular}

\begin{tabular}{|c|c|c|c|c|c|c|c|c|c|c|c|}
\hline \multicolumn{12}{|c|}{ Employees-Only Data - Factors and Loadings } \\
\hline \multicolumn{3}{|c|}{ MI } & \multicolumn{4}{|c|}{ PercT } & \multicolumn{2}{|c|}{ Trlnt } & \multirow{2}{*}{$\begin{array}{c}\begin{array}{c}\text { TrBeh } \\
\text { Own }\end{array} \\
\begin{array}{c}\text { Own } \\
\text { Trusting } \\
\text { Behavior }\end{array}\end{array}$} & \multicolumn{2}{|c|}{ TrBeh Other's } \\
\hline$\underset{t}{M s r m n}$ & $\begin{array}{c}\text { Analysi } \\
\mathrm{s}\end{array}$ & Imp & Ben & $\begin{array}{c}\text { Integrit } \\
y\end{array}$ & Cmptnc & $\begin{array}{c}\text { Prdctblt } \\
y\end{array}$ & $\begin{array}{l}\text { Will to } \\
\text { Dep }\end{array}$ & $\begin{array}{l}\text { Sub } \\
\text { Prob } \\
\text { Dep }\end{array}$ & & $\begin{array}{c}\text { Other's } \\
\text { Recprcl } \\
\text { Trstng } \\
\text { Bhvr }\end{array}$ & $\begin{array}{l}\text { Other's } \\
\text { Trust } \\
\text { Outcom } \\
\text { e Bhvrs }\end{array}$ \\
\hline Ml-1 & MI-4 & $\begin{array}{c}\text { Ml- } \\
7 \\
\end{array}$ & $\begin{array}{c}\text { PercT- } \\
1 \\
\end{array}$ & $\begin{array}{l}\text { PercT- } \\
4\end{array}$ & PercT-8 & $\begin{array}{c}\text { PercT- } \\
12\end{array}$ & $\begin{array}{c}\text { Trlnt- } \\
1\end{array}$ & $\begin{array}{c}\text { Trlnt- } \\
4\end{array}$ & TrBeh-1 & TrBeh-6 & $\begin{array}{c}\text { TrBeh- } \\
11\end{array}$ \\
\hline MI-2 & MI-5 & $\begin{array}{c}\text { MI- } \\
8\end{array}$ & $\begin{array}{l}\text { PercT- } \\
2\end{array}$ & $\begin{array}{l}\text { PercT- } \\
5\end{array}$ & PercT-9 & $\begin{array}{c}\text { PercT- } \\
13\end{array}$ & $\begin{array}{c}\text { Trint- } \\
2\end{array}$ & $\begin{array}{c}\text { Trlnt- } \\
5\end{array}$ & TrBeh-2 & TrBeh-7 & $\begin{array}{c}\text { TrBeh- } \\
12\end{array}$ \\
\hline \multirow[t]{3}{*}{ Ml-3 } & MI-6 & $\begin{array}{c}\text { Ml- } \\
9\end{array}$ & $\begin{array}{c}\text { PercT- } \\
3\end{array}$ & $\begin{array}{l}\text { PercT- } \\
6\end{array}$ & $\begin{array}{c}\text { PercT- } \\
10\end{array}$ & $\begin{array}{c}\text { PercT- } \\
14\end{array}$ & $\begin{array}{c}\text { Trlnt- } \\
3\end{array}$ & $\begin{array}{c}\text { Trlnt- } \\
6\end{array}$ & TrBeh-3 & TrBeh-8 & $\begin{array}{c}\text { TrBeh- } \\
13\end{array}$ \\
\hline & & & & $\begin{array}{c}\text { PercT- } \\
7\end{array}$ & $\begin{array}{c}\text { PercT- } \\
11\end{array}$ & & & & TrBeh-4 & TrBeh-9 & $\begin{array}{c}\text { TrBeh- } \\
14\end{array}$ \\
\hline & & & & & & & & & TrBeh-5 & $\begin{array}{c}\text { TrBeh- } \\
10\end{array}$ & \\
\hline
\end{tabular}

Figure 10: Final Combined Data Extracted Factors and Loadings

\begin{tabular}{|c|c|c|c|c|c|c|c|c|}
\hline \multicolumn{7}{|c|}{ Combined Data - Factors and Loadings } \\
\hline P2T & \multicolumn{3}{|c|}{ IT } & MI & PercT & TrInt & TrBeh Own & TrBeh Other's \\
\hline Factor 1 & Factor 1 & Factor 2 & Factor 3 & Factor 1 & & Factor 1 & Factor 1 & Factor 1 \\
\hline P2T-3 & IT-15 & IT-10 & IT-1 & MI-4 & & Trlnt-1 & TrBeh-1 & TrBeh-6 \\
\hline P2T-5 & IT-16 & IT-11 & IT-2 & MI-7 & & TrInt-2 & TrBeh-2 & TrBeh-7 \\
\hline P2T-6 & IT-17 & IT-12 & IT-3 & MI-8 & & TrInt-3 & TrBeh-3 & TrBeh-8 \\
\hline P2T-7 & IT-19 & IT-13 & & MI-9 & & Trlnt-4 & TrBeh-4 & TrBeh-10 \\
\hline P2T-8 & IT-20 & & & & & TrInt-5 & TrBeh-5 & TrBeh-11 \\
\hline & IT-21 & & & & & Trlnt-6 & & TrBeh-12 \\
\hline & IT-22 & & & & & & & TrBeh-13 \\
\hline & & & & & & & & TrBeh-14 \\
\hline
\end{tabular}


Figure 11: Final Students-Only Extracted Factors and Loadings

\begin{tabular}{|c|c|c|c|c|c|c|c|c|c|}
\hline \multicolumn{10}{|c|}{ Students-Only Data - Factors and Loadings } \\
\hline $\begin{array}{c}\mathbf{P 2} \\
T\end{array}$ & \multicolumn{4}{|c|}{ IT } & MI & PercT & Trlnt & $\begin{array}{c}\text { TrBeh } \\
\text { Own }\end{array}$ & $\begin{array}{l}\text { TrBeh } \\
\text { Other's }\end{array}$ \\
\hline & $\begin{array}{c}\text { Factor } \\
1\end{array}$ & $\begin{array}{c}\text { Factor } \\
2\end{array}$ & $\begin{array}{c}\text { Factor } \\
3\end{array}$ & $\begin{array}{c}\text { Factor } \\
4\end{array}$ & $\begin{array}{c}\text { Factor } \\
1\end{array}$ & $\begin{array}{c}\text { Factor } \\
1\end{array}$ & $\begin{array}{c}\text { Factor } \\
1\end{array}$ & Factor 1 & Factor 1 \\
\hline & IT-14 & IT-11 & IT-23 & IT-1 & $\mathrm{Ml}-7$ & PercT-1 & Trlnt-1 & TrBeh-1 & TrBeh-6 \\
\hline & IT-15 & IT-12 & IT-24 & IT-2 & $\mathrm{MI}-8$ & PercT-2 & Trlnt-2 & TrBeh-2 & TrBeh-7 \\
\hline & IT-16 & IT-13 & IT-25 & IT-3 & MI-9 & PercT-3 & Trlnt-3 & TrBeh-3 & TrBeh-8 \\
\hline & IT-17 & & & & & PercT-5 & TrInt-4 & TrBeh-4 & TrBeh-10 \\
\hline & IT-19 & & & & & PercT-7 & Trlnt-5 & TrBeh-5 & TrBeh-11 \\
\hline & IT-20 & & & & & PercT-8 & Trlnt-6 & & TrBeh-12 \\
\hline & IT-21 & & & & & PercT-9 & & & TrBeh-13 \\
\hline & IT-22 & & & & & $\begin{array}{c}\text { PercT- } \\
10\end{array}$ & & & TrBeh-14 \\
\hline & & & & & & $\begin{array}{c}\text { PercT- } \\
11\end{array}$ & & & \\
\hline
\end{tabular}

Figure 12: Final Employees-Only Extracted Factors and Loadings

\begin{tabular}{|c|c|c|c|c|c|c|}
\hline \multicolumn{7}{|c|}{ Employees-Only Data - Factors and Loadings } \\
\hline P2T & IT & MI & PercT & TrInt & TrBeh Own & TrBeh Other's \\
\hline & Factor 1 & Factor 1 & & Factor 1 & Factor 1 & Factor 1 \\
\hline & IT-20 & Ml-4 & & TrInt-1 & TrBeh-1 & TrBeh-6 \\
\hline & IT-21 & Ml-7 & & TrInt-2 & TrBeh-2 & TrBeh-7 \\
\hline & IT-22 & Ml-8 & & TrInt-3 & TrBeh-3 & TrBeh-8 \\
\hline & & & & TrInt-4 & TrBeh-4 & TrBeh-10 \\
\hline & & & & TrInt-5 & TrBeh-5 & TrBeh-11 \\
\hline & & & & TrInt-6 & & TrBeh-12 \\
\hline & & & & & & TrBeh-13 \\
\hline & & & & & & TrBeh-14 \\
\hline
\end{tabular}


Figure 13: Parsimony

\begin{tabular}{|c|c|c|c|c|c|c|c|}
\hline$\frac{\text { Combined }}{\underline{\text { Data }}}$ & $\begin{array}{l}\text { Propensity } \\
\text { to Trust }\end{array}$ & $\begin{array}{l}\text { Institutional } \\
\text { Trust }\end{array}$ & $\begin{array}{l}\text { Management } \\
\text { Intervention }\end{array}$ & $\begin{array}{c}\text { Perceived } \\
\text { Trustworthiness }\end{array}$ & $\begin{array}{l}\text { Trusting } \\
\text { Intentions }\end{array}$ & $\begin{array}{l}\text { Trust } \\
\text { Beh. } \\
\text { Own }\end{array}$ & $\begin{array}{c}\text { Trust } \\
\text { Beh. } \\
\text { Other's }\end{array}$ \\
\hline $\begin{array}{l}\text { Can we } \\
\text { Increase } \\
\text { Parsimony? }\end{array}$ & Yes & Yes & Yes & NA & No & No & Yes \\
\hline$\underline{\text { Student Data }}$ & $\begin{array}{l}\text { Propensity } \\
\text { to Trust }\end{array}$ & $\begin{array}{l}\text { Institutional } \\
\text { Trust }\end{array}$ & $\begin{array}{l}\text { Management } \\
\text { Intervention }\end{array}$ & $\begin{array}{l}\text { Perceived } \\
\text { Trustworthiness }\end{array}$ & $\begin{array}{l}\text { Trusting } \\
\text { Intentions }\end{array}$ & $\begin{array}{l}\text { Trust } \\
\text { Beh. } \\
\text { Own }\end{array}$ & $\begin{array}{l}\text { Trust } \\
\text { Beh. } \\
\text { Other's }\end{array}$ \\
\hline $\begin{array}{l}\text { Can we } \\
\text { Increase } \\
\text { Parsimony? }\end{array}$ & NA & 1/4 Factors & Yes & Yes & No & No & Yes \\
\hline$\frac{\text { Employee }}{\text { Data }}$ & $\begin{array}{l}\text { Propensity } \\
\text { to Trust }\end{array}$ & $\begin{array}{l}\text { Institutional } \\
\text { Trust }\end{array}$ & $\begin{array}{l}\text { Management } \\
\text { Intervention }\end{array}$ & $\begin{array}{l}\text { Perceived } \\
\text { Trustworthiness }\end{array}$ & $\begin{array}{l}\text { Trusting } \\
\text { Intentions }\end{array}$ & $\begin{array}{l}\text { Trust } \\
\text { Beh. } \\
\text { Own }\end{array}$ & $\begin{array}{l}\text { Trust } \\
\text { Beh. } \\
\text { Other's }\end{array}$ \\
\hline $\begin{array}{l}\text { Can we } \\
\text { Increase } \\
\text { Parsimony? }\end{array}$ & NA & Yes & Yes & NA & No & No & Yes \\
\hline
\end{tabular}




\section{Bibliography}

Ajzen, I. (2001). Nature and operation of attitudes. Annual review of psychology, 52, 27-58.

Ajzen, I. (2006). Perceived behavioral control, self-efficacy, locus of control, and the theory of planned behavior. Journal of Applied Social Psychology, 32(4), 665-683.

Ajzen, I. (2011). The theory of planned behaviour: Reactions and reflections. Psychology \& Health, 26(9), 1113-1127.

Ajzen, I., \& Fishbein, M. (1974). Factors influencing intentions and the intention-behavior relation. Human Relations, 27(1), 1-15.

Ashworth, P., Bannister, P., Thorne, P., \& Unit, S. o. (1997). Guilty in whose eyes? University students' perceptions of cheating and plagiarism in academic work and assessment. Studies in higher education, 22(2), 187-203.

Bandura, A. (1977). Self-efficacy: toward a unifying theory of behavioral change. Psychological Review, 84(2), 191-215.

Barber, B. (1983). The logic and limits of trust. New Brunswick, NJ: Rutgers University Press.

Barney, J. B., \& Hansen, M. H. (1994). Trustworthiness as a Source of Competitive Advantage. Strategic Management Journal, 15, 175-190.

Buckley, P. J., Glaister, K. W., Klijn, E., \& Tan, H. (2009). Knowledge accession and knowledge acquisition in strategic alliances: the impact of supplementary and complementary dimensions. British Journal of Management, 20(1), 598-609.

Butler, J. K. (1991). Toward understanding and measuring conditions of trust: Evolution of a conditions of trust inventory. Journal of Management, 17(1), 643-663.

Chan, D. (1998). Functional relations among constructs in the same content domain at different levels of analysis: A typology of composition models. Journal of applied psychology, 83(2), 234. 
Cohen, L., Manion, L., \& Morrison, K. (2000). Research methods in education. London: RoutledgeFalmer.

Coleman, J. (1990). Foundations of Social Theory. Cambridge, MA.: Belknap Press.

Colquitt, J. A., Scott, B. A., \& LePine, J. A. (2007). Trust, trustworthiness, and trust propensity: a meta-analytic test of their unique relationships with risk taking and job performance. Journal of applied psychology, 92(4), 909.

Costigan, R. D., Iiter, S. S., \& Berman, J. J. (1998). A multi-dimensional study of trust in organizations. Journal of managerial issues, 303-317.

Davis, J. H., \& Mayer, R. C. (1999). The Effect of the Performance Appraisal System on Trust Management: A Field Quasi-Experiment. Journal of Applied Psychology, 84(1), 123-136.

DeVellis, R. F. (2016). Scale development: Theory and applications (Vol. 26). Sage publications.

Dirks, K. T. (1999). The effects of interpersonal trust on work group performance. Journal of Applied Psychology, 84(3), 445-455.

Ellonen, R., Blomqvist, K., \& Puumalainen, K. (2008). The role of trust in organisational innovativeness. European Journal of Innovation Management, 11(2), 160-181.

Ennen, N. L. (2015). The importance of trust for satisfaction, motivation, and academic performance in student learning groups. Social Psychology of Education, 18(3), 615-633.

Farris, G. F., Senner, E. E., \& Butterfield, D. A. (1973). Trust, culture, and organizational behavior. Industrial Relations: A Journal of Economy and Society, 12(2), 144-157.

Ferber, R. (1977). Research by convenience. Journal of Consumer Research, 4(1), 57-58.

Field, A. (2013). Discovering statistics using IBM SPSS statistics. Sage.

Fukuyama, F. (1995). Trust: The social virtues and the creation of prosperity. World and I, 10(1), 264-268. 
Gedeon, S. (2014). How to measure and build intra- and inter- organizational trust. International Journal of Business and Globalisation, 14(1), 122-142.

Gill, H., Boies, K., Finegan, J. E., \& McNally, J. (2005). Antecedents of Trust: Establishing a Boundary Condition for the Relation Between Propensity to Trust and Intention to Trust. Journal of Business and Psychology, 19(3), 287-302.

Golembiewski, R. T., \& McConkie, M. (1975). The centrality of interpersonal trust in group processes. In C. L. Cooper, Theories of group processes (pp. 131-185). New York: Wiley.

Gulati, R. (1995). Does Familiarity Breed Trust? The Implications of Repeated Ties for Contractual Choice in Alliances. The Academy of Management Journal, 38(1), 85-112.

Gulati, R., \& Nickerson, J. A. (2008). Interorganizational Trust, Governance Choice, and Exchange Performance. Organization Science, 19(5), 688-708.

Hardeman, W., Johnston, M., Johnston, D., Bonetti, D., Wareham, N., \& Kinmonth, A. L. (2002). Application of the theory of planned behaviour in behaviour change interventions: a systematic review. Psychology and Health, 123-158.

Hosmer, L. T. (1995). Trust: The Connecting Link between Organizational Theory and Philosophical Ethics. The Academy of Management Review, 20(2), 379-403.

Jimmieson, N., Peach, M., \& White, K. (2008). Utilizing the Theory of Planned Behavior to Inform Change Management : An Investigation of Employee Intentions to Support Organizational Change. The Journal of Applied Behavioral Science, 44(2), 237-262.

Koenig, M. A., \& Harris, P. L. (2005). The role of social cognition in early trust. Trends in cognitive sciences, 9(10), 457-459.

Korsgaard, M. A., Brower, H. H., \& Lester, S. W. (2015). It Isn't Always Mutual: A Critical Review of Dyadic Trust. Journal of Management, 41(1), 47-70. 
Krueger, N. F. (1993). The impact of prior entrepreneurial exposure on perceptions of new venture feasibility and desirability. Entrepreneurship Theory and Practice, 18(1), 5-21.

Landers, R. N. (2015). An inconvenient truth: Arbitrary distinctions between organizational, Mechanical Turk, and other convenience samples. Industrial and Organizational Psychology, 8(2), 142-164.

Larzelere, R. E., \& Huston, T. L. (1980). The Dyadic Trust Scale: Toward Understanding Interpersonal Trust in Close Relationships. Journal of Marriage and Family, 42(3), 595604.

Lawler, E. (1992). The ultimate advantage: Creating the high-involvement organization. The Journal of Academic Librarianship, 19(3), 178.

MacCallum, R. C., Widaman, K. F., Zhang, S., \& Hong, S. (1999). Sample size in factor analysis. Psychological methods, 4(1), 84.

Martin, D. (2014). Towards a model of trust. Journal of Business Strategy, 35(4), 45-51.

Mayer, R. C., Davis, J. H., \& Schoorman, F. D. (1995). An Integrative Model of Organizational Trust. The Academy of Management Review, 20(3), 709-734.

McAllister, D. J. (1995). Affect- and Cognition-Based Trust as Foundations for Interpersonal Cooperation in Organizations. The Academy of Management Journal, 38(1), 24-59.

McKnight, D. H., \& Chervany, N. L. (2001). Trust and distrust definitions: One bite at a time. In Trust in Cyber-societies (pp. 27-54). Berlin, Heidelberg: Springer.

McKnight, D. H., Cummings, L. L., \& Chervany, N. L. (1996). Trust formation in new organizational relationships. Carlson School of Management, University of Minnesota.

McKnight, D. H., Cummings, L. L., \& Chervany, N. L. (1998). Initial Trust Formation in New Organizational Relationships. The Academy of Management Review , 23(3), 473-490.

Merriam Webster. (2017). Ontology. Retrieved from Merriam Webster Dictionary: https://www.merriam-webster.com/dictionary/ontology 
Misztal, B. A. (2002). Normality and trust in Goffman's theory of interaction order. Sociological Theory, 19(3), 312-324.

Morris, M. W., Leung, K., Ames, D., \& Lickel, B. (1999). Views from inside and outside: Integrating emic and etic insights about culture and justice judgment. Academy of Management Review, 24(4), 781-796.

Noy, N. F., \& McGuinness, D. L. (2001). Ontology development 101: A guide to creating your first ontology.

Nunes, M. B., \& McPherson, M. (2003). Constructivism vs. Objectivism: Where is difference for Designers of e-Learning Environments? Advanced Learning Technologies, 2003, 496500 .

Nunnally, J. (1978). Psychometric methods. New York: McGraw-Hill.

Osborne, J. W., \& Costello, A. B. (2009). Best practices in exploratory factor analysis: Four recommendations for getting the most from your analysis. Pan-Pacific Management Review, 12(2), 131-146.

Panayides, P. M., \& Venus Lun, Y. (2009). The impact of trust on innovativeness and supply chain performance. International Journal of Production Economics, 122(1), 35-46.

Pardo-del-Val, M., Martínez-Fuentes, C., \& Roig-Dobón, S. (2012). Participative management and its influence on organizational change. Management Decision, 50(10), 1843-1860.

Park, J., Lee, K. H., \& Kim, P. S. (2016). Participative Management and Perceived Organizational Performance: The Moderating Effects of Innovative Organizational Culture. Public Performance \& Management Review, 39(2), 316-336.

Pavlou, P. A. (2002). Institution-based trust in interorganizational exchange relationships: the role of online B2B marketplaces on trust formation. The Journal of Strategic Information Systems, 11(3), 215-243. 
Peterson, R. A. (2000). A meta-analysis of variance accounted for and factor loadings in exploratory factor analysis. Marketing Letters, 11(3), 261-275.

Podsakoff, P. M., \& Organ, D. W. (1986). Self-Reports in Organizational Research: Problems and Prospects. Journal of Management, 12(4), 531-544.

Qiang, L., Yuanyuan, W., \& Wensheng, N. (2015). The Prediction Model of Dynamic Trust Relationship based on the Influence of Fuzzy Weight. The Open Cybernetics \& Systemics Journal, 9(1), 2709-2717.

Reise, S. P., Waller, N. G., \& Comrey, A. L. (2000). Factor analysis and scale revision. Psychological assessment, 12(3), 287.

Ring, P. S., \& Van de Ven, A. H. (1992). Structuring cooperative relationships between organizations. Strategic Management Journal, 13(1), 483-498.

Rotter, J. B. (1967). A new scale for the measurement of interpersonal trust. Journal of personality.

Rotter, J. B. (1971). Generalized expectancies for interpersonal trust. American psychologist, $26(5), 443$.

Rousseau, D. M., Sitkin, S. B., Burt, R. S., \& Camerer, C. (1998). Not so different after all: A cross-discipline view of trust. Academy of Management Review, 23(3), 393-404.

Saunders, M. (2010). Organizational trust: a cultural perspective. Cambridge: Cambridge University Press.

Schoorman, F., Mayer, R., \& Davis, J. (2007). An integrative model of organizational trust: Past, present, and future. Academy of Management Review, 32(2), 344-354.

Sigmund, K., \& Nowak, M. A. (2005). Evolution of indirect reciprocity. Nature, 437(7063), 1291-1298.

Snedecor, G. W., \& Cochran, W. G. (1989). Statistical Methods (8th ed.). Iowa State University Press. 
Stevens, J. P. (2012). Applied multivariate statistics for the social sciences. Routledge.

Stevenson, M. A. (1997). T1-IE Antecedents and Consequences of Interpersonal Trust in MixedMotive Dyadic Negotiation. Columbus: The Ohio State University.

Streiner, D. L. (1994). 10 Figuring Out Factors: The Use and Misuse of Factor Analysis. A Guide for the Statistically Perplexed: Selected Readings for Clinical Researchers. Canadian Journal of Psychiatry, 39(3), 135-140.

Suhr, D. D. (2006). Exploratory or Confirmatory Factor Analysis? Cary: SAS Institute.

Tabachnick, B. G., \& Fidell, L. S. (2007). Multivariate analysis of variance and covariance. Using multivariate statistics, 3, 402-407.

Tavakol, M., \& Dennick, R. (2011). Making sense of Cronbach's alpha. International journal of medical education, 2, 53.

Terry, D. J., Hogg, M. A., \& White, K. M. (1999). The theory of planned behaviour: selfidentity, social identity and group norms. British Journal of Social Psychology, 38(3), 225-244.

Tschannen-Moran, M., \& Hoy, W. K. (1999). Five faces of trust: an empirical confirmation of urban elementary schools. Journal of School Leadership, 9, 184-208.

Tschannen-Moran, M., \& Hoy, W. K. (2000). A multidisciplinary analysis of the nature, meaning, and measurement of trust. Review of Educational Research, 70(4), 547-593.

Tyler, T. R., \& Kramer, R. M. (1995). Trust in organizations: Frontiers of theory and research. Thousand Oaks, CA.: Sage.

Walters, D., Halliday, M., \& Glaser, S. (2002). Added value, enterprise value and competitive advantage. Management Decision, 40(9), 823-833.

Welter, F., \& Smallbone, D. (2006). Exploring the role of trust in entrepreneurial activity. Entrepreneurship Theory and Practice, 30(4), 465-475. 
Wilkinson, L. (1999). Statistical methods in psychology journals: Guidelines and explanations. American psychologist, 54(8), 594.

Youssef, C. M. (2007). Positive organizational behavior in the workplace the impact of hope, optimism, and resilience. Journal of management, 33(5), 774-800.

Zaheer, A., McEvily, B., \& Perrone, V. (1998). Does Trust Matter? Exploring the Effects of Interorganizational and Interpersonal Trust on Performance. Organization Science, 9(2), 141-159. 